듬 SCHOOL of GRADUATE STUDIES

EAST TENNESSEE STATE UNIVERSITY
East Tennessee State University Digital Commons@ East Tennessee State University

$5-2014$

\title{
Vitamin D Status of College Students: Implications for Health Leaders
}

Eileen M. Cress

East Tennessee State University

Follow this and additional works at: https://dc.etsu.edu/etd

Part of the Community Health and Preventive Medicine Commons, Educational Leadership Commons, International and Community Nutrition Commons, and the Public Health Education and Promotion Commons

\section{Recommended Citation}

Cress, Eileen M., "Vitamin D Status of College Students: Implications for Health Leaders" (2014). Electronic Theses and Dissertations. Paper 2366. https://dc.etsu.edu/etd/2366

This Dissertation - Open Access is brought to you for free and open access by the Student Works at Digital Commons @ East Tennessee State University. It has been accepted for inclusion in Electronic Theses and Dissertations by an authorized administrator of Digital Commons @ East

Tennessee State University. For more information, please contact digilib@etsu.edu. 
Vitamin D Status of College Students: Implications for Health Leaders

\begin{abstract}
A dissertation
presented to

the faculty of the Department of Educational Leadership and Policy Analysis

East Tennessee State University
\end{abstract}

In partial fulfillment

of the requirements for the degree

Doctor of Education in Educational Leadership

by

Eileen McKenna Cress

May 2014

Dr. Catherine Glascock, Chair

Dr. Donald Good

Dr. Pamela Scott

Dr. Deborah Slawson

Keywords: public health leadership, vitamin D sufficiency, vitamin D insufficiency, vitamin D deficiency 


\begin{abstract}
Vitamin D Status of College Students: Implications for Health Leaders

by
\end{abstract}

\title{
Eileen McKenna Cress
}

Vitamin D deficiency is considered to be a pandemic with implications for compromised bone health and other chronic diseases. Few studies have examined vitamin D status in college-aged individuals where prevention of future health consequences is still possible. Serum vitamin D 25(OH)D status and vitamin D intake were examined in 98 college students ages 18-29 years during winter. BMI was classified as $<25$ and 25 or greater. Race was categorized as Caucasian or other. Overall, 69.5\% had suboptimal serum vitamin D levels, <30ng/mL. Only 8 students (8.2\%) met the EAR (400 IU) per day for vitamin D intake. $t$ tests were used to determine if there were significant differences in serum vitamin D level and dietary intake based on gender, race and BMI. Significant differences were found in serum vitamin D level when compared by gender and race. Females tended to have a higher serum vitamin D level than males. Those representing minorities had lower serum vitamin D levels than Caucasians; One hundred percent of the minority students had suboptimal serum vitamin D levels. Based on these findings, dietitians should increase efforts to target college-aged individuals in educational programming related to factors affecting vitamin D synthesis, vitamin D intake, and health consequences of suboptimal vitamin D status, particularly in winter. Consideration should be given to vitamin D fortification of foods that meet the preferences of today's consumer. 


\section{DEDICATION}

This paper is dedicated to God for creating me as a person who values life-long learning and has a strong passion for helping others improve their health and wellness. I am thankful for the opportunity to complete this graduate coursework and for the numerous blessings along the way. Thanks you to my amazing family who provided support and encouragement during this journey. My husband Jim selflessly assumed some of my regular roles to allow me the time I needed to study and write during the course of this doctoral program. My amazing daughters Chelsea and Alyssa who permitted me the quiet time needed to work and who provided extra help around the house when needed. Jasmine provided me with a constant source of amusement the past 9 months, with puppy antics that made me laugh and forget the stressors of life. Ebony, my perpetual companion, provided unconditional love and affection. Sometimes that's all we need to motivate us to continue.

My parents Lawrence and Imogene McKenna raised me to be a caring, compassionate individual and inspired me to reach higher, leap further, seek challenges, and to learn something new every day. Looking down from above, Dad would surely be proud of me for accomplishing this goal. Mom has inspired me along this journey in her gentle and supportive ways and provided ongoing assurance that I could accomplish this goal. Thank you Mom and Dad. Your positive influence in my life is eternal. 


\section{ACKNOWLEDGEMENTS}

Dr. Catherine Glascock supported me from the beginning of this doctoral program and research idea despite it not being traditional research to the ELPA program. She allowed me to be creative and to step outside of the norm to focus on an area of research that can help improve the health of individuals and to make a contribution to nutrition and public health professions. She guided me through the process from the beginning of my course work, where we made a connection and found commonalities. She encouraged me, reassured me, and supported my ideas. What a great mentor and friend she has become. Thank you for your patience and understanding and supportive talks along this journey.

Dr. Donald Good, the stats expert. What would I have done without his assistance and his humor? No doubt, the study of statistics took on new meaning with Dr. Good's perspective. His expertise regarding the statistical analysis of the study data and detailed edits of this manuscript were also very much appreciated.

Dr. Pamela Scott guided me through inspirational leadership courses and inspired me to reach new heights. In addition to her amazing courses, Dr. Scott reviewed and edited this manuscript and offered valuable insight for improvement.

Dr. Deborah Slawson, is a cherished friend and mentor. Many thanks to her for sharing valuable ideas and for her constant support and encouragement throughout the doctoral program and the research experience.

Mrs. Marion Stiles, nutrition graduate student, assisted with the data collection for the research study. Her patience was amazing, especially when bombarded with 40 participants on day 1 of the data collection. She spent countless hours organizing the data into a wonderful Excel file to be used in the data analysis, saving me endless hours of frustration. 
Dr. Susan Twaddle assisted me with the statistical analysis of this research. I truly appreciate the gift of her wisdom and the friendship that grew from this collaboration.

Dr. Debbie Dotson is a prized colleague whose friendship and encouragement has been invaluable to me. Debbie's intuitiveness in saying just the right things at the right time helped motivate me to continue this journey more than she will ever realize. She has been a breath of fresh air and an angel from above throughout this doctoral program.

Dr. Lisa Ousley and her remarkable staff at the ETSU Student Health Clinic were instrumental in processing the study subjects with regards to the blood sample.

My thanks to the Dean's office in The College of Clinical and Rehabilitative Health Sciences, East Tennessee State University for believing in and supporting this research with a $\$ 10,000$ grant, without which this project would not have been possible.

Ms. Barbara Chamberlain assisted with formatting issues related to this manuscript that the author could not have resolved without her amazing help. I will be forever grateful for her kind assistance. 


\section{TABLE OF CONTENTS}

Page

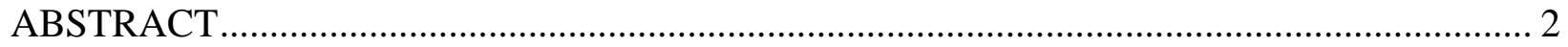

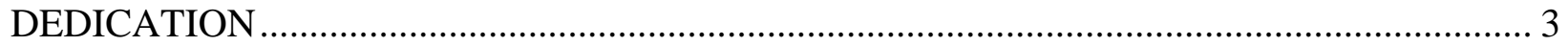

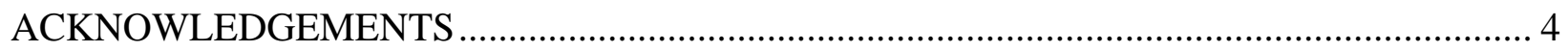

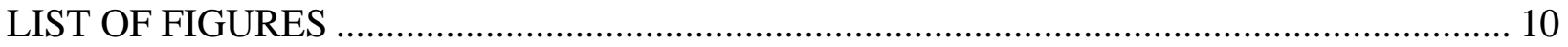

\section{CHAPTER}

1. INTRODUCTION ............................................................. 11

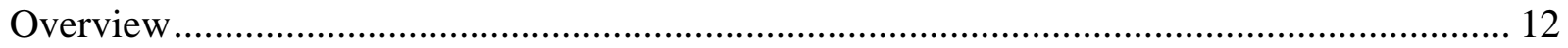

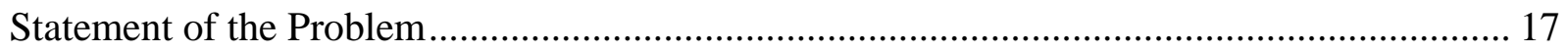

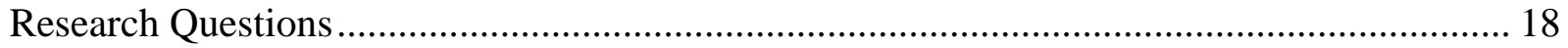

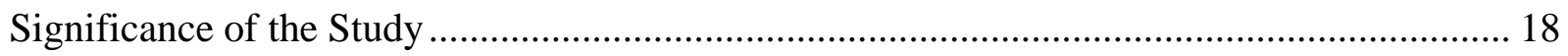

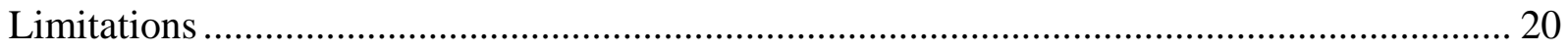

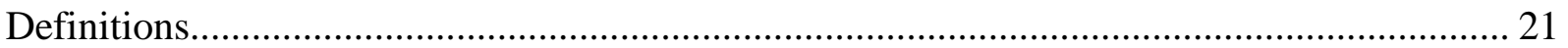

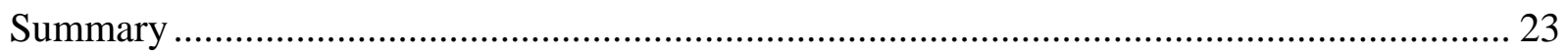

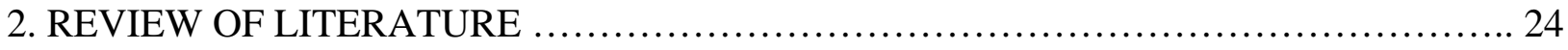

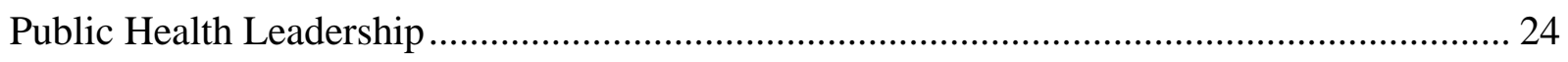

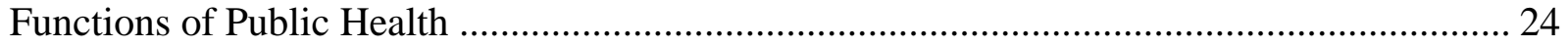

Leadership Training in Public Health ........................................................................... 25

Leadership Traits for Public Health Leaders ............................................................... 27

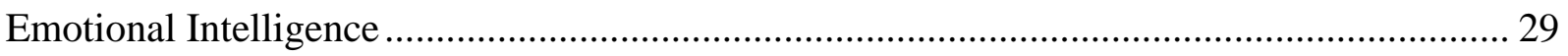

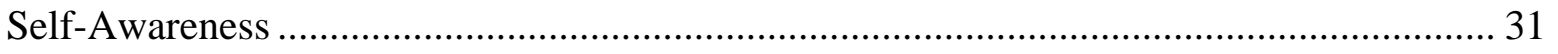

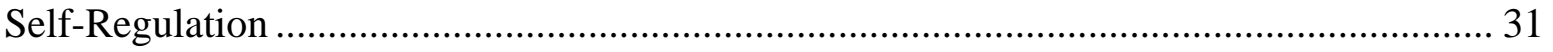


Motivation

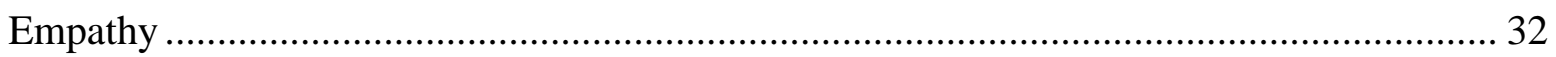

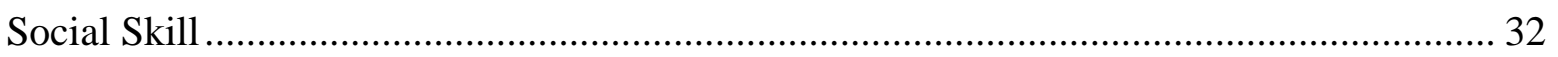

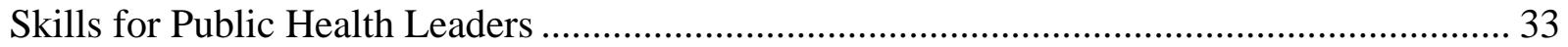

Leadership Theories and Public Health ..................................................................... 37

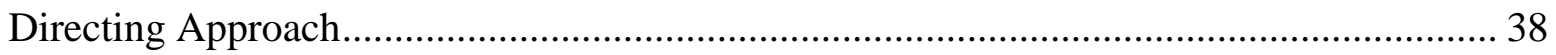

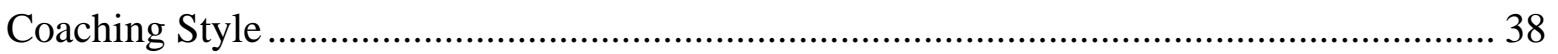

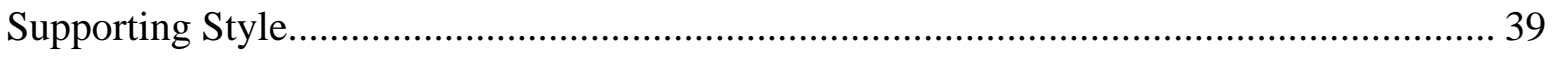

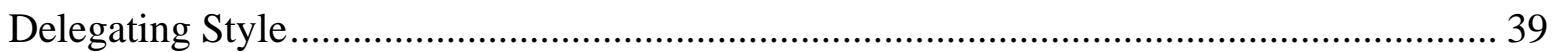

Leadership Abilities Needed for Public Health .............................................................. 39

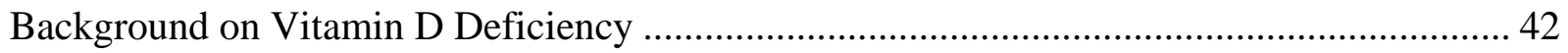

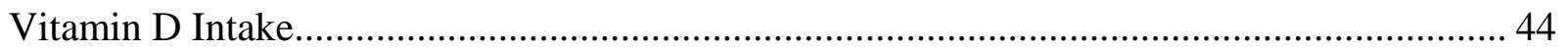

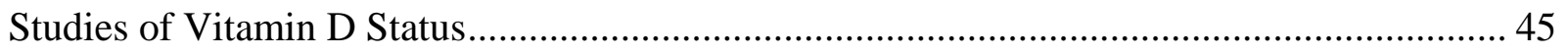

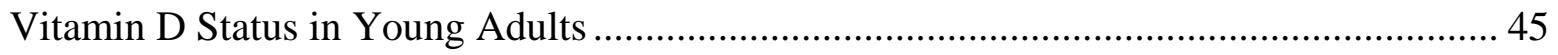

Vitamin D Status in Children ages 1 to 18 ................................................................. 48

Vitamin D Deficiency and Disease Risk ..................................................................... 51

Vitamin D and Cancer Risk ................................................................................. 51

Vitamin D and Links to Other Health Concerns............................................................. 52

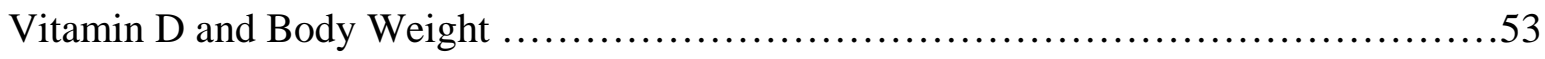

Vitamin D Status and Race.................................................54

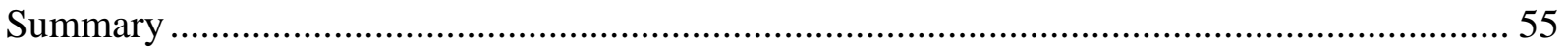

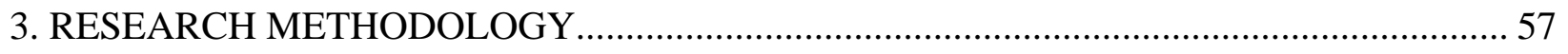

Research Questions and Null Hypotheses .................................................................. 57 
Sample

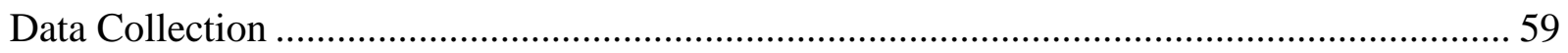

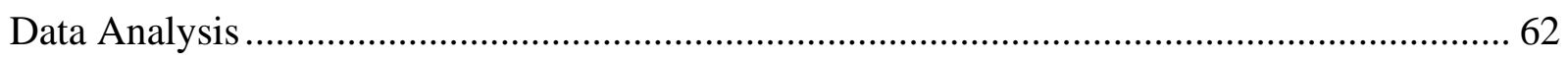

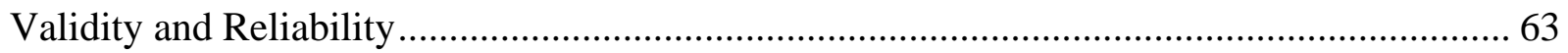

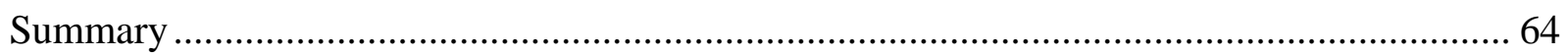

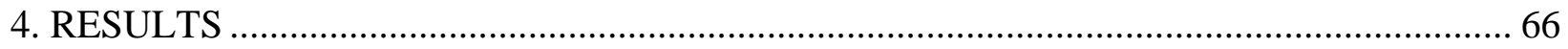

Research Questions and Analysis ....................................................................................... 70

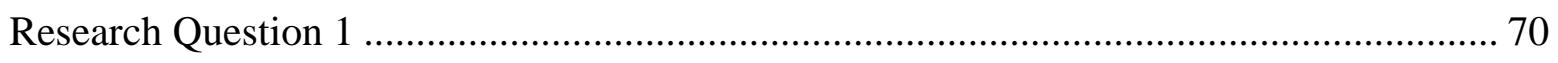

Research Question 2 ................................................................................................. 72

Research Question 3 ............................................................................................... 73

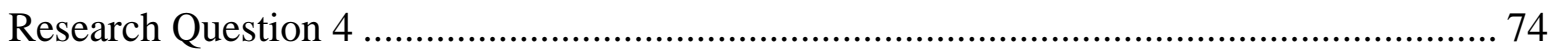

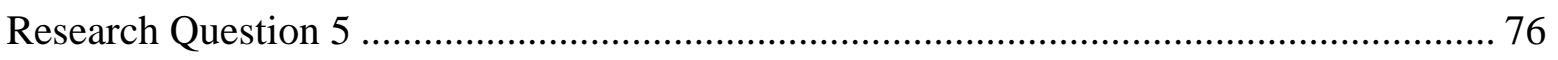

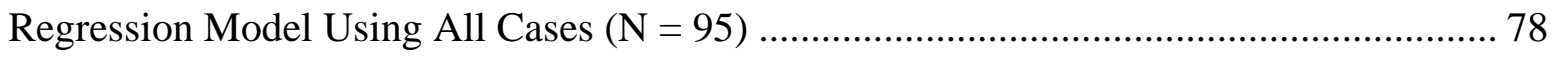

Regression Model with Outliers Removed ( $\mathrm{N}=92)$...................................79

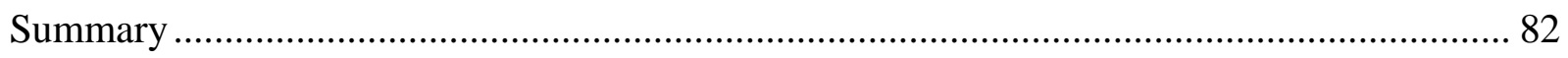

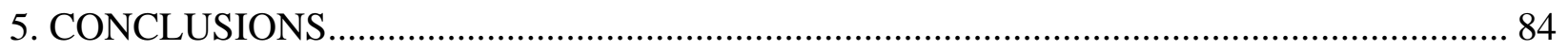

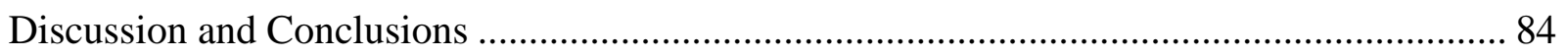

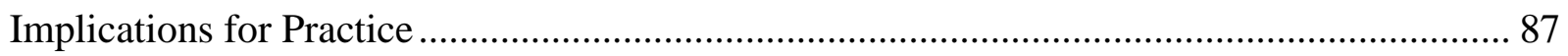

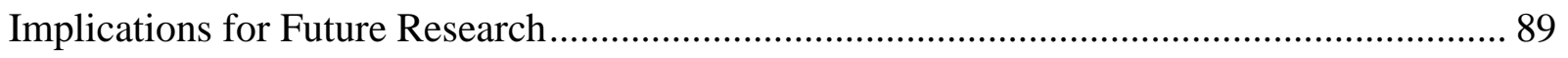

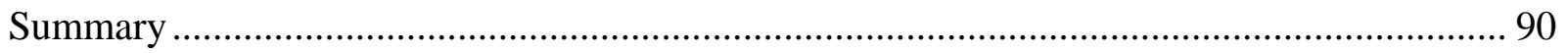

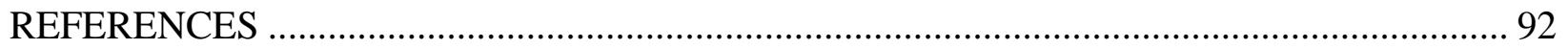

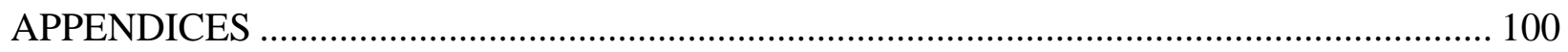

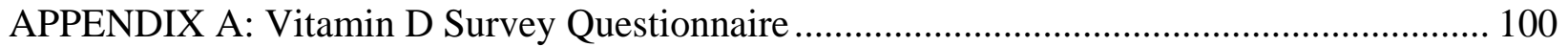


APPENDIX B: Permission to Use Vitamin D Food Frequency Questionnaire

APPENDIX C: Frequency Tables 


\section{LIST OF FIGURES}

Figure $\quad$ Page

1. Overview of Vitamin D Synthesis, Intake, and Activation ................................................. 13

2. Scatterplot for Serum Vitamin D and Body Mass Index .................................................. 74

3. Scatterplot for Serum Vitamin D Level and Age........................................................ 75

4. Normal Probability Plot for the Regression Model Using All Cases $(\mathrm{N}=95) \ldots \ldots \ldots \ldots \ldots \ldots \ldots . . . . . . . . .78$

5. Scatterplot for the Regression Standardized Residuals and Standardized Predicted Values

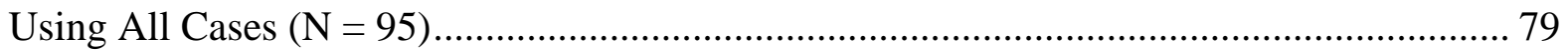

6. Normal Probability Plot for the Regression Model with No Outliers $(\mathrm{N}=92) \ldots \ldots \ldots \ldots \ldots \ldots . . . . . . .81$ 7. Scatterplot for the Regression Standardized Residuals and Standardized Predicted Values for

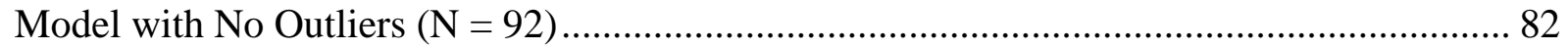




\section{CHAPTER 1}

\section{INTRODUCTION}

The researcher examined the vitamin D status of college-aged students aged 18-29 and the factors related to serum vitamin D level in this age group at East Tennessee State University. The dietary habits of college-aged students in relation to intake of vitamin D rich foods and supplements using a food frequency questionnaire were explored. Differences in vitamin D status among the variables of gender, race, academic major (health related compared to nonhealth related majors), and dining location, (on or off campus) were examined. The relationship between dietary consumption of vitamin $\mathrm{D}$ and body mass index to serum vitamin $\mathrm{D}$ status was also examined.

There was no previous research on whether increased knowledge in health related areas might influence vitamin D status: the evaluation of vitamin D status based on a student's academic major (health related versus nonhealth related) was an exploratory question. East Tennessee State University is an Academic Center for Health Sciences that includes the following colleges: The College of Nursing, The College of Medicine, The College of Pharmacy, The College of Clinical and Rehabilitative Health Sciences, and The College of Public Health. Additional areas of study are available in The College of Arts and Sciences, The College of Education, and The College of Business and Technology. The researcher wanted to explore possible differences in serum vitamin D $25(\mathrm{OH})$ D levels among students in health related majors compared to students in nonhealth related majors.

Whether a student ate meals on or off campus was another exploratory question with no previous research available. The researcher wanted to determine if there were differences in vitamin D status based on whether a student ate meals on campus or off campus. Because some 
college students consume the majority of their food from campus dining, differences in these areas may provide additional information to help improve the health of college students.

\section{Overview}

Vitamins promote and regulate body activities and play a crucial role in overall health and well-being. One of the main functions of vitamin $\mathrm{D}$ in the body is to maintain bone health. Without adequate vitamin D, absorption of calcium and phosphorus, which are crucial for bone health, is decreased. Holick (2007) suggested that with insufficient Vitamin D calcium absorption is decreased to $10 \%$ to $15 \%$ of optimal, and phosphorus absorption is lessened to $60 \%$ of optimal. Vitamin D is a fat soluble vitamin obtained from sun exposure, foods, and supplements. Because very few foods contain vitamin D, sun exposure is the major source of vitamin D for humans. When ultraviolet rays from sunlight strike the skin, 7-dehydrocholesterol present in the skin is converted to previtamin $\mathrm{D}_{3}$. In this form vitamin $\mathrm{D}$ is biologically inert and must undergo two hydroxylations in the body to become activated (ODS, 2011). The first hydroxylation occurs in the liver where vitamin D is converted to 25-hydroxyvitamin D 25(OH) D. The second occurs in the kidney where the active form of vitamin D is formed, 1, 25dihydroxyvitamin D. Figure 1 illustrates vitamin D activation in the human body (Ross, Taylor, Yaktine, \& Heather, 2011). 


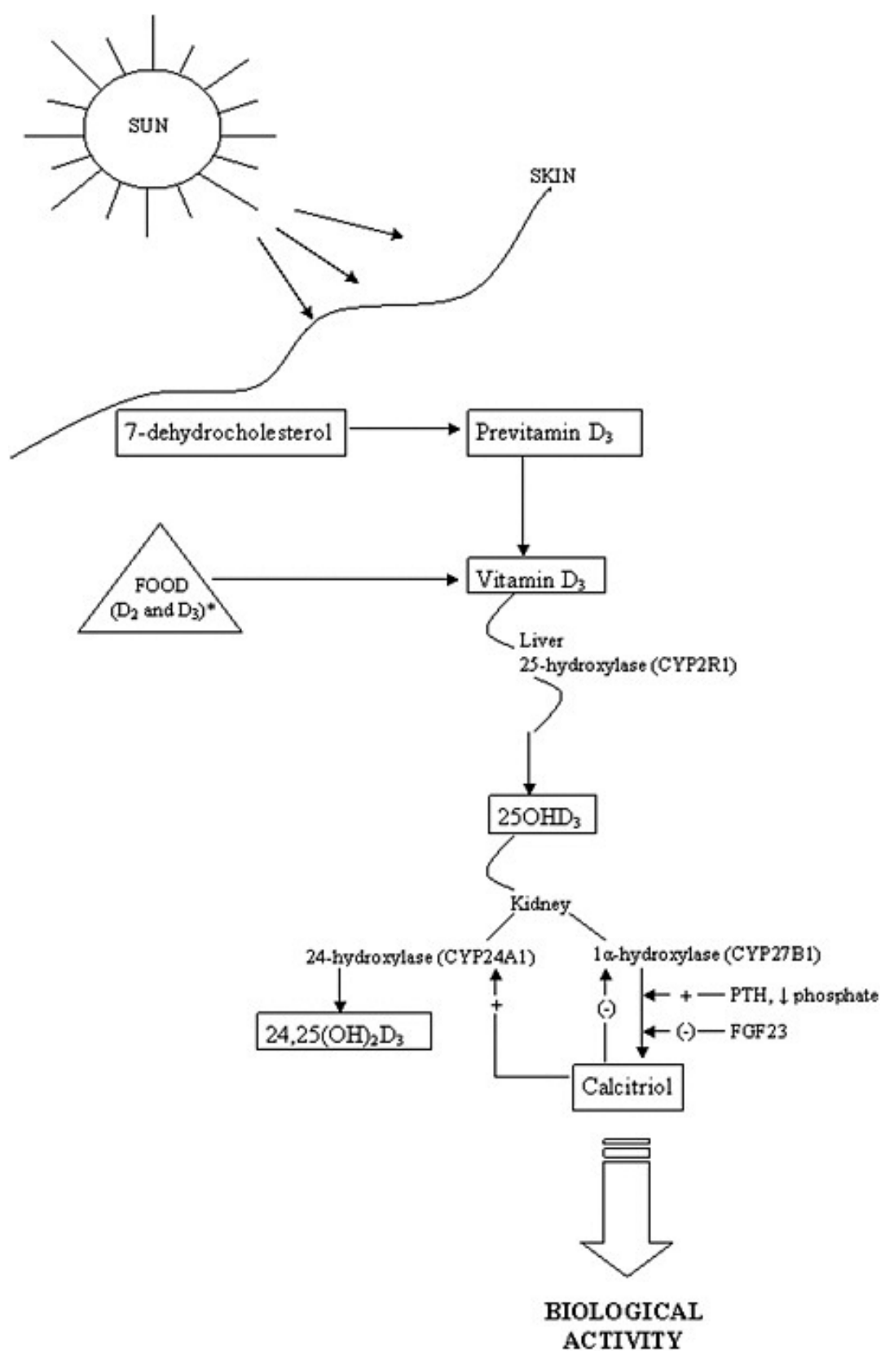

Figure 1. Overview of Vitamin D Synthesis, Intake, and Activation (Ross et al., 2011)

Experts recommend the serum circulating 25-hydroxyvitamin D 25(OH) D level to measure vitamin D status in individuals (Holick et al., 2011; ODS, 2011), which is the combined form of cutaneous synthesis from the sun and dietary sources (Calvo, Whiting, \& Barton, 2005). Optimal serum levels of Vitamin D are defined as 30 nanograms per milliliter $(\mathrm{ng} / \mathrm{mL})$ or higher 
(Holick et al., 2011). Vitamin D insufficiency is defined as a 25(OH)D between 21-29 ng/mL and vitamin D deficiency is recognized as a 25 (OH) D below $20 \mathrm{ng} / \mathrm{mL}$ (Holick et al., 2011). Several references report vitamin D levels in nanomoles per liter (nmol/l) instead of nanograms per milliliter (ng/mL). For improved readability, all literature references regarding vitamin D levels are reported in $(\mathrm{ng} / \mathrm{mL})$. Conversion of $\mathrm{nmol} / \mathrm{l}$ to $\mathrm{ng} / \mathrm{mL}$ is accomplished by dividing nmol/l by 2.5 (Looker et al., 2011).

According to Holick (2007) exposure of arms and legs to sunlight for an average of 10 minutes, depending on the time of day, season of year, and latitude, can provide around 3,000 International Units (IU) of vitamin $\mathrm{D}_{3}$. In comparison, an eight ounce glass of vitamin $\mathrm{D}$ fortified milk provides around $100 \mathrm{IU}$ and a 3.5 ounce portion of wild salmon contains approximately 600-1,000 IU of vitamin $\mathrm{D}_{3}$ (Holick, 2007). Over the counter vitamin supplements vary in their content of vitamin D, ranging anywhere between 400 IU to 2,000 IU (Holick, 2007). Recommended Dietary Allowances (RDA) and Adequate intake (AI) levels of vitamin D as set by the Institute of Medicine in 2011are 600 IU daily for ages 1-70, and $800 \mathrm{IU}$ for adults over 70 years (IOM, 2011). Prior to 2011, RDAs and AI for vitamin D were set at 200 IU age 1-50 years, $400 \mathrm{IU}$ age 51-70 years, and $600 \mathrm{IU}$ for those older than 70 (Moore, Murphy, East, \& Holick, 2004). Holick et al. (2011) suggested that vitamin D synthesized through the action of sunlight on the skin may last at least twice as long in the blood compared with sources consumed by mouth.

Barger-Lux, Heaney, Dowell, Chen, and Holick (1998) studied oral dosing of vitamin D supplements and the effect on serum vitamin D levels in healthy men and concluded that raising serum vitamin D levels to optimal levels may take higher doses than were recommended at that 
time. These researchers suggested that an additional intake of about $1700 \mathrm{IU}$ per day is required to raise serum 25(OH)D levels from $20 \mathrm{ng} / \mathrm{mL}$ to an optimal level of $32 \mathrm{ng} / \mathrm{mL}$.

Several factors are known to inhibit vitamin D synthesis in the skin. Season of the year, time of day, latitude, presence of clouds, skin melanin content, and use of sunscreen can affect UV radiation and therefore synthesis in the skin (ODS, 2011). Seasonal variations of the sun's strength occur and are caused by the change in the angle at which the sun reaches the earth (Holick \& Chen, 2008). Less ultraviolet rays reach the earth's surface during winter months, as well as in early morning and later afternoon hours, thereby decreasing the ability to synthesize vitamin $\mathrm{D}_{3}$ in the skin. In conditions of full cloudiness, ultraviolet rays can be reduced by as much as 50\% (ODS, 2011). At latitudes above or below $33^{\circ}$, sunlight is inadequate to produce synthesis of vitamin D in the skin during winter months (Holick et al., 2011; Webb et al., 1988).

Additionally, dark skin pigmentation can inhibit synthesis of vitamin D in the skin as much as 99.9\% (Holick, 2006). Sunscreen with a sun protection factor of eight or more blocks ultraviolet rays and inhibits synthesis of previtamin $\mathrm{D}_{3}$ in the skin. (ODS, 2011). Holick and Chen (2008) reported that a sunscreen with a protective factor of 15 absorbs $99 \%$ of the ultraviolet rays and thus decreases vitamin $\mathrm{D}_{3}$ synthesis in the skin by $99 \%$. Body mass index and content of body fat are inversely related to vitamin $\mathrm{D}_{3}$ levels (Holick, 2006). Individuals with a body mass index at or above 30 have lower serum levels of vitamin $\mathrm{D}_{3}$ than nonobese individuals (ODS, 2011). This inverse relationship is thought to be related to how fat cells seize more of the vitamin and decrease its level in circulation (Holick, 2006; ODS, 2011).

Few foods naturally contain vitamin D. It can be found naturally in fatty fish such as wild caught salmon and tuna and fish liver oils (Holick, 2008; ODS, 2011). The majority of dietary vitamin D in the diets of Americans comes from fortified foods. In the United States milk 
has been fortified with vitamin D since the 1930s to prevent rickets, a bone disease in children caused by inadequate vitamin D (ODS, 2011). A few other foods may be fortified such as: certain brands of orange juice, breakfast cereals, yogurts, and margarine.

Dietary supplements can improve vitamin D intake but vary in the amount of vitamin D provided. Most supplements in the United States are in the form of vitamin $\mathrm{D}_{3}$, cholecalciferol. One area of concern regarding supplements is that the United States Food and Drug Administration does not regulate or verify quality of nutritional supplements (LeBlanc, Perrin, Johnson, Ballatore, \& Hillier, 2013). In the absence of regulations regarding quality, there is little proof that dietary supplements do indeed provide what is stated on the manufacturer's label. Voluntary quality testing of supplements is available by manufacturer request through the US Pharmacopeial Convention (USP) but is not required. LeBlanc et al. (2013) studied the potency of over the counter vitamin D supplements purchased at four different stores and found that these supplements contained $52 \%$ to $135 \%$ of the expected dose. Only one supplement in the test group was USP verified; that supplement was found to be the most accurate, with all pills in the sample falling within $10 \%$ of the expected dose.

Factors such as dietary inadequacy, impaired absorption, increased requirement, or increased excretion can lead to nutrient deficiencies (ODS, 2011). In the case of vitamin D, a deficiency can result from low dietary intake, inadequate sun exposure, kidney disease, or absorption problems in the gastrointestinal tract (ODS, 2011). Additionally, concern over increased skin cancer risk with sun exposure has led to higher incidences of use of sun screen, that blocks vitamin D synthesis in the skin (Calvo et al., 2005). The most commonly known forms of vitamin D deficiency are rickets and osteomalacia, which are bone diseases in children and adults respectively (ODS, 2011). Symptoms of vitamin D deficiency can be subtle and 
undetectable in initial stages. Studies of osteoporosis risk suggest that the risk depends on the level of peak bone mass and the rate at which bone is lost (Heaney, 2000).

Peak bone mass is achieved somewhere between the ages of 16 and 30(Wang, 2008). This study of vitamin D status among college students looked at a population of individuals prior to the end of peak bone formation years. Information about vitamin D levels in this group can help inform health professionals about possible risk of poor bone health and other adverse health conditions linked to vitamin D deficiency. The best indicator of vitamin D status is serum concentration of 25-hydroxyvitamin D, [25(OH) $\mathrm{D}_{3}$ ] (Holick et al., 2011; ODS, 2011). Vitamin D insufficiency is defined as 25(OH)D between $21-29 \mathrm{ng} / \mathrm{mL}$, and vitamin D deficiency is defined as 25(OH)D below 20 ng/mL (Holick, 2007; Holick et al., 2011; IOM, 2011). Experts on vitamin D levels required for optimal health recommend levels at or above $30 \mathrm{ng} / \mathrm{mL}$ with the most desirable levels in the range of 36 to $40 \mathrm{ng} / \mathrm{mL}$ (Bischoff-Ferrari, Giovanni, Willett, Dietrich, \& Dawson-Hughes (2006); Vieth et al., 2007).

\section{Statement of the Problem}

The purpose of this study was to examine the vitamin D status and vitamin D intake of students at East Tennessee State University in order to identify if this age group is at risk of inadequate vitamin D status. Vitamin D deficiency is considered to be a worldwide problem affecting individuals of all ages (Holick, 2008; Holick \& Chen, 2008; Raiten \& Piccano, 2004). Holick (2007) estimated that one billion individuals worldwide have inadequate levels of vitamin $\mathrm{D}$ and that vitamin D inadequacy has been reported in all age groups and in many international populations. Deficiency of vitamin D causes rickets in children and leads to osteomalacia and bone fractures in adults. Inadequacy of vitamin D has also been linked to numerous diseases such as cancers, hypertension, and autoimmune diseases (Holick, 2008). Looker et al. (2011) 
examined data from several NHANES surveys. Their analysis determined that in 2001-2006, $24 \%$ of the U.S. population was at risk of vitamin D inadequacy with serum levels of 12-19 $\mathrm{ng} / \mathrm{mL}$, and another $8 \%$ were at risk of deficiency with levels less than $12 \mathrm{ng} / \mathrm{mL}$. Risk of vitamin D deficiency increased between the years 1988-1994 and 2001-2002 in both genders but did not change between the years 2001-2002 and 2005-2006. Looker et al. (2011) also found differences in vitamin D status related to age, gender, race, and ethnic differences. Risk of vitamin D deficiency was lower in children aged 1-8 years and males, particularly among nonHispanic whites.

Studies have associated vitamin D deficiency with numerous chronic health conditions, which is a concern for leaders in public health. Promoting health and reducing incidence of chronic diseases is a major focus of public health initiatives (USDHHS, 2013).

\section{Research Questions}

The following research questions were investigated in this study:

1. Is there a significant difference between vitamin D 25(OH)D levels when compared by gender, race, and academic major?

2. Is there a significant relationship between vitamin $\mathrm{D} 25(\mathrm{OH}) \mathrm{D}$ level and body mass index?

3. Is there a significant relationship between vitamin $\mathrm{D} 25(\mathrm{OH}) \mathrm{D}$ level and age?

4. Is there a significant difference between vitamin D intake from food and supplements when compared by gender, race, and academic major?

5. To what extent can BMI and dietary intake of vitamin D predict vitamin D 25(OH)D level? 


\section{Significance of the Study}

The purpose of this study was to examine vitamin D levels among college students aged 18-29 and to examine the factors related to vitamin D status in this population. Many studies of vitamin D levels have focused on the elderly and young children, but few studies have addressed young adults. Because vitamin D inadequacy has been linked to an increased risk of chronic diseases, information about the status of vitamin D in college-aged students may help to inform health leaders regarding possible preventative health measures for this population.

Public health policy has traditionally focused on vitamin D deficiency in relation to eliminating the bone disease rickets caused by a deficiency of vitamin D (Raiten \& Piccano, 2004). According to a report of the National Institutes of Health Conference (2003), new concerns have emerged regarding a resurgence of rickets as well as high prevalence of vitamin D deficiency among individuals in the United States and the reported relationship between vitamin D status and numerous adverse health conditions (Raiten \& Piccano, 2004). Scholars have identified likely causes of vitamin D insufficiency: lower intakes of vitamin D fortified foods, reduced intakes of calcium rich foods, increased use of sun block along with decreased exposure to sunlight, decreased ultraviolet light exposure due to increased air pollution, and effects of food insecurity among poorer individuals (Holick et al., 2011; Vieth et al., 2007; Zitterman, 2006).

Weishar and Vergili (2013) reported that vitamin D status is a biological determinant of health disparities. Public health leaders are concerned with the overall health of the US population and with eliminating health disparities, as evidenced by two of the four goals of the Healthy People 2020, the United States government's plans for the health of the public: to “Attain high-quality, longer lives free of preventable disease, disability, injury, and premature death", and "To achieve health equity, eliminate disparities, and improve the health of all 
groups” (USDHHS, 2013, p.1). Because vitamin D inadequacy has been associated with a number of adverse health conditions, it is important to explore the vitamin D status of younger individuals as a possible route toward prevention of future undesirable health concerns. There is a lack of research on the status of vitamin D among college-aged students, an age where the possibility of avoidance of future diseases or negative health outcomes still exists.

Another reason for exploring vitamin D status in college-aged students involves health care costs. There is growing concern regarding the high cost of health care and affordability in the United States. A retrospective study by Peiris, Bailey, and Manning (2008) of health care costs associated with vitamin D deficiency in 886 veterans found overall costs were higher by $39 \%$ in the group that was deficient in vitamin D. Deficiency of vitamin D was related to more frequent emergency room and clinic visits as well as increased days of hospitalization and other required services. In another study of 136 veterans, McKinney et al. (2011) found a significantly higher risk for 3-day longer stay in patients in intensive care unit (ICU) settings. Of those who survived the ICU, 28\% had a lower rate of vitamin D deficiency compared to 53\% in the nonsurvivors. Furthermore, the risk of death was significantly higher in those with vitamin D deficiency.

\section{Limitations}

Limitations of this study include its narrow scope. Only 97 students at East Tennessee State University were evaluated for this study. College-aged students in other areas of the country may have different eating and sun exposure habits, both of which can impact vitamin D levels. The use of self -reported data regarding food intake, multivitamin use, and sun exposure is another limitation of this study. The accuracy of this information is dependent on the candor of the study participants. An additional limitation of this study is that vitamin D intake is difficult to 
measure with precision. Food frequency questionnaires rely on participant memory and candor in the reporting of food intake and portion amounts.

The use of an outside source to draw blood samples for vitamin D analysis was another limitation of this study. During initial set up of the study it was determined that participants would first complete the study survey and anthropometric measurements, then report immediately to the student health clinic, for the blood sample to be drawn. Due to previously unknown restrictions at the student health clinic, not all participants had their blood drawn immediately afterwards. In some cases, study subjects were required to wait up to 1 week for the blood test. Therefore, they could have increased consumption of vitamin D rich foods or supplements during the waiting period, or they could have experienced increased sun exposure between the time of the survey and the blood draw and this may have had an impact on their vitamin D levels.

\section{Definitions}

The following terms are defined and hereinafter used in this study:

1. Adequate intake (AI): The $\mathrm{AI}$ is a recommended average daily nutrient intake level, based on experimentally derived intake levels or approximations of observed mean nutrient intake by a group (or groups) of apparently healthy people that are assumed to be adequate as set by the National Academy of Sciences. In the judgment of the Standing Committee on the Scientific Evaluation of Dietary Reference Intakes, the AI is expected to meet or exceed the amount needed to maintain a defined nutritional state or criterion of adequacy in essentially all members of a specific apparently healthy population (National Academy of Sciences (2013). 
2. Body mass index: Body Mass Index (BMI) is a number calculated from a person's weight and height. BMI provides a reliable indicator of body fatness for most people and is used to screen for weight categories that may lead to health problems. To calculate BMI, divide weight in pounds (lbs) by height in inches (in) squared and multiply by a conversion factor of 703. (Centers for Disease Control and Prevention, 2011)

3. Hydroxylation: Hydroxylation is a chemical process that introduces a hydroxyl group $(\mathrm{OH})$ into an organic compound in a position where one did not exist before (Free Dictionary, 2013).

4. Metabolic syndrome: Metabolic syndrome is the name given for a group of factors that raises risk for heart disease. An individual's risk of heart disease, diabetes, and stroke increases with the number of risk factors. A diagnosis of metabolic syndrome includes the presence of at least three of the risk factors. These factors include large waistline, high triglycerides, low high density lipoproteins, high blood pressure, and high fasting blood sugar (NIH, 2011).

5. Obesity: Obesity is defined as a body mass index of greater than 30 (Centers for Disease Control and Prevention, 2011).

6. Osteomalacia: Osteomalacia refers to a softening of bones, in adults, often caused by a vitamin D deficiency. Soft bones are more likely to bow and fracture than are harder, healthy bones. Muscle weakness and achy bone pain are the major sign and symptom of osteomalacia. Treatment for osteomalacia involves replenishing low levels of vitamin D and calcium, and treating any underlying disorders that may be causing the deficiencies (Mayo Clinic, 2013). 
7. Recommended Daily Allowance (RDA): The RDA is the average daily level of intake sufficient to meet the nutrient requirements of nearly all (97\%-98\%) healthy people (National Academy of Sciences (2013).

8. Rickets: Rickets is the softening and weakening of bones in children, usually because of an extreme and prolonged vitamin D deficiency (Mayo Clinic, 2013).

9. Vitamin D deficiency: Vitamin D deficiency is defined as a vitamin D 25(OH)D level of less than $20 \mathrm{ng} / \mathrm{mL}$ (Holick et al., 2011; ODS, 2011).

10. Vitamin D inadequacy: Vitamin D inadequacy is a term used to generally describe vitamin D 25(OH)D level less than optimal, $30 \mathrm{ng} / \mathrm{mL}$.

11. Vitamin D insufficiency: Vitamin D deficiency is defined as a vitamin D 25(OH)D level of 21-29 ng/mL (Holick et al., 2011; ODS, 2011).

12. Vitamin D sufficiency: Vitamin D sufficiency is defined as a vitamin D 25(OH)D level of $30 \mathrm{ng} / \mathrm{mL}$ or greater (Holick et al., 2011; ODS, 2011).

13. Vitamin D 25(OH)D: Vitamin D 25(OH)D is the measurement of the major circulating form of vitamin D, in the blood and is considered the ideal standard for determining the vitamin D status of individuals (Holick, 2005).

\section{Summary}

Vitamin D insufficiency and deficiency has been shown to have detrimental effects on the health of individuals worldwide. Additionally there is evidence that vitamin D deficiency may lead to higher costs of caring for the heath of individuals. Public health leaders are concerned with both the health of individuals and the cost of health care for all. The available evidence linking vitamin D inadequacy to other health problems provides reason for further study of the vitamin D status in all age groups. Because few studies have explored vitamin D 
status in college-aged students, this study is intended to examine vitamin D levels and the factors related to vitamin D status in this population. 


\section{CHAPTER 2}

\section{REVIEW OF LITERATURE}

The purpose of this quantitative study was to explore the vitamin D 25(OH) D status among students ages 18-29 at East Tennessee State University and the factors related to vitamin D level in this population. Vitamin D sufficiency is defined as a level equal to or greater than 30 $\mathrm{ng} / \mathrm{mL}$; vitamin D deficiency is defined as less than $20 \mathrm{ng} / \mathrm{mL}$; vitamin D insufficiency is defined as $21-29 \mathrm{ng} / \mathrm{mL}$ (Holick et al., 2011).Vitamin D status in this age group has not been well studied, and the significance of this research has implications for health leaders. Review of the literature investigating the vitamin D status of college-aged students and implications for health leaders included the following areas: Public Health Leadership, Background on Vitamin D Deficiency, Vitamin D Intake, Studies of Vitamin D Status in Young Adults, Studies of Vitamin D Status in Children, Vitamin D and Disease Risk, Vitamin D Status Related to Body Weight, Vitamin D Status and Race.

\section{Public Health Leadership}

According to the World Health Organization (2013), "Public health refers to all organized measures (whether public or private) to prevent disease, promote health, and prolong life among the population as a whole. Its activities aim to provide conditions in which people can be healthy and focuses on entire populations, rather than individual patients or diseases. Thus, public health is concerned with the total system and not only the eradication of a particular disease”(p.1).

\section{Functions of Public Health}

The World Health Organization (2013) recognizes three main public health functions. These are assessment and monitoring of the health of communities and populations at risk in 
order to identify health problems and priorities; the formulation of public policies designed to solve local and national health problems and priorities; and to assure that all populations have access to appropriate and cost-effective care, including health promotion and disease prevention services.

"The term global public health recognizes that, as a result of globalization, forces that affect public health can and do come from outside state boundaries and that responding to public health issues now require attention to cross-border health risks, including access to dangerous products and environmental change.”(World Health Organization, 2013, p.1).

Rapid changes continually occur in the public health landscape. For health agencies and organizations to be effective amidst this fluid environment it is essential to have leaders with proper skills and ongoing training for the continued development of leadership expertise. Implications for health leaders with regards to vitamin D insufficiency and links to illness and increased medical costs are numerous. Health leaders can work to inform the public, conduct research and disseminate information, advise policy changes at local, state, and national levels, develop partnerships, form teams and coalitions interested in improving health outcomes, and provide educational programs and opportunities. Public health leadership involves a number of skills that include: “decision making, risk taking, building internal capacity, creating sustainable vision and translating that to a mission, communicating, system thinking, strategic thinking, building teams with the institution," and learning from both experience and others (Novick, Morrow, \& Mays, 2008, p. 283).

\section{Leadership Training in Public Health}

In response to the Institute of Medicine report on The Future of Public Health (IOM, 1998), which called for training and development of public health workers to meet the changing 
demands of public health concerns, the National Public Health Leadership Development Network created a framework of standards for leadership development in public health (Novick et al., 2008; Wright et al., 2000). This initiative led to the National Public Health Leadership Institute (PHLI), founded by the CDC in 1991.

According to Wright et al. (2000) the major leadership skill development areas identified include transformation, legislation and politics, transorganization, and team dynamics. Transformation refers to the ability of public health leaders to be systems thinkers and be visionary. It also involves the need for leaders to have strong analytical and critical thinking skills. Public health leaders should be able to develop long-term strategic plans to handle future issues (Novick et al., 2008). The area of legislation and politics requires leaders to be able to negotiate and work well with others to meet the constant changes associated with the public health landscape. Public health concerns occur in all areas and in all communities, both nationally and locally. Therefore, effective public health leaders should be politically savvy and remain informed about public health policy (Novick et al., 2008). Transorganization engages leaders to think beyond their own skills and collaborate with others outside of their own organization to unify direction while capitalizing on the various skills many bring to the team. Team dynamics deals with training leaders to develop team-oriented structures and systems and to serve in facilitation and mediation roles.

In their review of outcomes from this leadership training initiative, Umble et al. (2005), reported that participants of this training described that their experience helped them recognize that public health activities are often best implemented through partnerships. Most (96\%) of the participants stated that they had increased their discussions with other leaders in both the amount and the frequency of contacts. "Collaborative leadership development contributes to social 
capital of the public health community, defined as the resources available to leaders and organizations through professional and interorganizational networks” (Umble et al., 2005, p. 642). Furthermore, they suggest that the improvement of social capital should have greater focus in the future.

\section{Leadership Traits for Public Health Leaders}

Rowitz (2014) suggested that public health leadership involves commitment to communities and to the values important to the community. Additionally, he discussed that community includes the global world. There are numerous theories of leadership and many scholars have reported on essential skills required of leaders in all organizations. Rowitz (2014) identified the five most important skills for public health leaders and suggested that all leadership skills described by others grow out of these five traits:

1. "Ability to identify the most useful information and to use it" (p.5), includes the ability to sift through large amounts of new information daily and to be able to translate it into what is relevant to public health and public health action. Information from numerous sources such as health data statistics, technical reports about public health, funding sources and opportunities to acquire new funding, and program opportunities or threats needs to be sorted, analyzed, and disseminated into areas of public health leadership and action. Because this requires a huge amount of time, public health leaders must be adept at recognizing the most relevant information quickly and to make the most of that information toward improving public health.

2. “Ability to take risks and follow through”(p.5), translating ideas into action with well-defined projected outcomes. Leaders in public health need to be creative and futuristic and willing to take risks with new ideas in order to improve the public's health. Taking risks involves some 
degree of uncertainty, but effective public health leaders should be open to new ideas and be able to apply them to crucial situations in order to lead positive change. Public health leaders should evaluate all outcomes and decide whether to continue on the same course or attempt a new approach toward improving the public's health.

3. "Ability to communicate at many different levels"(p.5) including being culturally competent and social network savvy. Public health leaders today need to be able to communicate effectively both verbally and in writing. The need for cultural competence in communicating is essential because public health crosses many avenues of race, religion, gender, nationality, ethnicity, native language, and sexuality. Public health leaders also need good listening skills to be able to understand the needs of the public they serve. Additionally, knowledge of communicating via social networks such as Facebook and Twitter and other internet opportunities such as blogs will help public health leaders to reach more of the public they serve.

4. "Ability to act as systems thinkers with an understanding of how complexity affects their work"(p.5). Systems thinkers look at the big picture rather than just one element. The public health system has many parts that can and should work together. Leaders in public health are often challenged with leading change that may not be popular in order to change things for the better of the public. In this sense, change may also lead to undesirable and unexpected outcomes which demand that the public health leader be flexible and responsive to these potential outcomes.

5. “Ability to motivate and work with others"(p.5), which includes emotional intelligence capabilities. It is not just technical skill that public health leaders require; rather they must understand people and how to work with culturally diverse groups. They must be able to 
work effectively with community partners, colleagues, governing bodies, politicians, and the general public. The concept of emotional intelligence as described by Goleman (1998) is discussed further in the next section.

\section{Emotional Intelligence}

Goleman (1998) described emotional intelligence as a set of traits that include selfawareness, self-regulation, motivation, empathy, and social skill. In his study of almost 200 global companies Goleman identified that the qualities usually associated with leadership: intelligence, toughness, determination, and vision were not enough for true leadership effectiveness. Goleman argued that emotional intelligence proved to be twice as important as other leadership skills. He posited that emotional intelligence is even more crucial at higher levels of leadership. Goleman and Bradberry and Graves (2009) argued that emotional intelligence increases with age and can be learned. They posited that with sincere desire and determination, leaders can improve their emotional intelligence. The five components of emotional intelligence are described in Table 1 and further discussed following the table. 
Table 1

Five Components of Emotional Intelligence

\begin{tabular}{|c|c|c|}
\hline \multirow{2}{*}{ Self-Awareness } & Definition & Characteristics \\
\hline & $\begin{array}{l}\text { The ability to recognize } \\
\text { and understand your } \\
\text { moods, emotions, and } \\
\text { their effect on others. }\end{array}$ & $\begin{array}{l}\text { Self-confidence } \\
\text { Honest self-assessment } \\
\text { Self-deprecating sense of humor. }\end{array}$ \\
\hline Self-Regulation & $\begin{array}{l}\text { The capacity to control or } \\
\text { redirect disruptive } \\
\text { impulses and moods. } \\
\text { The tendency to hold } \\
\text { judgment and think } \\
\text { before acting. }\end{array}$ & $\begin{array}{l}\text { Trustworthiness and integrity } \\
\text { Comfort with ambiguity } \\
\text { Openness to change. }\end{array}$ \\
\hline Motivation & $\begin{array}{l}\text { A drive to work beyond } \\
\text { expectations. } \\
\text { A desire to pursue goals } \\
\text { with determination. }\end{array}$ & $\begin{array}{l}\text { Strong drive to achieve. } \\
\text { Optimistic outlook. } \\
\text { Commitment to organizational goals. }\end{array}$ \\
\hline Empathy & $\begin{array}{l}\text { The knack for } \\
\text { understanding other } \\
\text { people's emotional } \\
\text { makeup. }\end{array}$ & $\begin{array}{l}\text { Skill in developing and keeping } \\
\text { talented individuals. } \\
\text { Cultural awareness and sensitivity. }\end{array}$ \\
\hline & $\begin{array}{l}\text { Talent in handling others } \\
\text { based on their emotional } \\
\text { reactions. } \\
\text { Skill in managing } \\
\text { relationships and } \\
\text { networking. }\end{array}$ & $\begin{array}{l}\text { Service commitment to clients and } \\
\text { customers. } \\
\text { Effective in leading change. } \\
\text { Persuasiveness. }\end{array}$ \\
\hline Social Skill & $\begin{array}{l}\text { Aptitude in finding } \\
\text { common ground and } \\
\text { build rapport. }\end{array}$ & Team building talent. \\
\hline
\end{tabular}

Table 1 Adapted from Goleman (1998). 


\section{Self-Awareness}

As the first component of emotional intelligence, Goleman (1998) described that selfawareness involves individuals having a thorough knowledge of their own emotions and what drives them. They should also understand their own moods and how their moods and emotions impact their followers and others. Persons who understand their own emotions can be more honest with themselves and others. Self -aware individuals are more self -confident and have defined values and goals and can easily turn away from ideas that do not support their values. These individuals can honestly admit failures and discuss what they learned from past failures in a humorous fashion; they can easily discuss their own strengths and weaknesses and are open to constructive criticism without feeling threatened. This trait allows leaders to honestly evaluate themselves as well as the organization they lead.

\section{Self-Regulation}

Goleman (1998) described self- regulation as the component of emotional intelligence that allows individuals to control the natural impulses within all of us. Leaders are not exempt from emotions and feelings, but the ability to control these emotions and channel them in useful avenues establishes an environment conducive to building trust and fairness. Goleman (1998) suggested that productivity is improved in this type of environment. Additionally, self-regulation increases an individual's ability to adapt to change, which is a crucial skill for leaders. Novick et al. (2008) suggested that the situational leadership model may be the most effective for public health leaders. Situational leadership theory recognizes that change is constantly occurring within organizations and that leaders must adapt to change in order to be effective (Northouse, 2010). Another benefit of self-regulation among leaders is that it improves integrity and thereby enhances the strength of organizations (Goleman, 1998). According to Goleman when leaders 
forego impulses to be less than truthful and choose to adhere to their defined sense of values, it is recognized by others and builds long-lasting positive relationships.

\section{Motivation}

Motivation is a key component of successful leaders. Goleman (1998) described motivation as the drive to achieve just to be accomplished regardless of external factors such as salary or status. Individuals with high motivation exhibit passion for their work and energy for change. They are constantly looking for better ways to do things and will not usually choose the easy path. These individuals also feel strongly about measuring progress in an ongoing fashion and to continually raise the bar toward improvement. They are able to combine self-regulation with motivation when the outcome measures do not meet expectations and remain optimistic. Empathy

Goleman (1998) described empathy as the component of emotional intelligence that requires leaders to consider the feelings of others. In public health leadership this skill is crucial because public health is concerned with teaching and assisting people to make positive changes to improve health outcomes. Public health leaders must be aware of the feelings and cultural habits of the population they serve and must not be judgmental about the views of others. Public health leaders must be open to ways to reach all of the public, and this involves an understanding of the individuals that make up the public, which today can be extremely diverse.

\section{Social Skill}

Goleman (1998) described social skill as an outcome of the other three components of emotional intelligence and involves leaders being friendly with the purpose of moving people in the desired direction. Individuals exhibiting a great deal of social skill are able to find commonality with all kinds of people, and they have a knack for building connections with 
others. Leaders with social skill believe in the team approach to meeting goals and are proficient at managing teams. These individuals are also great at motivating others through the use of persuasion either through an emphasis on reason or emotional pleas, depending on the circumstances.

In summary, leaders in public health should participate in ongoing leadership training to enhance their skills and knowledge. They should be able to quickly identify information pertinent to the public health landscape in order to address the most important issues. They should be risk takers and avid communicators. These leaders should be systems thinkers and be able to look at the big picture, which today involves global issues. Public health leaders should be positive role models and be able to motivate others. Improving emotional intelligence can assist leaders in any area to be more effective. Emotional intelligence improves with age and maturity, but individuals can learn the components of emotional intelligence and work to apply

them to become better leaders. Today's leaders face many challenges that include understanding the needs of numerous cultural groups, changing family values, and a global economy. Increased emotional intelligence can provide a foundation to support leaders in today's rapidly changing environment.

\section{Skills for Public Health Leaders}

In addition to identifying the five most important skills for public health leadership, Rowitz (2014) also discussed 16 principles that public health leaders should employ to guide their actions. The following is a summary of these principles.

Principle 1: Using existing core functions of public health as a guide to the changes that are needed, public health leaders must evaluate the health status of the population, the ability of the community to deal with its health priorities and to implement preventive measures to lessen 
the chance of public health predicaments. Leaders must be knowledgeable of the present state of health affairs and have the vision to realize new ideas that are built on past experiences.

Principle 2: Public health leaders believe that health promotion and disease prevention is fundamental to public health. Public health differs from the acute care medical system that focuses on treatment and rehabilitation because public health emphasizes prevention. Therefore, public health leaders will become teachers and mentors for the community and promote the vision of good health for all. Leaders in public health desire that access to excellent quality comprehensive health care be available to all members of the community

Principle 3: Community coalitions are essential to build resources and a system based on shared responsibility. Health care to meet the needs of a community requires many entities working together. Resources should be shared and public health leaders can lead the development of coalitions which support sustainable community programs and health care systems that can benefit communities. Community coalitions should have defined leaders, collaborative trust among members, representatives with expertise in varied areas who have a position of power and are involved in decision making, and have credibility within the community so that it will be taken seriously.

Principle 4: Public health leaders should seek health for all citizens based on the principle that all people are created equal. In today's diverse society, public health leaders must be culturally responsive. Programs should be developed with a sense of equality by gender, race, ethnicity, language, and socioeconomic status. Public health leaders should create and follow policies that support inclusion and monitor the effectiveness of reaching all members of the community. 
Principle 5: Public health agency leaders should collaborate with the local board of health, local and county boards, and other stakeholders with a philosophy of equality and trust. Because they are charged with protecting the interests of the community, shared leadership and vision are crucial to effectively meeting the needs of the community.

Principle 6: Public health leaders should learn how to be effective mentors from others who are more experienced public health leaders. Because they are in a unique position to help community members make better health choices, they should learn and develop the role of mentoring others.

Principle 7: Public health leaders should work tirelessly to develop and improve personal leadership skills through lifelong learning. The need for ongoing leadership training in public health was identified by the Institute of Medicine report on The Future of Public Health (IOM, 1998) that called for training and development of public health workers to meet the changing demands of public health concerns. In response, the National Public Health Leadership Development Network created a framework of standards for leadership development in public health (Novick et al., 2008; Wright et al., 2000). This initiative led to the National Public Health Leadership Institute (PHLI), founded by the CDC in 1991.

Principle 8: Public health leaders must be committed to personal growth and improved self-esteem. A leader with high self-esteem is more effective at leading and inspiring others and also in building strong organizations. Improving emotional intelligence (Goleman, 1998) may assist public health leaders in this area.

Principle 9: Public health leaders must consider that public health involves the whole community and is built on democratic ideals and values with respect for all individuals as part of the American society. The infrastructure of the public health community incorporates the entire 
community and comprises physical, psychological, emotional, economic and social health of all of its members.

Principle 10: Public health leaders need to think on a global level but act on a local level. Public health threats from other regions or countries must be evaluated for potential concerns in the local community and public health leaders must be proactive toward outside threats.

Principle 11: Public health leaders should be good managers and assure that their current systems are functioning effectively. But they must also be leaders and change agents and be able to move their agencies forward. This requires dynamic leadership skills and managerial tools.

Principle 12: Public health leaders should walk the walk and inspire others to follow. This principle emphasizes that public health leaders should lead by example and enthusiastically work to move community members, partners, and stakeholders in desired directions for improved population based health promotion and disease prevention.

Principle 13: Public health leaders should be proactive, rather than reactive. This requires the development of action plans and assessment methods to continually evaluate and respond to community needs. Through action planning and assessment public health leaders can create programs that prevent problems from occurring and evaluate outcomes for needed modifications of programs.

Principle 14: Leadership is essential in every level of the public health system. Individuals in all levels of the system can lead change and take leadership roles to improve the public's health. The essence of this principle is that shared leadership through formation of a team is most effective in dealing with public health concerns.

Principle 15: Public health leaders must understand what a community is. Essentially, a community is defined as "people living together who participate in common practices; depend 
upon each other; make decisions together; identify themselves as part of something larger than the sum of their individual relationships; and commit themselves for the long term to their own, one another's and the group’s well-being”(Rowitz, 2014, p. 11). An understanding of the community and how members of the community think can assist public health leaders to empower community members to share the responsibility for improving their own health.

Principle 16: Public health leaders should practice what they preach. If a leader is promoting good health practices, they should follow these themselves to inspire others. When others observe conflicts between what a leader says and does, they lose trust and respect for that leader and are less likely to follow.

In summary, the complexity of leading in public health is affected by many factors. Leaders in the public health sector must be flexible and adaptable in a changing environment. They must be committed to supporting the improvement of health for the entire population without prejudice and they must be culturally responsible. They must work to develop their own leadership skills and be committed to lifelong learning. They must set positive examples for others to follow and work to build collaborative teams of leaders among community partners and stakeholders at all levels of the community.

\section{Leadership Theories and Public Health}

Although many leadership theories are recognized, Novick et al. (2008) suggested that Blanchard's situational leadership model may be the most effective for public health leaders. Situational leadership theory recognizes that change is constantly occurring within organizations and that employees continually advance and retreat along the developmental continuum (Northouse, 2010). Developmental levels of employees vary according to skill and interest level. According to Northouse (2010) individuals at a high development level know how to complete 
assigned tasks and are interested and confident in their work. In contrast, persons at a low development level lack the skill required for specific assigned tasks but believe that they can complete the job. Situational leadership theory emphasizes that different situations require different types of leadership. Leaders should be flexible and adapt their leadership style to the needs of their subordinates based on the follower's skills and motivation (Northouse, 2010; Novick et al., 2008). Situational leadership theory identifies four leadership styles required to deal effectively with followers. These are directing, coaching, supporting, and delegating (Northouse, 2010; Novick et al., 2008).

\section{Directing Approach}

The directing approach of leaders involves giving directions, establishing goals and methods of evaluation, setting time lines, defining roles, and showing how the goals are to be achieved (Northouse, 2010). Directing is appropriate when followers have low motivation level and low skill for a task. Directing involves providing close supervision of followers and communication is one-way between leader and followers and is considered high directive and low supportive.

\section{Coaching Style}

Coaching style described by Northouse (2010) involves providing encouragement and seeking input from followers. The leader is concerned with achieving goals while meeting the socioemotional needs of followers. This style uses more two-way communication and is appropriate when followers have high motivation level but low skill level for a task. This style is considered high directive and high supportive. 


\section{Supporting Style}

The third style of situational leadership described by Northouse (2010) is the supporting style that involves less focus on goals and a greater use of supportive behaviors. Supporting style involves high support and low directive behavior and is appropriate when followers have a high degree of ability but low motivations for a task. The leader must find ways to motivate followers to complete the task. This may involve active listening, giving praise, seeking input from followers, and providing feedback. Communication must be two-way.

\section{Delegating Style}

Delegating is the fourth style of leadership described by Northouse (2010). This approach is appropriate when followers have a high ability and a high degree of motivation to complete a task. Followers require little supervision and assume responsibility for completing tasks on their

own. The leader is less involved in planning, control, and clarification of goals; instead the leader allows followers to assume responsibility to complete the task in the way they desire.

In summary, the situational leadership theory emphasizes the need for flexibility. Leaders in public health can use this style of leadership to lead change in communities. Being aware of the level of commitment toward change that members of the community have can assist public health leaders to adapt their leadership approach to the needs of the individuals and the communities they serve.

\section{Leadership Abilities Needed for Public Health}

Leadership in public health involves social change through identification of health risks and concerns and motivating a course of actions to eliminate health disparities (Rowitz, 2014). After analyzing the varied leadership theories and traits of effective leaders, Rowitz (2014) 
extracted 10 leadership abilities and practices especially crucial to successful public health leadership in the $21^{\text {st }}$ century. These are:

1. Public health leaders must be knowledge synthesizers and be aware of past, present, and future events and be experts in their field. They must be able to move public health organizations in a forward direction. Intelligence by itself is not adequate; they must also have self-awareness, self-control, self-confidence, commitment, integrity, superior communication skills and be change agents for the community they serve.

2. Public health leaders must use knowledge creatively to guide their actions. This requires sifting through huge amounts of information daily and being able to ignore information that is not pertinent. Effective public health leaders should have enthusiasm for their role and this can create a natural flow of creative thought from the information gathered.

3. Public health leaders need to be able to create; share and commit to a vision and to its corresponding mission and be flexible to modify the vision to please public health partners. An effective vision takes into account different scenarios that might occur in the presence of particular factors. Effective visioning also requires that partners and stakeholders share the vision so that they support it. Public health leaders should be able to project a long-term vision that expands on the possibilities of the future and be flexible enough to realize the need for modification to meet the needs of partners. Additionally, public health leaders should be adept at matching the vision to a mission and put an action plan into place to meet the vision.

4. Public health leaders should cultivate community collaboration and partnerships that involves respecting the needs and wants of partners. Public health leaders serve communities and need 
the support of community members and partners within the community. Shared leadership allows participation of all stakeholders and fosters a sense of team spirit and collaboration.

5. Public health leaders need to have entrepreneurial skills to assist with finding funding sources. Funding is paramount to sustainability of public health programs. Public health leaders should be able to find funding sources from many resources including private sector sources; collaboration with community organizations can help provide additional funding opportunities.

6. Public health leaders should be systems thinkers and turn the organization into a learning organization that involves making the system the guiding catalyst for change, thereby enhancing the public health organizations ability to keep pace with the constant changes in society. Systems thinking realizes that all elements are connected and events or activities that occur in one area affect the others. Public health leaders should try to determine strategies for leading change while they consider the challenges of the system.

7. Public health leaders need to set priorities relative to the needs of the community they serve. These decisions are frequently influenced by political issues and community concerns. This makes collaboration with community partners an essential element to help evaluate and determine the needs of the community and how they will be prioritized.

8. Public health leaders need to form community coalitions and build teams to conquer health concerns. Public health leaders must involve others in the decision making process to be able to assure that the needs of all partners in the community are being met. Having representatives from all community groups helps empower the community to address its own concerns. 
9. Public health leaders must become masters of the latest management and leadership techniques and put innovative ideas into practice. This involves life-long learning and keeping current with the latest management and leadership techniques to determine is any new ideas can help them become more effective leaders and to help strengthen the public health organization.

10. Public health leaders must act as a friend and humanitarian to everyone in the public health organization and community. This requires public health leaders to have empathy toward others and to respect the values and cultures of all partners, stakeholders, and community members.

In summary, public health leaders need a variety of characteristics to be effective leaders. An understanding of the complexity of public health in a global society is essential to effective public health leadership. Additionally, being visionary, using systems thinking, building collaborative relationships and teams within communities, having entrepreneurial ability, and being a humanitarian provide a strong foundation for effective public health leadership.

\section{Background on Vitamin D Deficiency}

Humans obtain vitamin D from sun exposure, food sources, or from nutritional supplements (Holick, 2007). Health professionals have not considered vitamin D deficiency a problem due to the disappearance of rickets following vitamin $\mathrm{D}$ fortification of milk in the 1930s. A decline in milk consumption in the U.S. population is well documented. Data from the United States Department of Agriculture (USDA) dietary intake surveys indicate that the number of preadolescent children who did not drink milk daily rose from $12 \%$ to $24 \%$ between the study years 1977-78 and 2007-08. During the same time period the consumption of milk at least three times per day dropped from 31\% to 18\% in preadolescents (Stewart, Dong, \& Carlson, 2013). 
The percent of adolescents and adults who did not drink milk daily rose from $41 \%$ to $54 \%$ between the study years 1977-78 and 2007-08; while the amount who drank milk three or more times per day declined from $13 \%$ to $4 \%$ (Stewart et al., 2013).

According to experts (Heaney, 2004; Holick, 2006; Holick \& Chen, 2008; Vieth et al., 2007) vitamin D deficiency is currently considered as a major health problem with implications for several health conditions. Because very few foods naturally contain vitamin D, humans require sun exposure to synthesize vitamin D in the skin. Deficiency of vitamin D is known to cause rickets in children and lead to osteoporosis and osteomalacia in adults (Holick, 2008). Vitamin D is important for bone health because it enhances calcium and phosphorus absorption required for healthy bone. In the absence of adequate vitamin $\mathrm{D}$, absorption of calcium and phosphorus is decreased. Holick (2007) suggested that calcium absorption is decreased to $10 \%$ to $15 \%$ of optimal, and phosphorus absorption is lessened to $60 \%$ of optimal. Heaney (2004) proposed that undetected bone disease may be present before the diagnosis of rickets or osteoporosis, due to a vitamin D insufficiency. According to Holick (2006) and Bischoff-Ferrari, et al. (2006) vitamin D insufficiency is also implicated in other health conditions such as limitations in achieving peak bone mass, inadequate muscle function, type 1 diabetes mellitus, periodontal disease, hypertension, and many cancers.

Results of studies of vitamin D status and related health implications have brought increased attention to the evaluation of vitamin D in humans. Studies of vitamin D status in older adults have consistently found high incidences of vitamin D insufficiency (Bischoff-Ferrari et al., 2006; Chapuy et al., 1997; Holick, 2005, 2006). One of the reasons for decreased vitamin D in the elderly is that aging is connected to decreases levels of the precursor of vitamin $\mathrm{D}$ found in the skin (Holick \&Chen, 2008). Data from the 2000 to 2004 NHANES, conducted by the 
National Center for Health Statistics (NCHS) Centers for Disease Control (CDC) and prevention, looked at vitamin D status among all age groups. In a comparison of the data from the NHANES III study of 1988-1994 versus NHANES 2000-2004, Looker et al.(2008) postulated that mean serum vitamin D level of the U.S. population were significantly lower in the latter years. Both studies included a nationally representative sample of participants where data were collected through direct interviews and physical exams . Results of these surveys have implications for health leaders because of the connection between vitamin D level and overall health. Decreased level of vitamin D in the U.S. population among younger age groups are thought to be related primarily to a combination of overall declines in milk intake and increased use of sunscreen (Looker et al., 2008).

Tangpricha, Pearce, Chen, and Holick (2002) reported vitamin D deficiency in 37 \% of healthy young adults aged 17 to 35 years. Similarly Thomas et al. (1998) found vitamin D insufficiency among 57\% of medical inpatients in the United States. Holick (2006) attributes insufficiency of vitamin D to lack of sun exposure, age related decline in skin synthesis capabilities, and low intake of vitamin D rich foods.

Studies of vitamin D insufficiency and links to overall health have increased concerns that vitamin D status is more important than has been previously considered. Poor vitamin $\mathrm{D}$ status in youth and young adults could possibly have future health consequences for reasons related to formation of peak bone mass, muscle strength, and the links to numerous diseases (Stein et al., 2006).

\section{Vitamin D Intake}

Data regarding the intake of vitamin D from foods and supplements from the Third National Health and Nutrition Examination Survey (NHANES III) and the Continuing Survey of 
Food Intake by Individuals (CSFII) was evaluated by Moore et al. (2004). NHANES III is a nationally representative database of 24-hour dietary recalls from 29,105 nonbreastfeeding individuals during 1988-1994. CSFII data were collected using two 24-hour recalls for 18,931 nonbreastfeeding individuals during 1994-1996 and in 1998. Comparing intake by age groups from age 1 to older than 70, and between genders, there was a lower intake of vitamin D from food sources among females than males in both teens and adults. The highest intakes of vitamin D from food sources were in males ages $9-13$. Furthermore, less than $10 \%$ of adults ages $51-70$ and less than $2 \%$ of adults over age 70 met vitamin D requirements from food alone. Similarly, Bailey et al. (2010) examined data on vitamin D intake in the US population from a subsequent NHANES survey of 2005-2006. Children ages 1-3 years had the highest prevalence of meeting vitamin D requirements from food sources, while females age 14-18 years along with adults age 71 and older had the lowest occurrence of meeting estimated vitamin D requirements.

Weng, Shults, Leonard, Stallings, and Zemel (2007) explored risk factors for low serum vitamin D among 382 healthy children aged 6-21 years living in the northeastern United States. Their study found 53\% of the subjects had total vitamin D intake less than 200 IU per day, which was the recommended daily adequate intake at the time of this study.

\section{Studies of Vitamin D Status}

\section{Vitamin D Status in Young Adults}

Vitamin D status has been well studied among children and older adults because of the concerns of rickets, bone health, osteoporosis, and fractures. Few studies of vitamin D status involving young adults are available. Holick et al. (2011) suggested that young adults aged 19-50 years are at risk of vitamin D deficiency due to a decline in outdoor recreation and increased use of sunscreen. Obtaining information on the vitamin D status of young adults is a reasonable 
consideration of preventive health because of the connection between vitamin $\mathrm{D}$ status and compromised bone health later in life and the links relating vitamin D deficiency to other chronic diseases. Information on younger individuals could help inform health leaders regarding policy decisions and recommendations for this population.

In a study of healthy young adults (Tangpricha et al., 2002) evaluated vitamin D level at the end of winter in four age groups: 18 to 29 years, 30 to 39 years, 40 to 49 years, and greater than or equal to 50 years in Boston, Massachusetts. They concluded that $36 \%$ of the young adults, ages 18 to 29 years, had vitamin D deficiency and that this age group also had lower vitamin $\mathrm{D}$ levels than the oldest age group, placing this age group at equal to greater risk of vitamin D deficiency than older adults. Another finding of this study was that the frequency of vitamin D insufficiency was higher in subjects who did not take a multivitamin supplement. This study also found that serum level of vitamin D was not associated with dietary milk intake. According to the researchers, one reason for this is the fact that milk has a variable amount of vitamin D. This was identified by Holick, Shao, Liu, and Chen (1992) in a study of vitamin D content of milk and infant formula. They reported that only $29 \%$ of 42 milk samples studied contained $80 \%-120 \%$ of the label statement, $62 \%$ of the milk samples contained $<80 \%$ of the label value, and 3 of 14 samples of skim milk had no measurable vitamin D.

Binkley et al. (2007) studied 93 adults with a mean age of 24 years, in Honolulu, Hawaii, and found $51 \%$ of this population with insufficient vitamin D level, despite adequate sun exposure. Results suggest that sun exposure may not ensure adequate vitamin D status. Binkley at al. (2007) posited that other factors such as a reduction in cutaneous production of $\mathrm{D}_{3}$ in the skin or abnormalities of transport from the skin to the circulation may play a crucial role in synthesis of vitamin D. 
Seventy-seven female college students aged 19-24 years were studied by Nakamura, Nashimoto, Matsuyama, and Yamamoto (2001) to determine if this age group was at risk of vitamin D insufficiency and if vitamin D level was a predictor of bone strength. They concluded that $40.3 \%$ of the healthy young women were insufficient in vitamin D. Additional findings included a significant positive relationship between vitamin D level and measure of bone strength.

Al-elq (2012) studied vitamin D status of 198 medical students in a Saudi medical school. The mean age of the students was 19.54 years. Among this group, all students were low in vitamin D; 96 \% were vitamin D deficient, and the remaining $4 \%$ were vitamin D insufficient. The high prevalence of vitamin D deficiency in this group can be related to the traditional practice of purdah, where all skin is covered and not exposed to sunlight, thereby blocking sun rays for synthesis of vitamin $\mathrm{D}$ in the skin. This helps to explain why some of the sunniest areas of the world have high incidences of vitamin D deficiency (Holick \& Chen, 2008).

An examination of vitamin D status among 290 hospitalized patients with a mean age of 62 years and an age range of 18-99 years, in Boston, Massachusetts found 164 (57\%) of patients deficient in vitamin D. Of those, 65 (40\%) were severely deficient with a serum concentration of 25-hydroxyvitamin D less than $8 \mathrm{ng} / \mathrm{mL}$. Another 99 of those patients were moderately deficient with a 25-hydroxyvitamin D serum level of 8-15 ng/mL (Thomas et al., 1998).

Gozdzik et al. (2008) studied wintertime vitamin D level of 107 university students in Toronto, Canada. Results indicated that $84.4 \%$ of the study participants had serum vitamin D level less than $30 \mathrm{ng} / \mathrm{mL}$, and 40.6\% had vitamin D level less than $20 \mathrm{ng} / \mathrm{mL}$. The mean concentration of 25 -hydroxyvitamin D was 15.79 in this group. Gozdzik and colleagues also noted that mean total vitamin D intake from foods and supplements was lower than Healthy 
Canada's recommendation of $200 \mathrm{IU}$ per day. Moreover, the factors that appeared to influence vitamin D serum level in this study were vitamin D intake and skin pigmentation; those with darker skin pigmentation having lower vitamin D level.

A cross sectional study by Nakamura et al. (2001) looked at vitamin D level of 77 healthy young women ages 19-66. Forty-two percent of subjects less than 30 years of age had mean vitamin D concentrations less than $13.6 \mathrm{ng} / \mathrm{mL}$ compared to only $10.3 \%$ in those older than 30 . These findings suggest that young adults may be at a higher risk than older adults.

Galan et al. (2012) examined vitamin D level among 28 white professional football players in Spain to establish the required concentration of serum vitamin D to maintain vitamin D sufficiency from October throughout the winter until February. The results indicated that the serum vitamin D level required in October to maintain vitamin D sufficiency throughout the winter months was $48.9 \mathrm{ng} / \mathrm{mL}$. Two thirds of the subjects were deficient in vitamin D in early February. Almost a third of the group, with vitamin D level above $40 \mathrm{ng} / \mathrm{mL}$ in October, experienced a drop in vitamin D level to less than $30 \mathrm{ng} / \mathrm{mL}$ in early February.

Vitamin D Status in Children ages 1 to 18

Studies of vitamin D status in younger children have also found high level of vitamin D insufficiency. Gordon, DePeter, Feldman, Estherann, and Emans (2004) evaluated vitamin D deficiency among 307 healthy adolescents aged 11 to 18 years, in Boston, Massachusetts. Mean age of participants was 14.7 years. Two hundred of the participants were female, 107 were male. The study found vitamin D deficiency in $24.1 \%$ of the participants. No significant differences were noted between males and females. However, the results noted a positive correlation between vitamin $\mathrm{D}$ deficiency and consumption of soft drinks, fruit juice, and tea and an inverse relationship between deficiency of vitamin D and consumption of milk and cold cereal. 
An examination of vitamin D status during winter months in 168 girls aged 4 to 8 years living in northeast Georgia was conducted by Stein et al. (2006). Vitamin D deficiency was not recognized in this study group; however, the mean vitamin D concentration was $19 \%$ lower in black girls than in white girls. Because the age of puberty is the most crucial period for bone development, this may indicate risk of future vitamin D insufficiency in black girls at a critical time in their development (Stein et al., 2006).

Kemp et al. (2007) studied vitamin D status in black and Hispanic children aged 1 to 8 years in a New Jersey clinic in both summer and winter months. They found $12 \%$ of 142 children had vitamin D insufficiency in winter months, compared to $0.7 \%$ with vitamin D insufficiency in summer months. This is likely due to expected sun exposure being higher in summer months, contributing to improved vitamin D level.

Another study by Harkness and Cromer (2005) studied vitamin D deficiency among 370 adolescent females in Cleveland, Ohio, and found $17 \%$ of the girls were deficient and $54 \%$ of the girls were insufficient in vitamin D. Additionally, the mean vitamin D level between black and white girls was significantly different, with higher levels among whites. Seasonal differences in vitamin D level were noted, with higher level in spring and summer months when sun exposure is typically greater. Another finding was a negative correlation between body weight and vitamin D level.

Sullivan, Rosen, Halteman, Chen, and Holick (2005) explored seasonal variations in vitamin D level over a 3-year period, among 23 healthy girls, ages 9 to 11 years in Bangor, Maine. They observed a $28 \%$ decrease in vitamin D level between September and March. Forty-eight percent of the participants were insufficient in vitamin D at some point during the 3- 
year study. Seventeen percent of the participants demonstrated vitamin D insufficiency in both September and March.

Similarly, Weng et al. (2007) examined vitamin D level among 382 healthy children aged 6-21 in the northeastern United States. Their results indicated 55\% of the subjects had vitamin D $<30 \mathrm{ng} / \mathrm{mL}$, with a mean concentration of $28 \mathrm{ng} / \mathrm{mL}$. Among the children whose levels were taken in winter months, prevalence of vitamin D deficiency was $51 \%$ in whites and $94 \%$ in blacks.

An investigation of vitamin D level and other factors, among 93 children, ages 10 to14, of different ethnicities in Houston Texas revealed $17 \%$ of the participants to be vitamin D deficient, and $73 \%$ to be insufficient (Abrams et al., 2005). Rovner and O’Brien (2008) conducted a review of numerous studies of vitamin D status in children and concluded that vitamin D insufficiency among children in the United States is widespread.

Fuleihan et al. (2001) studied vitamin D deficiency among 346 school children ages 1-16 years was conducted in Beirut, Lebanon. Results indicated that $65 \%$ of the students were deficient in vitamin D in the winter months and $40 \%$ at the end of the summer, when sunlight exposure was maximized. Girls had lower levels than boys with the lowest levels reported among the girls wearing traditional head and full body covering.

Shin et al. (2012) explored vitamin D adequacy among 188 Korean adolescents ages 1213 years. They found $98.9 \%$ of males and $100 \%$ of females to have serum vitamin D concentrations less than $30 \mathrm{ng} / \mathrm{mL}$. These results suggest a greater degree of risk of vitamin D related concerns among the Korean population than in other countries where studies have been reported. 


\section{Vitamin D Deficiency and Disease Risk}

\section{Vitamin D and Cancer Risk}

Links between vitamin D deficiency and numerous health conditions are well established. In the area of cancer research, vitamin D deficiency has been found to have an association with several different forms of cancer. Because cancer can be such a devastating illness, affecting huge numbers of individuals, research into possible causes of cancer is ongoing. Numerous studies have demonstrated that low levels of vitamin D are associated with increased risk of colorectal cancer and mortality (Cross, Bises, Lechner, Manhardt, \& Kallay, 2005; Davis \& Dwyer, 2007; Tangripcha et al., 2005; Wu et al., 2007). One study of pancreatic cancer and vitamin D level in men ages 50-69 by Stolzenberg-Solomon (2006) found higher incidences of pancreatic cancer in those subjects with high level of vitamin D at the beginning of the study. In a review of data from NHANES III, Freedman, Looker, Chang, and Graubard (2007) found no association between vitamin D level and cancer mortality from all forms of cancer. They did however find an inverse relationship between vitamin D status and mortality from colorectal cancer.

Garland et al. (2006) reviewed 63 studies of vitamin D status and cancer risk. These included 30 studies of colon cancer, 13 of breast cancer, 26 of prostate cancer, and 7 of ovarian cancer. Of the studies related to colon cancer and vitamin D status, 20 indicated a statistically significant benefit of vitamin D on colon cancer risk or mortality. Five others linked marginal statistical significance to a risk of colon or rectal cancer. Nine of the 16 studies that looked at risk of breast cancer and vitamin D status reported a negative relationship between vitamin D status and risk of breast cancer. Furthermore, in 13 of the 26 studies of prostate cancer, researchers found a favorable association between vitamin D level and risk of prostate cancer. 
Among the 7 studies of risk of ovarian cancer and vitamin D status, the authors found higher rates of mortality linked to less sunlight or lower intake of vitamin D in five of the studies. Thus, there is a good argument that adequate vitamin D status may provide preventative effects on the health of individuals, and this is particularly crucial in younger adults prior to the usual onset of many possible chronic health conditions.

\section{Vitamin D and Links to Other Health Concerns}

Relationships between vitamin D level and other health concerns have also been found. Munger, Levin, Hollis, Howard, and Aschero (2006) reviewed 146 cases of multiple sclerosis in army and navy medical records. A significant decrease in the risk of multiple sclerosis with increased vitamin D level was noted among whites and was greater in individuals less than 20 years of age. But no associations were found between vitamin D and multiple sclerosis risk among Hispanics and blacks.

Additionally, there is evidence linking vitamin D insufficiency with cardiovascular disease risk. Wang et al. (2008) conducted a longitudinal study of 1,739 participants and found an inverse relationship between vitamin D status and cardiovascular disease. Lind et al. (1995) found that increased risk of cardiovascular risk in middle aged men was associated with lower vitamin D level. In a study of myocardial infarction among 179 subjects, Scragg, Jackson, Holdaway, Lint, and Beaglehole (1990) found a relationship between lower vitamin D level and higher incidences of myocardial infarction. Moreover, Lind et al. (1995) found that reduced vitamin D is related to higher incidences of high blood pressure and other cardiovascular risk factors in middle aged men.

Fung, Steffen, and Zhou (2012) examined the risk of developing metabolic syndrome, defined as a combination of abdominal obesity, elevated blood pressure, high blood glucose, low 
high density lipoprotein level, and high triglyceride level that increases risk of coronary artery disease. Their study identified an inverse relationship between diet plus supplemental vitamin D intake and development of metabolic syndrome. Similarly, Reis, van Muhlen, Miller, Michos, and Appel (2009) studied whether low serum vitamin D level was associated with risk of cardiovascular disease in US adolescents age 12-19 years, based on data from the 2001-2004 NHANES survey. They concluded that low serum vitamin D level is strongly associated with hypertension, hyperglycemia, and metabolic syndrome in US adolescents.

\section{Vitamin D Status and Body Weight}

Obesity and vitamin D status are strongly linked. Researchers have reported an inverse relationship between body mass index and vitamin D level in all age groups (Holick, 2006; Liel, Ulmer, Shary, Hollis, \& Bell ,1988; Looker et al. 2008; Looker et al. 2011; Wortsman, Matsuoka, Chen, Lu, \& Holick, 2000). Similarly, Arunabh, Pollack, Yeh, and Aloia (2003) studied the relationship between vitamin D levels and percentage body fat in 410 healthy women aged 20-80 years and found that percent body fat is inversely related to vitamin D levels in healthy women. A study by Parikh et al. (2004) examined vitamin D level between obese and nonobese subjects among 302 healthy adults. They found vitamin D level was significantly lower in obese than nonobese subjects in both Caucasian and African-American adults.

NHANES III data from 1988 to 1994 found mean serum concentration of vitamin D was lower in obese women with a body mass index of 30 or more than in those with body mass indexes in the normal range of 18.5 to less than 25 (Nesby-O’Dell, 2002). Individuals with a body mass index at or above 30 have lower serum level of vitamin $\mathrm{D}_{3}$ than nonobese individuals (ODS, 2011). Vitamin D is a fat soluble vitamin and the inverse relationship between obesity 
and vitamin D status is thought to be related to fat cells seizing more of the vitamin and decreasing its level in circulation (Holick, 2006; ODS,2011).

Given the fact that obesity rates have risen in the United States, this presents additional health concerns (Looker et al., 2008). While it is not known whether there is a direct association between vitamin D status in overweight individuals and the rise in obesity rates seen in the United States, this suggests an area for further research.

\section{Vitamin D Status and Race}

Numerous studies have found an association between vitamin D status and race. One reason is because darker skin makes less vitamin D precursors compared with lighter skin (Park \& Johnson, 2005). Weng et al. (2007) studied 382 children aged 6-21 years in the northeast United States and found 94\% of healthy black children deficient in vitamin D compared to 51\% in whites. Additionally, $19 \%$ of blacks had levels less than $10 \mathrm{ng} / \mathrm{mL}$, a level clinically associated with osteomalacia, rickets, and clinical myopathy. Data from the NHANES III study (19881994) indicate that, compared to whites, the prevalence of poor vitamin D status was 1.6 times to 2 times higher in Mexican Americans and 2.4 to 4 times higher in non-Hispanic blacks (Park \& Johnson, 2005).

Nesby-O’Dell et al. (2002) examined the prevalence of vitamin D deficiency (defined as less than $15 \mathrm{ng} / \mathrm{mL}$ for their study) in NHANES III data of 1,546 black women and 1,426 white women. They concluded that $42.4 \%$ of black women had vitamin D deficiency compared to $4.2 \%$ in white women. Furthermore, they found that among the 243 black women who consumed the adequate intake of vitamin D from supplements (200 IU/d), 28.2\% had vitamin D deficiency. A study of vitamin D deficiency in 637 participants in southern Arizona found a mean serum vitamin D level of 26.1 among all subjects. Fifty-five percent of blacks and $37.6 \%$ of 
Hispanics had vitamin D concentrations less than $20 \mathrm{ng} / \mathrm{mL}$ compared to $22.7 \%$ in whites (Jacobs et al., 2008). Similarly, Stein et al. (2006) studied 168 girls aged 4-8 and found mean vitamin D concentration was 19\% lower in black girls.

Harris (2006) reported unique concerns associated with vitamin D and African Americans. Healthy blacks do not achieve optimal vitamin D status because dark skin pigmentation reduces production of vitamin $\mathrm{D}$ in the skin. Because of mounting evidence that vitamin D has protective effects against numerous health conditions such as cardiovascular disease, bone disease, and cancer, and blacks have higher incidence of these than whites, health leaders should place emphasis on vitamin D level among blacks, according to Harris. Elimination of health disparities is a goal of the US government's plan "Healthy People 2020" (USDHHS, 2013).

\section{Summary}

Public health leadership is concerned with disease prevention, health promotion, and improved life for all individuals. The identification of health problems and disseminating relevant evidence based information to the public are crucial roles of health leaders. Public health leaders can and should stay abreast of current evidence regarding health recommendations and then work to assure that the public interest is best served. This can be best accomplished by leaders who are committed to life-long learning and to improving their own leadership skills. Public health leaders should be systems thinkers and should work to improve their emotional intelligence that can assist them to motivate and work well with others. Leaders in public health should be flexible and able to adapt to a fluid environment. They should also lead without prejudice and be culturally aware. 
Vitamin D deficiency is currently viewed as a major health problem with implications for several health conditions and increased medical costs. Evidence suggests that vitamin D status in all age groups is insufficient, overall milk consumption and vitamin D intake have declined and that the use of sunscreen has increased. Therefore, it seems clear that public health leaders should take a leading role in disseminating health information related to vitamin D. 


\section{CHAPTER 3}

\section{RESEARCH METHODOLOGY}

This chapter consists of a description of the study, research questions, sample, data collection methods, and data analysis methods that were used in this study. This was an exploratory quantitative study designed to investigate the vitamin D status of students at East Tennessee State University and the factors associated with vitamin D status in this population as reported by the students themselves. Descriptive statistics were used to organize, summarize, and report the data.

\section{Research Questions and Null Hypotheses}

The following research questions served as the guide for this study:

1. Is there a significant difference between vitamin D 25(OH)D levels when compared by gender, race, and academic major?

$\mathrm{H}_{0} 1_{1}$ : There is no significant difference between vitamin $\mathrm{D} 25(\mathrm{OH}) \mathrm{D}$ levels when compared by gender.

$\mathrm{H}_{0} 1_{2:}$ There is no significant difference between vitamin $\mathrm{D} 25(\mathrm{OH}) \mathrm{D}$ levels when compared by race.

$\mathrm{H}_{0} 1_{3}$ : There is no significant difference between vitamin $\mathrm{D} 25(\mathrm{OH}) \mathrm{D}$ levels when compared by academic major.

Is there a significant relationship between vitamin D 25(OH)D level and body mass index?

$\mathrm{H}_{\mathrm{o}} 2_{1}$ : There is not a significant relationship between vitamin D $25(\mathrm{OH}) \mathrm{D}$ level and body mass index.

2. Is there a significant relationship between vitamin D $25(\mathrm{OH}) \mathrm{D}$ level and age? 
$\mathrm{H}_{0} 3_{1}$ : There is not a significant relationship between vitamin D 25(OH)D level and age.

3. Is there a significant difference between total vitamin $D$ intake from food and supplements when compared by gender, race, and academic major?

$\mathrm{H}_{0} 4_{1}$ : There is no significant difference between vitamin $\mathrm{D}$ intake from food and supplements based on gender.

$\mathrm{H}_{0} 4_{2}$ : There is no significant difference between vitamin $\mathrm{D}$ intake from food and supplements based on race.

$\mathrm{H}_{0} 4_{3}$ : There is no significant difference between vitamin $\mathrm{D}$ intake from food and supplements based on academic major.

4. To what extent can BMI and dietary intake of vitamin D predict vitamin D $25(\mathrm{OH}) \mathrm{D}$ level?

$\mathrm{H}_{0} 5_{1}$ : Dietary intake of vitamin D and BMI cannot predict vitamin D 25(OH)D level.

Sample

The study sample included 98 students from East Tennessee State University (ETSU), aged 18-29 years. The goal of the sample size was determined to be 100 based on the costs of the study, which was covered by a Dean’s Research Enhancement Grant Award of \$10,000 awarded to the researcher. Total costs were $\$ 100$ per subject which included a $\$ 75.00$ fee for the blood test, a $\$ 5$ fee for the blood draw, and a $\$ 20.00$ stipend to each study participant. A random selection of volunteer participants was obtained through the placement of study recruitment flyers in public buildings throughout campus. The flyers directed participants to the study area in Hutcheson Hall, ETSU where they were enrolled in the study on a first come, first served basis until the goal of 100 participants was reached. 
One of the unique features of this study involved the date of the data collection. IRB approval was finalized early in February and the data collection was initiated immediately. The data collection immediately preceded Valentine's Day and I believe that influenced subjects to participate in order to obtain the $\$ 20$ stipend.

\section{Data Collection}

Permission to conduct the research was obtained from the Institutional Review Board (IRB) of ETSU. The study was initiated immediately upon final IRB approval and occurred during the first 3 weeks of February, 2013. Recruitment flyers were posted in public buildings on the campus of ETSU and in the buildings of religious centers near campus, with approval of their directors. A winter month was chosen to conduct the study because of anticipated less frequent sun exposure by participants.

Study participants were directed to the study location in Hutcheson Hall, ETSU by the recruitment flyer. The researcher or the trained clinical nutrition graduate assistant, under the direction of the researcher, obtained informed consent. Consent forms contained the components required by the ETSU IRB guidelines. Disclosure of the purpose, duration, procedures, and possible risks and benefits were included. Possible risks or discomforts were discussed with each participant. These involved slight bleeding, redness, or swelling of the skin at the site of the blood draw. Participants were also told of possible benefits of the study that included the results of their vitamin D assay, and free follow-up medical and nutrition services if they provided an electronic mail address for follow-up contact. They were also told that if their vitamin D 25(OH )D was suboptimal, less than $30 \mathrm{ng} / \mathrm{mL}$, they would receive notification from Dr. Lisa Ousley, Director of the ETSU Student Health Clinic, and would be eligible to receive a free referral to 
her to discuss possible treatment options. Additionally, they would receive information from the researcher via electronic mail describing nutritional interventions to increase vitamin D status.

Assurance that the study involved no financial costs to participants and that participation was voluntary was included in the informed consent. Specific information related to compensation for completion of all components of the study was included. The identity of participants was protected through the use of random numbers. As required by the IRB, data will be kept in locked storage and destroyed after 5 years.

After obtaining informed consent the researcher or graduate assistant administered the study survey that included two parts and can be seen in Appendix A. Part one included demographical information of age, gender, race, use of vitamin supplements, student meal dining location, current academic major, and whether or not the participant had recently traveled to a sunny location. Examining differences in vitamin D status based on a student's dining location was exploratory. The researcher wanted to determine if eating meals on or off campus influenced vitamin D status. Recent travel to a sunny location was included because sun exposure can influence vitamin D status. Part two of the survey included the food frequency questionnaire to establish reported intake of vitamin D from foods.

The category of the student's academic major was included in this study as an exploratory question. Within ETSU are several health related colleges: The College of Nursing, The College of Medicine, The College of Pharmacy, The College of Clinical and Rehabilitative Health Sciences, and The College of Public Health. Additionally, ETSU houses The College of Education, The College of Arts and Sciences, and The College of Business and Technology. The researcher wanted to explore differences in vitamin D 25(OH)D levels among students in health 
related majors compared to students in nonhealth related majors. There was no previous research in this area.

Following completion of the survey demographic questionnaire, the researcher or graduate assistant obtained and recorded the anthropometric measurements of height, weight, BMI, and body fat percentage of each participant. Assessment of body fat percentage was measured with an Omron bioelectrical impedance analyzer, a noninvasive, hand held caliper. Height was measured using a Charder HM-200P Portstat height measurement stadiometer. Weight was measured using a Healthometer weight tracking scale. The same instruments were used for each participant.

After completing the anthropometric measurements and the survey questionnaire, subjects were provided instructions on how to obtain the blood draw and directions to the clinic, which was a short walk to another ETSU building. They were given a voucher that identified them as a study participant to prevent fees being charged to them. Participants were instructed to have the voucher stamped at the clinic to verify completion of the blood test and return it to the researcher by the subjects in order to receive the $\$ 20$ stipend.

During the process of data collection, one expectation was not met. The initial agreement with the ETSU Student Health Clinic was that participants would be scheduled for the required blood draw immediately after completion of the anthropometric tests and the survey. Due to unanticipated rapid response of participants, study subjects were not consistently able to obtain an immediate appointment for the blood test. On the first day the study opened, 45 participants requested to be enrolled in the study. On day two, over 30 participants requested to be enrolled. It is interesting to note here that the study opened on the week of Valentine's Day and we believe that the financial incentive of the study positively impacted participation. Several participants 
made comments during the screening process that they could use the money to purchase Valentine gifts. Neither the clinic nor the researcher anticipated this large volume of participants and the clinic had to schedule some blood draw appointments for future dates. The clinic reported delays in some of the blood tests of up to 9 days following the participant's completion of the survey. During this waiting period, some participants may have consumed more vitamin D from food and supplements or increased their sun exposure that may have had an influence on results.

\section{Data Analysis}

Data were analyzed using SPSS software. For the purpose of descriptive and regression analysis, vitamin D 25(OH)D level was divided into three categories: deficient $<20 \mathrm{ng} / \mathrm{mL}$, insufficient 20-29 ng/mL, and sufficient >/=30 ng/mL. Age was divided into two categories: 1821 and 22-29. Divisions in age were chosen in order to have an adequate number for the purposes of data analysis. Categorical divisions by race were Caucasian versus minorities. Seventy-seven participants were Caucasian and the remaining were of various ethnic minorities. Therefore minorities were grouped together for statistical purposes. BMI was grouped into two categories: <25 normal weight, and >/= 25 overweight or obese. Academic major was grouped into two groups: health related majors and nonhealth related majors. Frequency tables can be seen in Appendix C.

A series of single sample $t$-tests were conducted to analyze research questions 1 and 4 . Pearson correlation was used to analyze research questions 2 and 3. Research question 5 was analyzed with multiple regression. The level of significance used in each statistical analysis was .05 . 
Data from one participant was eliminated from the data analysis because the participant reported consuming an extremely high daily dose of vitamin D from cod liver oil. His reported intake was verified by the researcher; the subject reported that this was customary in Africa, his native home. Additionally, due to a very low number of study participants reporting that they ate on campus compared to eating off campus, there was inadequate data to evaluate vitamin D status and differences based on dining location. Furthermore only two participants reported having recently traveled to a sunny location, so this factor was not considered an influence on vitamin D status in the study sample.

\section{Validity and Reliability}

A survey of demographical information and anthropometric data was used to measure demographic characteristics of age, gender, race, use of vitamin supplements, dining location, academic major, and travel to sunny location. Validity was established with a presurvey test administered randomly to 10 nutrition undergraduate students and 10 nonnutrition undergraduate students. Reliability of the survey was enhanced by the fact that only the researcher or a trained graduate research assistant administered the survey in the same way to each participant. The researcher or the trained graduate assistant also conducted all of the anthropometric measurements of height, weight, BMI, and body fat percentage. The same instruments were used to measure the anthropometric tests for all participants.

The second part of the survey consisted of a previously validated food frequency questionnaire used to estimate vitamin D and calcium intake from food and supplements. With the author's permission, the survey was modified to remove the calcium rich foods because that information was not needed for the purpose of this study. The survey can be viewed in Appendix A. Permission to use and modify the food frequency survey tool was granted by the authors, 
(Taylor et al., 2009) and can be viewed in Appendix D. Permission was granted by the Institutional Review Board (IRB) of East Tennessee State University State University to have an expedited review status due to the limited risk involved with the study and the assurance of confidentiality of information. Vitamin D intake from food was calculated using Nutritionist Pro Software Program version 1.0 by Axxya Systems, LLC. Vitamin D intake from supplements was calculated by information obtained on the manufacturer's websites for the individual vitamins.

The final component of the study involved the blood draw. Arrangements were made prior to the initiation of the study to use the ETSU Student Health Clinic (SHC) for the collection of blood samples. To assure reliability policies and procedures already in place at the ETSU SHC were used for the purposes of this study, under the direction of the clinic director, Dr. Lisa Ousley. Blood was drawn by one of two clinic nurses employed by ETSU. Blood samples were processed through Synergy Labs and sent to Mayo Clinic for analysis. All blood samples were processed by high pressure liquid chromatography tandem mass spectrometry at the Mayo Clinic laboratory. Results of the blood tests were returned to the ETSU SHC by facsimile per protected measures, according to ETSU clinic policy. The clinic held the results per protected measures until picked up by the researcher on a weekly basis. Following ETSU IRB protocol the lab results were stored in a locked cabinet and will be destroyed after a period of 5 years.

\section{Summary}

Chapter 3 discussed the research design of the study, the research questions and null hypotheses, the sample, the procedures used for data collection, data analysis, and validity and reliability. Quantitative procedures were used to evaluate the vitamin D 25(OH) D status of participants and if differences in vitamin D 25(OH) D status and dietary intake of vitamin D existed due to gender, race, academic major, BMI, and age. Because sun exposure can increase 
vitamin D status, a winter month was selected to conduct the study. The study consisted of five research questions for which the data are analyzed in Chapter 4. 


\section{CHAPTER 4}

\section{RESULTS}

The researcher examined vitamin D 25(OH)D status and dietary intake of vitamin D from foods and supplements in students at East Tennessee State University. Differences in vitamin D 25(OH)D status based on gender, race, academic major, and BMI were analyzed. Additionally, dietary intake of vitamin D and BMI were evaluated for their relationship to vitamin D 25(OH)D status. Vitamin D 25(OH)D status in $\mathrm{ng} / \mathrm{mL}$ was determined from a blood test administered at the ETSU Student Health Clinic and analyzed at the Mayo Clinic. Vitamin D intake from foods and supplements was provided by survey data from the study participants. Vitamin D intake was calculated using Nutritionist Pro Software Program version 1.0 by Axxya Systems, LLC.

Characteristics of the study sample included 56\% $(n=55)$ female and $44 \%(n=43)$ male. Fifty-nine percent $(n=58)$ of the sample were 18-21years while $40.8 \%(n=40)$ were aged 2229. Seventy-nine percent $(n=77)$ of the sample were Caucasian with $21.4 \%(n=21)$ representing minorities. Most of the participants, 78.6\% $(n=77)$ did not eat meals on campus, versus $21.4 \%(n=21)$ with campus meal plans. Sixty-one percent $(n=60)$ of the sample were not overweight with a BMI of 25 or less while 38.8\% $(n=38)$ were overweight or obese. Most of the sample $61.2 \%(n=60)$ reported being in a nonhealth related major compared to $38.8 \%(n=38)$ in a health related major.

Table 2 presents the categories of gender, BMI, race, academic major, and level of vitamin D 25(OH)D for the study participants. Mean vitamin D 25(OH)D level was 25.08 $\mathrm{ng} / \mathrm{mL}, \mathrm{SD}=5.25$. Sufficient vitamin D 25(OH)D status was more common in females than males and in participants with normal body weight. Not surprisingly, Caucasians were more likely to be sufficient in vitamin D, which supports previous study findings and the known 
association between darker skin and declined vitamin D synthesis in the skin. Vitamin D status did not appear to be related to the participant’s academic major.

Comparisons of vitamin D status based on gender noted that $47.6 \%(n=20)$ of males were deficient in vitamin D compared to $17 \%(\mathrm{n}=9)$ females. Forty percent $(\mathrm{n}=23)$ of females had an insufficient level compared to 33.3\% $(n=14)$ males. Thirty-nine percent $(n=21)$ of females were sufficient in vitamin D compared to only $19.0 \%(n=8)$ males. Overall, $81 \%$ of males and $60.4 \%$ of females had suboptimal levels of vitamin D $25(\mathrm{OH}) \mathrm{D} ; 19 \%$ of males and 39.6\% of females had sufficient vitamin D status.

BMI was divided into two categories: normal, $<25$, and overweight, 25 or greater. Thirty-six percent $(n=21)$ of those who were not overweight had a sufficient vitamin D level compared to $21.6 \%(n=8)$ of the participants who were overweight. Insufficient vitamin D level was found in $34.5 \%(n=20)$ of those not overweight compared to $45.9 \%(n=17)$ of those who were overweight. Students with a normal BMI had a higher percentage of vitamin D sufficiency than those who were overweight. Overall, $63.8 \%$ of those with normal weight and $78.4 \%$ of those who were overweight had suboptimal levels of vitamin D 25(OH)D. Thirty-six percent of normal weight and $21.6 \%$ of overweight participants had sufficient vitamin D status.

Comparisons of vitamin D level by race found $21.3 \%(n=16)$ of Caucasians were deficient in vitamin D compared to 65\% $(n=13)$ of minorities. Forty percent $(n=30)$ of Caucasians were insufficient in vitamin D compared to 35.0\% ( $n=7)$ of minorities. Overall, $61 \%$ of Caucasians had suboptimal levels of vitamin D compared to $100 \%$ of minorities.

Comparisons of vitamin D by academic major indicated that 23.7\% $(n=9)$ of participants in a health related major were deficient in vitamin D compared to $35.1 \%(n=20)$ of those in 
nonhealth related majors. Forty-five percent $(n=17)$ of those in health related majors were insufficient in vitamin D versus 35.1\% $(\mathrm{n}=20)$ of nonhealth related majors. There was very little difference between majors in the level of vitamin D sufficiency with 31.6\% $(n=12)$ of health related majors sufficient compared to $29.8 \%(n=17)$ of nonhealth related majors with sufficient level. Overall, $68.4 \%$ of those in a health related major had suboptimal vitamin D status compared to $70 \%$ of those in nonhealth related majors. 
Table 2

Vitamin D 25(OH)D Status Based on Gender, BMI, Race, and Academic Major

Overall

$\mathrm{D}$

Level
Gender

Male $\quad$ Female $\quad>/=25$
BMI

Race

Academic Major

Health Nonhealth

Related Related

\begin{tabular}{llllllllllllllll}
\hline $\mathrm{n}$ & $\%$ & $\mathrm{n}$ & $\%$ & $\mathrm{n}$ & $\%$ & $\mathrm{n}$ & $\%$ & $\mathrm{n}$ & $\%$ & $\mathrm{n}$ & $\%$ & $\mathrm{n}$ & $\%$ & $\mathrm{n}$ & $\%$ \\
\end{tabular}

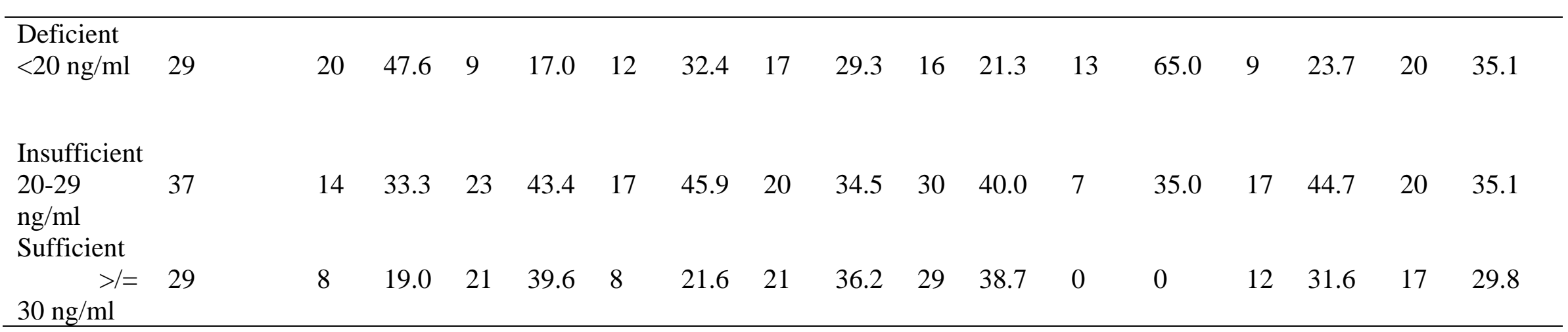

Table 2 represents a comparison of the serum vitamin D (25 OHD) status of participants based on gender, BMI, race, and academic major. Mean serum vitamin D 25(OH)D level among participants was $(M=25.08, S D 5.25) .69 .5 \%(n=66)$ of participants had suboptimal vitamin D 25 (OH)D level. Only 29 (31\%) students had sufficient vitamin D 25 (OH)D status. 


\section{Research Questions and Analysis}

\section{Research Question 1}

Is there a significant difference between vitamin D 25(OH)D levels when compared by gender, race, and academic major?

$\mathrm{H}_{0} 1_{1}$ : There is no significant difference between vitamin $\mathrm{D} 25(\mathrm{OH}) \mathrm{D}$ levels when compared by gender.

A $t$ test for independent means was conducted to evaluate the difference in serum vitamin D 25(OH)D level means between males and females. The dependent variable was serum vitamin D 25(OH)D level and the independent variable was gender. The $t$ test was significant, $t(93)=$ $3.49, p=.001$. Therefore, the null hypothesis was rejected. The effect size as measure by $\eta^{2}$ was medium (.12). That is, 12\% of the variance in vitamin D 25(OH)D level was accounted for by gender. The mean vitamin D 25(OH)D level for females ( $M=28.77$, $S D=10.76)$ was 7.0 $\mathrm{ng} / \mathrm{mL}$ higher than the mean for males $(\mathrm{M}=21.76, \mathrm{SD}=8.21)$ as seen in Table 2 . There was a significant difference between vitamin D 25(OH)D levels based on gender. Females tended to have a higher serum vitamin D 25(OH)D level than males. The 95\% confidence interval of the mean difference was 3.02 to 11.00 .

$\mathrm{H}_{\mathrm{o}} 1_{2}$ : There is no significant difference between vitamin D 25(OH)D levels when compared by race.

A $t$ test for independent samples was conducted to evaluate the difference in serum vitamin D 25(OH)D level means based on race. The dependent variable was serum vitamin D 25(OH)D level and the independent variable was race measured as Caucasians versus minorities. The $t$ test was significant, $t(93)=4.50, p<.001$. Therefore, the null hypothesis was rejected. The effect size as measured by $\eta^{2}$ was large $(0.18)$. Therefore, $18 \%$ of the variance in serum 
vitamin D 25(OH)D level was accounted for by race. The mean serum vitamin D 25(OH)D level for Caucasians $(M=27.91, S D=9.96)$ was almost $11 \mathrm{ng} / \mathrm{mL}$ higher than the mean for minorities $(M=17.30, S D=6.58)$ as seen in Table 2 . Caucasians tended to have a higher serum vitamin D 25(OH) D level than minorities. The 95\% confidence interval of the mean difference was 5.93 to 15.29 .

$\mathrm{H}_{0} 1_{3}$ : There is no significant relationship between vitamin D 25(OH)D levels when compared by academic major.

A $t$ test for independent samples was conducted to determine if there was a difference in serum vitamin D 25(OH)D level means between students with different academic majors. The dependent variable was serum vitamin D 25(OH)D level and the independent variable was academic major measured as health related majors versus non-health related majors. The $t$ test was not significant, $t(93)=1.72, p=.089$. Therefore, the null hypothesis was retained. The effect size as measured by $\eta^{2}$ was small (.03). That is, only $3 \%$ of the variance in vitamin D level was accounted for by academic major. The mean serum vitamin D 25(OH)D level for health related majors $(M=27.87, S D=11.76)$ was only $3.7 \mathrm{ng} / \mathrm{mL}$ higher than the mean for nonhealth related majors $(M=24.21, S D=8.98)$ as seen in Table 3. There was no significant difference between the vitamin D 25(OH)D levels of the health related and nonhealth related majors. The $95 \%$ confidence interval of the mean difference was -.57 to 7.89 . 
Table 3

Differences in Vitamin D 25(OH) D Level Based on Gender, Race, and Academic Major

\begin{tabular}{|c|c|c|c|c|c|c|c|c|c|c|c|c|}
\hline & \multicolumn{4}{|c|}{ Gender } & \multicolumn{4}{|c|}{ Race } & \multicolumn{4}{|c|}{ Academic Major } \\
\hline & \multicolumn{2}{|c|}{ Male } & \multicolumn{2}{|c|}{ Female } & \multicolumn{2}{|c|}{ Caucasian } & \multicolumn{2}{|c|}{ Other } & \multicolumn{2}{|c|}{$\begin{array}{l}\text { Health } \\
\text { Related }\end{array}$} & \multicolumn{2}{|c|}{$\begin{array}{c}\text { Nonhealth } \\
\text { Related }\end{array}$} \\
\hline & $\mathrm{M}$ & SD & $\mathrm{M}$ & SD & $\mathrm{M}$ & SD & $\mathrm{M}$ & SD & $\mathrm{M}$ & SD & $\mathrm{M}$ & SD \\
\hline $\begin{array}{l}\text { Vitamin } \\
\text { D } \\
25(\mathrm{OH}) \\
\text { D Level }\end{array}$ & 21.76 & 8.21 & 28.77 & 10.76 & 27.91 & 9.96 & 17.30 & 6.58 & 27.87 & 11.76 & 24.21 & 8.98 \\
\hline
\end{tabular}

Research Question 2

Is there a significant relationship between vitamin D 25(OH)D level and body mass index?

$\mathrm{H}_{\mathrm{o}} 2_{1}$ : There is not a significant relationship between vitamin D 25(OH)D level and body mass index.

Pearson correlation was conducted to evaluate the relationship between body mass index and serum vitamin D 25(OH)D level. The correlation was not significant, $r=-.06, N=95, p=$ .560. Therefore, the null hypothesis was retained. The correlation between body mass index and serum vitamin D 25(OH)D level showed a very weak negative relationship. Figure 5 shows the scatterplot for serum vitamin D 25(OH)D level and body mass index. 


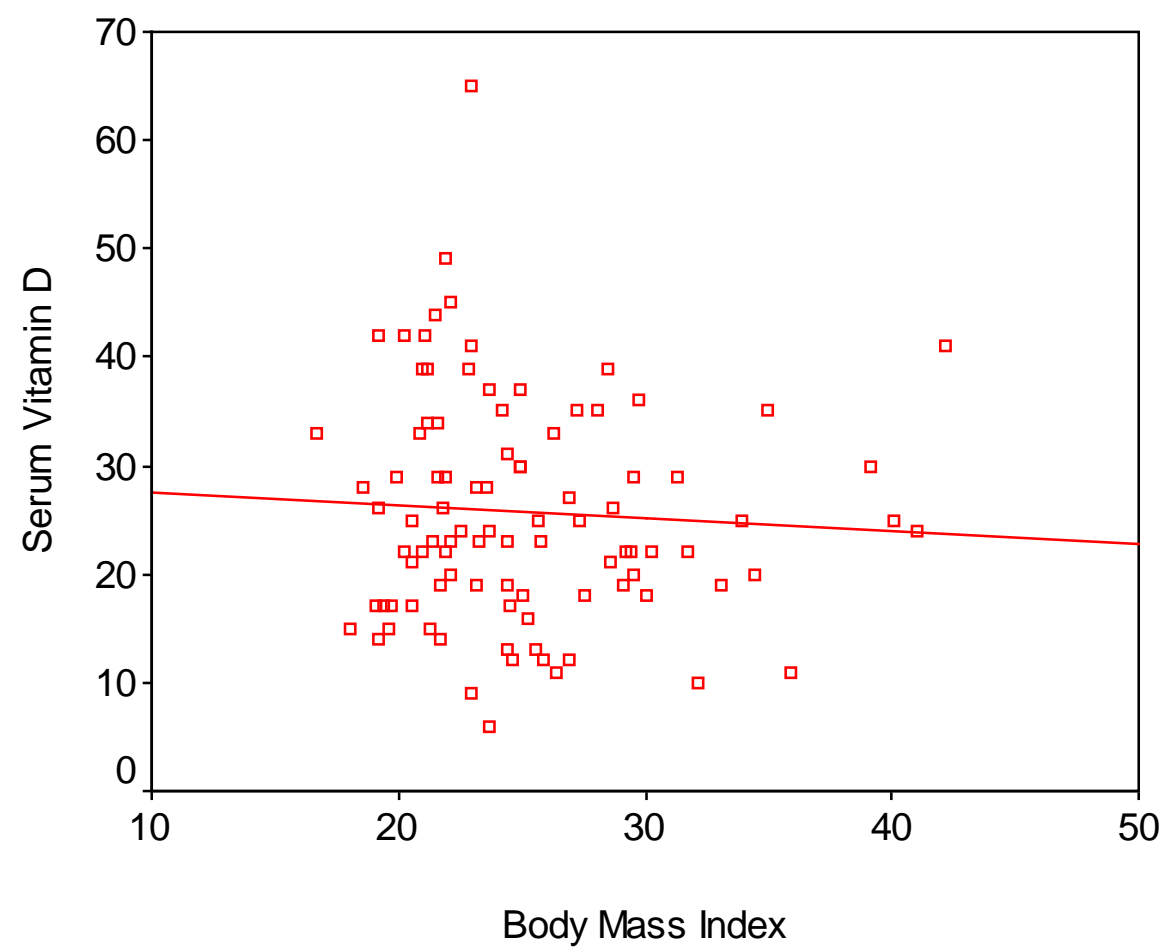

Figure 2. Scatterplot for Serum Vitamin D and Body Mass Index

Research Question 3

Is there a significant relationship between vitamin D 25(OH)D level and age?

$\mathrm{H}_{0} 3_{1}$ : There is not a significant relationship between vitamin D 25 (OHD) level and age.

A Pearson correlation was used to evaluate the relationship between age and serum vitamin D 25(OH)D level. The relationship was not significant, $r=-.12, N=95, p=.264$. Therefore, the null hypothesis was retained. The coefficient showed a very weak negative relationship between age and vitamin D level. Figure 6 shows the scatterplot for vitamin D level and age. 


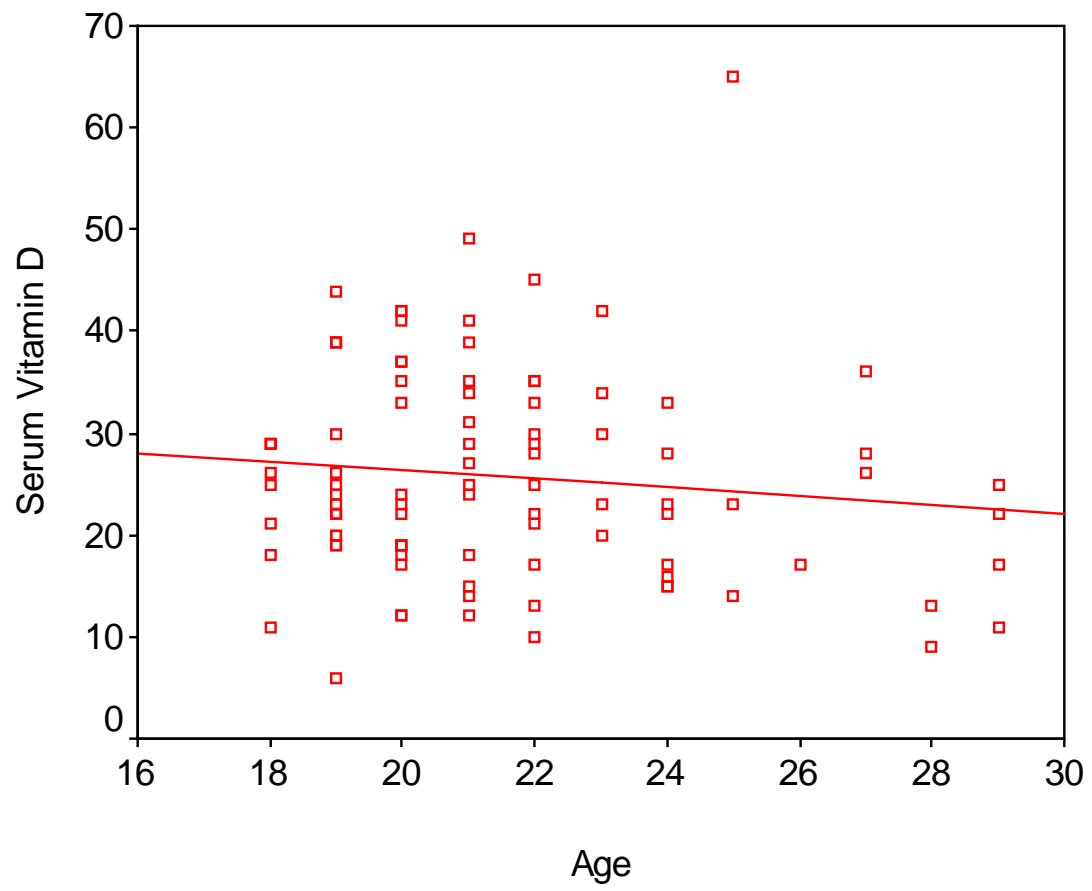

Figure 3. Scatterplot for Serum Vitamin D Level and Age

\section{Research Question 4}

This question examined the intake of vitamin D from foods and supplements and differences in vitamin D consumption compared by gender, race, and academic major. Overall vitamin D intake $(M=327.62, S D=422.94)$ was less than the Estimated Average Requirement (EAR) of 400 International Units (IU) per day as set by the Institute of Medicine of the National Academies (2011). Only 8 participants in this study met the EAR from food alone. Additionally, only 19 participants reported consistent intake of a vitamin supplement that contained vitamin D.

Question 4: Is there a significant difference between total vitamin D intake from food and supplements when compared by gender, race, and academic major?

$\mathrm{H}_{0} 4_{1}$ : There is no significant difference between vitamin $\mathrm{D}$ intake from food and supplements based on gender. 
A $t$ test for independent samples was conducted to evaluate the difference in vitamin $\mathrm{D}$ intake from food and supplements based on gender. The dependent variable was vitamin D intake and the independent variable was gender. The $t$ test was not significant, $t(95)=1.56, \mathrm{p}=$ .122. Therefore, the null hypothesis was retained. The effect size as measured by $\eta^{2}$ was small (.02). In other words, only $2 \%$ of the variance in vitamin D intake from food and supplements was accounted for by gender. The mean vitamin $\mathrm{D}$ intake for females $(M=384.72, S D 503.23)$ was 133 international units higher, but not significantly different, in females than the mean for males $(M=251.60, S D 271.04)$. Dietary vitamin D intake did not differ by gender. The 95\% confidence interval of the mean difference was -36.02 to 302.26.

$\mathrm{H}_{\mathrm{o}} 4_{2}$ : There is no significant difference between vitamin $\mathrm{D}$ intake from food and supplements based on race.

A $t$ test for independent samples was conducted to evaluate the differences in vitamin D intake from food and supplements means based on race as measured by Caucasian versus minorities. The dependent variable was vitamin $\mathrm{D}$ intake from food and supplements and the independent variable was race. The $t$ test was not significant, $t(95)=.03, p=.976$. Therefore, the null hypothesis was retained. The effect size as measured by $\eta^{2}$ was small $(<.01)$. That is, less than $1 \%$ of the variance in dietary vitamin D intake from food and supplements was accounted for by race. The mean vitamin D intake from food and supplements for Caucasians $(M=326.38, S D=353.50)$ was not significantly higher than the mean for minorities $(M=$ 323.15, $S D=625.51)$. Dietary vitamin D intake did not differ by race. The 95\% confidence interval of the mean difference was -207.12 to 213.57 .

$\mathrm{H}_{0} 4_{3}$ : There is no significant difference between vitamin $\mathrm{D}$ intake from food and supplements based on whether a student is in a health related major or a non health related major. 
A $t$ test for independent samples was conducted to determine if there was a difference in vitamin D intake from food and supplements means between students with different academic majors. The dependent variable was vitamin D intake from food and supplements and the independent variable was academic major defined as health related versus nonhealth related. The $t$ test was not significant, $t(95)=-.22, p=.830$. Therefore, the null was retained. The effect size as measured by $\eta^{2}$ was small $(<.01)$. In other words, less than $1 \%$ of the variance in dietary vitamin D intake was accounted for by academic major. The mean dietary vitamin D intake from food and supplements for those in health related majors $(M=314.18, S D=276.76)$ was 18.95 international units lower, but not significantly different, than the mean for those in a nonhealth related major $(M=333.14, S D=492.87)$. Dietary vitamin $\mathrm{D}$ intake did not differ based on academic major. The 95\% confidence interval of the mean difference was -193.24 to 155.34 . Research Question 5

To what extent can BMI and dietary intake of vitamin D predict vitamin D 25(OH)D level?

$\mathrm{H}_{0} 5_{1}$ : Dietary intake of vitamin D and BMI cannot predict vitamin D 25(OH)D level. A multiple regression analysis was conducted to evaluate the relationship between the set of predictor variables and the criterion variable. The predictor variables were body mass index and dietary vitamin D intake, while the criterion variable was vitamin D 25(OH)D level. An analysis of the residuals of the regression model was performed to investigate the assumptions of regression. While the histogram of the standardized residuals and the normal probability plot shown in Figure 4 indicated no obvious violation of the assumption of normality, the histogram of the residuals showed an outlier with a standardized residual of 3.75. However, the one-sample Kolmogorov-Smirnov test indicated the standardized residuals did not deviate significantly from 
a normal distribution, Kolmogorov-Smirnov $\mathrm{Z}=.84, p=.438$. The scatterplot of the standardized residuals regressed on the standardized predicted values shown in Figure 5 showed three observations that were distinct from the remaining observations: one in the upper left quadrant and two in the lower right quadrant. Mahalanobis Distance was used to locate multivariate outliers. The critical value of Chi Square with two degrees of freedom and $p<.001$ was 13.82. There were two subjects who had values of Mahalanobis Distance greater than the critical value of Chi Square. Finally, the correlation between body mass index and dietary vitamin D was weak. Therefore, the assumption of noncolinearity was met.

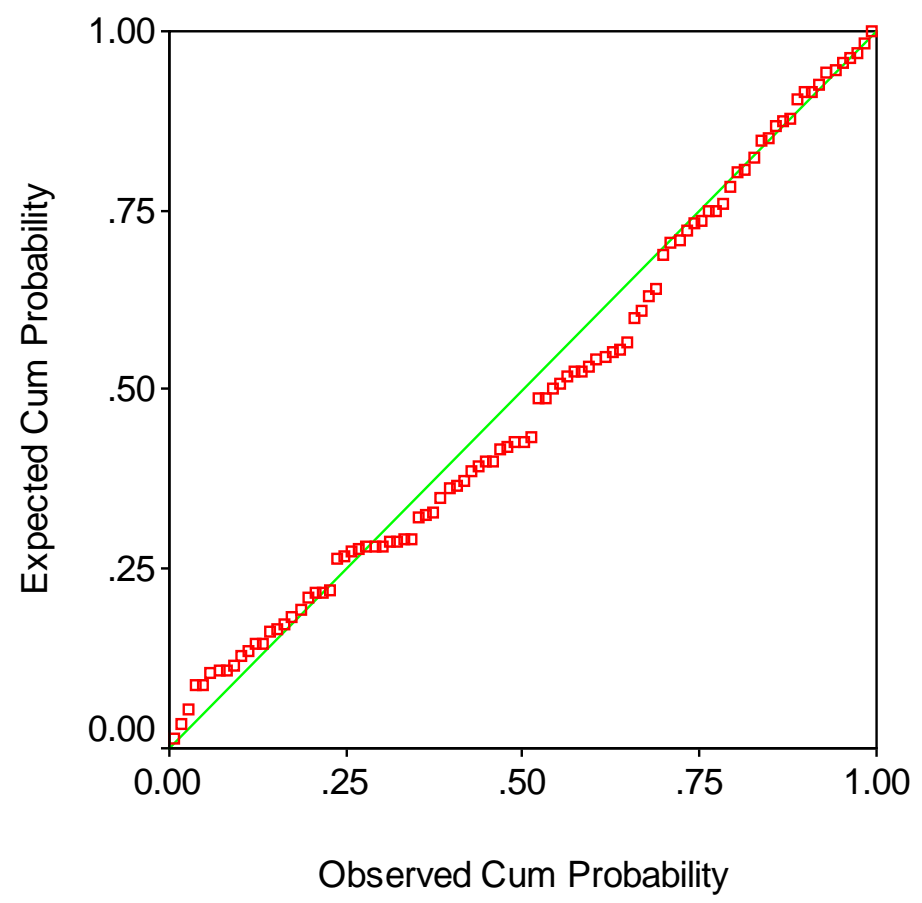

Figure 4. Normal Probability Plot for the Regression Model Using All Cases ( $\mathrm{N}=95)$ 


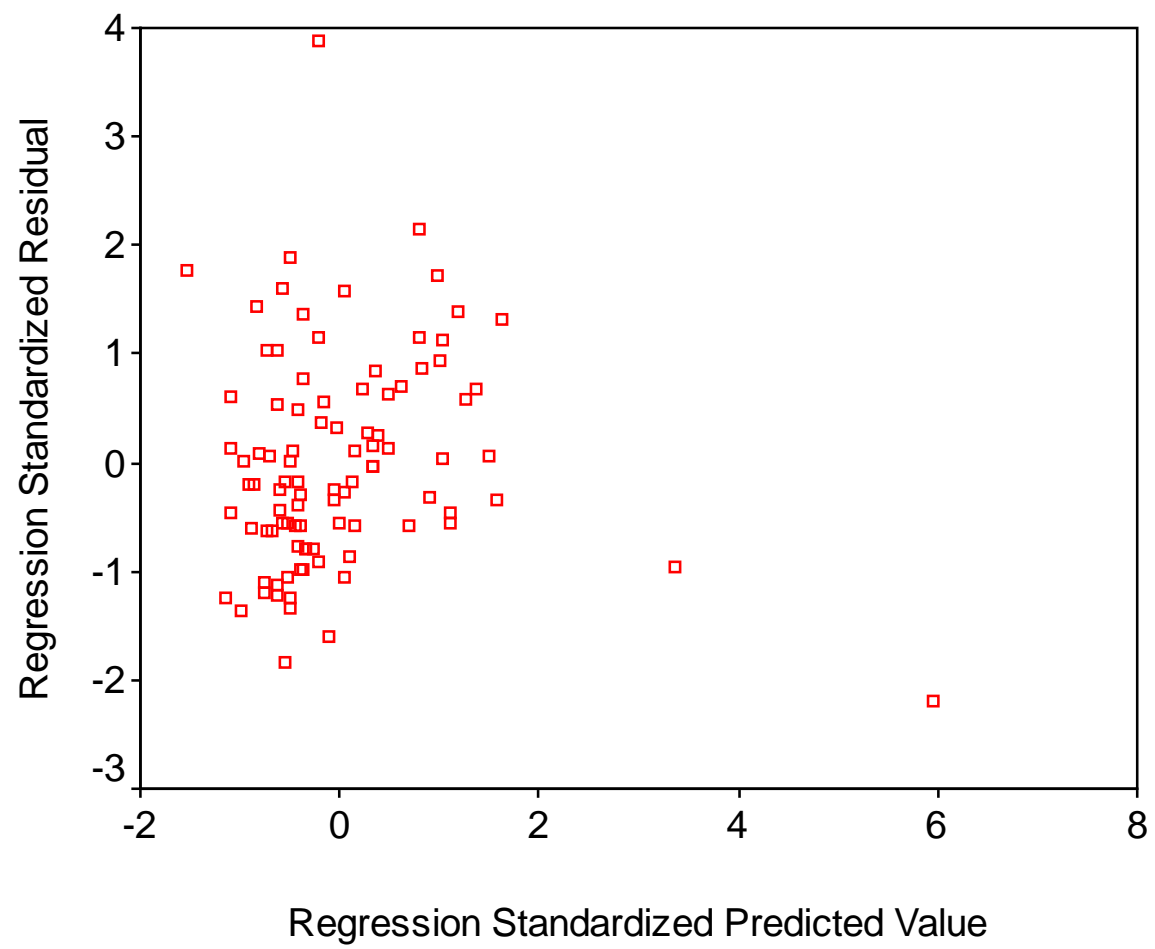

Figure 5. Scatterplot for the Regression Standardized Residuals and Standardized Predicted Values Using All Cases ( $\mathrm{N}=95)$

In light of the fact that regression is sensitive to outliers, the researcher made the decision to present the findings of the regression model that included all 95 cases, and then present the findings of the regression model with the three outliers removed from the data. The three outliers were two cases who had a Mahalanobis Distance value greater than the critical value of Chi Square (13.83) and the outlier who had a standardized residual of 3.75.

Regression Model Using All Cases ( $=95)$

The overall regression model showed that the relationship between body mass index and dietary vitamin $\mathrm{D}$ intake taken together as a set was not significantly related to vitamin D25(OH)D level, $F(2,92)=1.46, N=95, p=.238$. Therefore, the null hypothesis was retained. The multiple correlation coefficient was .18 . The $\mathrm{R}^{2}$ of .03 indicated that only $3 \%$ of the 
variance in vitamin $\mathrm{D} 25(\mathrm{OH}) \mathrm{D}$ level was accounted for by the linear combination of the two predictors, body mass index and dietary vitamin $\mathrm{D}$ intake.

Regression Model with Outliers Removed $(N=92)$

The histogram of the standardized residuals for the model that excluded outliers showed a fairly normal distribution. The normal probability plot is shown in Figure 6. The one-sample Kolmogorov-Smirnov test indicated the standardized residuals for the regression model that excluded outliers did not deviate from a normal distribution, Kolmogorov-Smirnov Z $=.95, p=$ .325. It was concluded that the assumption of normality was met. As shown in Figure 7, the scatterplot of the standardized residuals regressed on the standardized predicted values for the model that excludes outliers showed no discernible pattern. Therefore, the assumption of homoscedastity was met. Finally, the correlation between the predictors was very weak. Therefore, the assumption of noncolinearity of the regression model was met. 


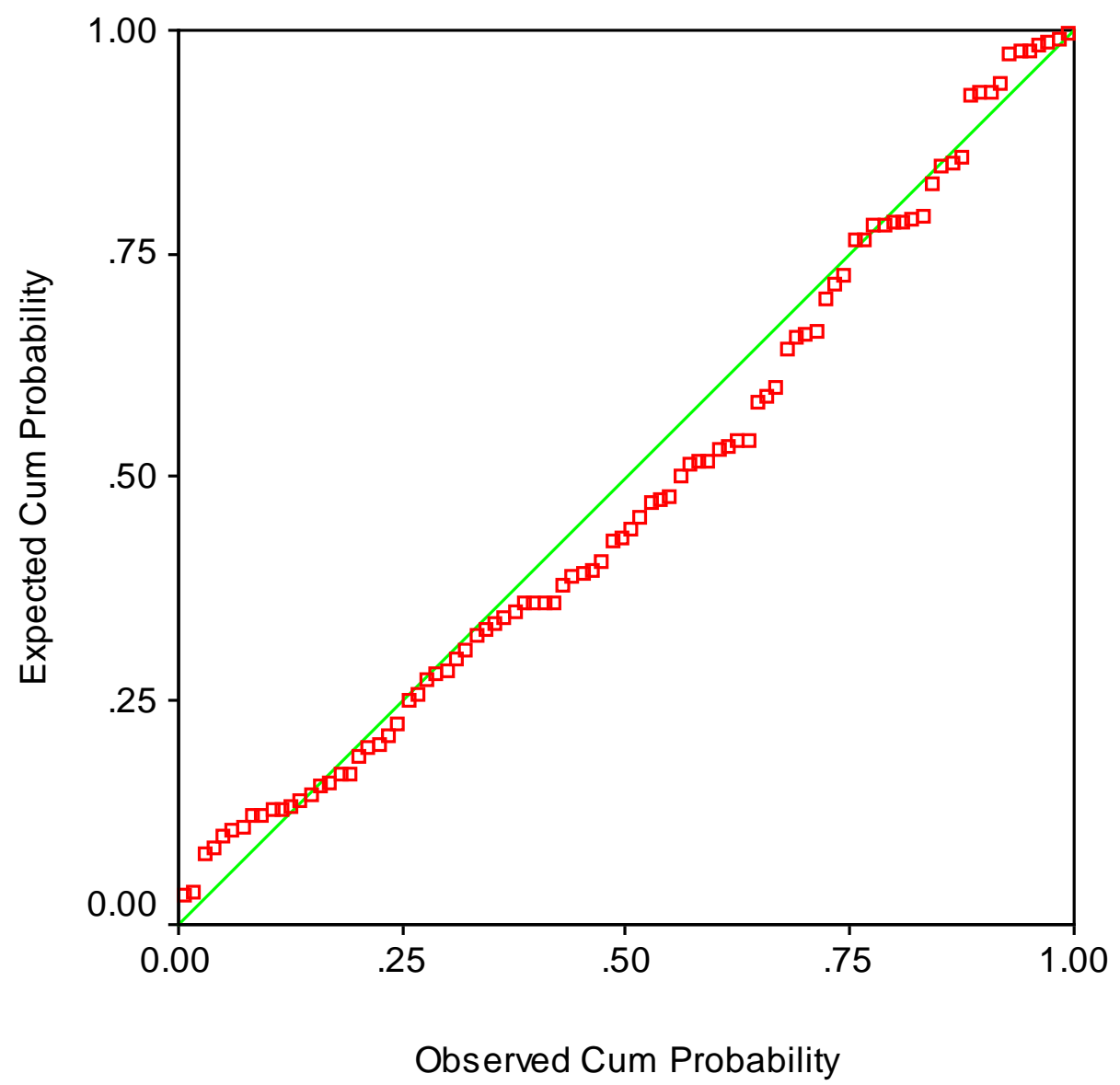

Figure 6. Normal Probability Plot for the Regression Model with No Outliers $(\mathrm{N}=92)$ 


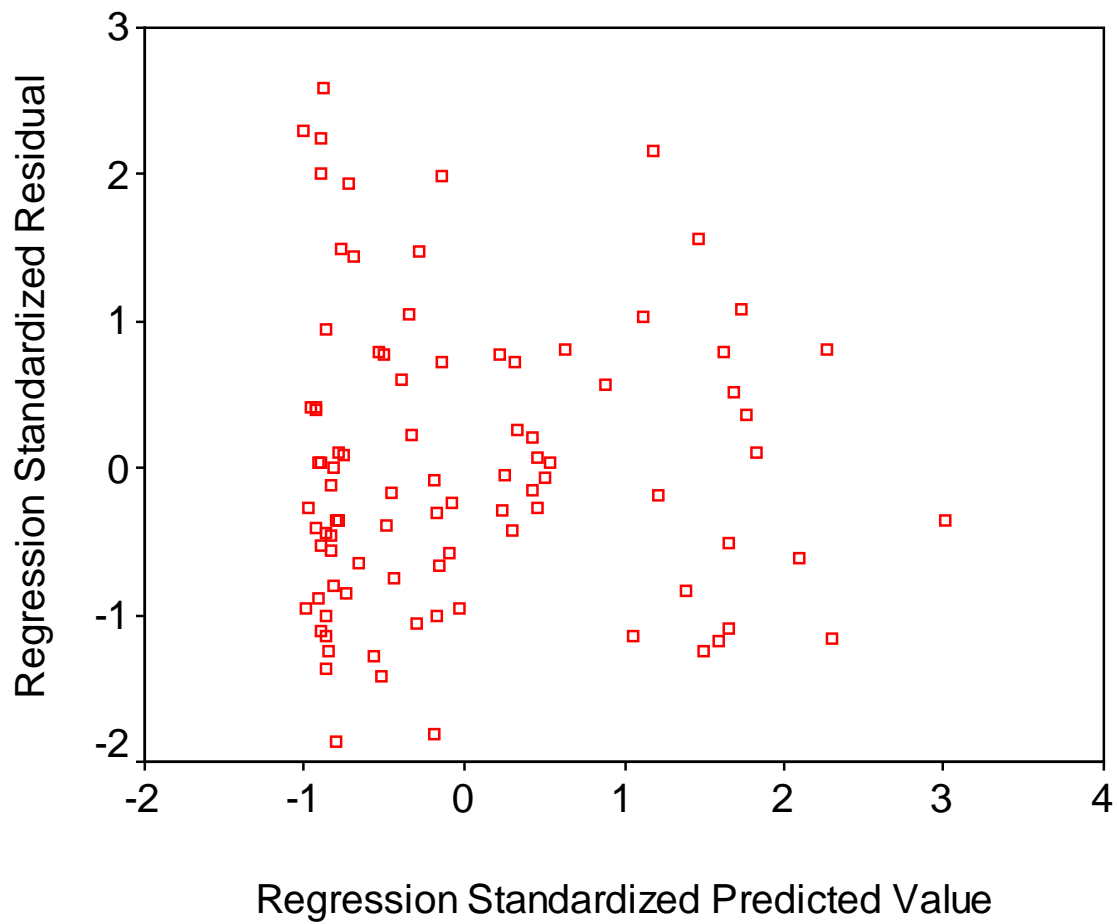

Figure 7. Scatterplot for the Regression Standardized Residuals and Standardized Predicted Values for Model with No Outliers $(\mathrm{N}=92)$

The overall regression for the model that excluded outliers showed that the relationship between body mass index and dietary vitamin $\mathrm{D}$ intake taken together as a set was significantly related to vitamin D25(OH)D level, $F(2,89)=10.79, N=92, p<.001$. Therefore, the null hypothesis was rejected. The multiple correlation coefficient was .44. The $\mathrm{R}^{2}$ of .20 indicated that $20 \%$ of the variance in vitamin D25(OH)D level was accounted for by the linear combination of the two predictors, body mass index and dietary vitamin D intake.

Table 4 shows the zero-order correlations, partial correlations and $\mathrm{r}^{2}$ change for the predictors body mass index and dietary vitamin D with vitamin D 25(OH)D level. As shown in the table, the correlation between body mass index and vitamin D 25(OH)D is very weak and remains very weak after controlling for dietary vitamin $\mathrm{D}$. The correlation between dietary 
vitamin D and vitamin D 25(OH)D is moderate and remains moderate after controlling for body mass index. The $r^{2}$ change is the additional amount of the variance accounted for by a predictor when it is entered into the regression model last. As shown in the table, body mass index explained less than $1 \%$ of the variance in vitamin D 25(OH)D after dietary vitamin D was entered in the model, while dietary vitamin D added an additional 19\% of the variance accounted for in vitamin D 25(OH)D when it was entered into the model after body mass index. In other words, there is no significant relationship between body mass and vitamin D 25(OH)D and it contributes virtually nothing in accounting for the variance in vitamin D 25(OH)D level. On the other hand, dietary vitamin D accounted for virtually all of the variance (19\%) in vitamin D 25(OH)D level. The multiple regression suggests that dietary vitamin D intake can contribute to improved serum vitamin D levels.

Table 4

The Bivariate and Partial Correlations and $r^{2}$ Change for Predictors with Vitamin $D$ (25 OHD) Level

\begin{tabular}{lccc}
\hline & Correlation & Partial Correlation & $r^{2}$ Change \\
\hline Body Mass Index & -.06 & -.02 & -.00 \\
Dietary Vitamin D & $.44^{*}$ & $.44^{*}$ & $.19 *$ \\
\hline$p<.001$ & & &
\end{tabular}

\section{Summary}

Chapter 4 presented the results of the data analyses for the research questions used in this study. For research questions 1 and $4, t$ tests were conducted to evaluate differences in vitamin $\mathrm{D}$ $25(\mathrm{OH})$ D levels and vitamin D intake when compared by gender, race, and academic major. Pearson correlation was conducted for research questions 2 and 3 that evaluated the relationship between vitamin D $25(\mathrm{OH})$ D level by age and gender. Multiple regression was used for 
research question 5 to evaluate the extent to which BMI and dietary intake of vitamin D predict vitamin D 25 (OH)D level. The results are discussed in Chapter 5. 


\section{CHAPTER 5}

\section{CONCLUSIONS}

The researcher evaluated vitamin D 25(OH)D status and intake among 98 students at East Tennessee State University. The goal of this study was to add to the body of research related to vitamin D status in an age group that had not been well studied and who are at risk of possible future health consequences related to poor vitamin D status. Comparisons of vitamin D status as measured by serum vitamin D 25(OH)D were made in the categories of gender, race, academic major, BMI, and age. Comparisons in dietary vitamin D intake were examined in the categories of gender, race, and academic major. Finally, whether BMI and dietary vitamin D intake can predict vitamin D 25(OH)D level was explored. Results of this study may have practical implications for leaders in nutrition and public health professions regarding wellness and disease prevention.

\section{Discussion and Conclusions}

Overall, 69.5\% (n=66) of the participants had serum vitamin D $25(\mathrm{OH}) \mathrm{D}$ levels that were suboptimal, or below $30 \mathrm{ng} / \mathrm{mL}$. Thirty-two percent $(\mathrm{n}=29)$ of participants had levels considered deficient or below $20 \mathrm{ng} / \mathrm{mL}$, while 39.0\% (n=37) had insufficient levels between 21 to $29 \mathrm{ng} / \mathrm{mL}$. These findings support those of Tangripricha et al. (2002) who found 37\% of healthy adults aged 17 to 35 years deficient in vitamin D 25(OH) D. Nakamura et al. (2001) found $40.3 \%$ of college-aged women to have insufficient levels of vitamin D 25(OH)D. In contrast, Godzick et al. (2008) found that $84.4 \%$ of university students in Toronto, Canada had suboptimal levels, which may reflect the higher latitude of the study location and the association with decreased UV rays reaching the skin for adequate vitamin D synthesis. 
Differences between serum vitamin D 25(OH)D level when compared by gender, race, and academic major were examined in research question 1. A significant difference $(p=.001)$ in serum vitamin D 25(OH)D level was found between males and females. Males tended to have a lower serum vitamin D 25(OH)D level $(M=21.76, S D=8.2)$ than females $(M=28.77, S D=$ 10.76). Reasons for these differences are not apparent. There may be differences in dietary supplement habits and in dietary intake that might contribute to differences in serum vitamin D 25 (OH) D level. Looker et al. (2011) reported that the risk of vitamin D deficiency increased in males aged 1-30 years until the age of 30. The risk of vitamin D deficiency in females aged 1-30 years increased until age 18. Further research is needed to understand differences in serum vitamin D level based on gender in the 18-29 year age group.

Not surprisingly, a significant difference $(\mathrm{p}<.001)$ was found in serum vitamin D 25 $(\mathrm{OH}) \mathrm{D}$ level between Caucasians and minorities. Caucasians had a higher serum vitamin D 25(OH)D level $(M=27.91)$ than minorities $(M=17.30)$. Sixty-one percent $(\mathrm{n}=46)$ of Caucasians had suboptimal serum vitamin D level compared to $100 \%(\mathrm{n}=20)$ of minorities. These results support previous findings by Park and Johnson (2005), Weng et al. (2007), Nesby- O’Dell et al. (2002), and Harris (2006) that found an association between serum vitamin D status and race. Darker skin pigmentation decreases synthesis of 7- dehydrocholesterol in the skin, which is the first step in vitamin D synthesis (see Figure 1).

Vitamin D status compared by academic major defined as health related versus nonhealth related major was an exploratory question. The researcher wanted to determine if students in a health related major had a higher serum vitamin D level than students in nonhealth related majors. Studying a health related major was not associated with higher serum vitamin D 25(OH)D level. 
The relationship between serum vitamin D 25(OH)D level and BMI was examined in research question 2. Although previous studies (Holick, 2006; Liel et al.,1988; Parikh et al., 2004; Nesby-O’Dell et al. 2002) found an inverse relationship between vitamin D status and BMI, this study found no significant relationship between serum vitamin D and BMI. These results may be because $61 \%$ of the participants in this study were not overweight. Additionally, most of the studies of vitamin D status and obesity are in older adults. Younger adults, as in this study, have a greater capacity to absorb all nutrients, including vitamin $\mathrm{D}$, than do older adults whose absorptive capacity has declined with age. In addition, younger adults are more likely to have increased summer sun exposure and maintain a reserve pool of vitamin D from sun exposure that is still measurable in winter months.

The relationship between serum vitamin D 25(OH)D level and age was examined in research question 3. The correlation was not significant. Age did not play a role in vitamin D status among participants in this study probably because there was little variance in the age of participants in this study; all of the participants were between the ages of 18-29.

Differences in dietary vitamin D intake based on gender, race, and academic major were examined in research question 4. No significant differences were found in dietary vitamin D intake based on all three categories. Overall dietary vitamin D intake was inadequate with only 8 participants meeting the EAR of 400 IU per day for vitamin D intake. Mean vitamin D intake from food and supplements was 327.62 IU per day. This supports findings by Moore et al. (2004) that concluded less that $10 \%$ of adults met the vitamin D requirement from food. Weng et al.(2007) also found similar results in children where 53\% of subjects consumed less than 200 IU per day of vitamin D. 
Whether BMI and dietary intake of vitamin D can predict serum vitamin D 25(OH)D level was examined in research question 5. BMI was not a predictor of vitamin D status; however, dietary vitamin D intake did have a positive correlation to vitamin D status. This suggests that increased vitamin intake can contribute to improved vitamin D status.

An interesting finding of this study was that all participants requested follow-up knowledge of their vitamin D status and provided electronic mail, contact information for the purpose of receiving results. All participants with low vitamin D status were sent nutritional information on improving vitamin D status via electronic mail, which can be viewed in Appendix B. All of these participants were also offered a free clinic appointment with Dr. Ousley at the ETSU Student Health Clinic to discuss possible treatment options. However, Dr. Ousley reported that no participant with low vitamin D status elected to schedule a free appointment.

Cod liver oil may play a positive role in vitamin D status. The African student who reported daily consumption of cod liver oil did have an optimal vitamin D level; all other minority students had suboptimal levels.

\section{Implications for Practice}

From this research it seems clear that the high incidence (69.5\%) of suboptimal vitamin D status in college-aged students at East Tennessee State University should be an area of concern and further research for dietetics professionals and public health leaders. Vitamin D is a crucial nutrient for bone health. Because maximum bone density is not achieved until about the age of 30, young adults are at risk of poor bone health related to vitamin D status. Evidence has linked vitamin D deficiency to other health conditions such as cancer, diabetes, and cardiovascular disease as well as increased medical costs. Based on these findings, registered dietitians and 
public health leaders should increase efforts to evaluate the vitamin D status of college-aged individuals and to target college-aged individuals in educational programming regarding the role vitamin D plays in wellness and ways to enhance their vitamin D status. Public health policy makers should take a role in assuring that the public is better informed regarding vitamin D and overall health and wellness for all age groups.

Particularly at East Tennessee State University, efforts should also be made to inform the community regarding factors that inhibit vitamin D synthesis in the skin. It is not general knowledge that vitamin D synthesis is blocked by the use of sunscreen; health professionals regularly encourage the use of sunscreen in all age groups. Therefore, recommendations should be made to allow 15-20 minutes of sun exposure prior to applying sunscreen in order to maximize vitamin D synthesis in the skin (Dr. L. Hudson, personal communication, October 2012). Additionally, health information related to vitamin $D$ synthesis in relation to time of day, latitude, season of year, and presence of clouds should be disseminated widely through public health channels so that individuals are more aware of the factors which inhibit vitamin D synthesis.

Vitamin supplements are not monitored for quality by the Food and Drug Administration; few over the counter products meet the quality guidelines expected. Dietitians and health leaders should inform the public that the use of over the counter supplements that are USP labeled provides an assurance of meeting expected quality standards noted on the label. Supplementation with vitamin D products that have USP labels should be recommended for individuals with inadequate dietary intake of vitamin D.

Because very few foods contain vitamin D and milk consumption has declined in all age groups, it is crucial that dietitians and health leaders consider alternatives for food fortification 
with vitamin D. Fortification of more commonly consumed foods could help improve vitamin D status. Considerations should be given to fortification of a variety of foods because different groups have diverse eating habits. Fortification alternatives should consider ethnic, regional, gender, age, and religious differences in food consumption habits.

\section{Implications for Future Research}

Additional research should be done on the vitamin D status of college students ages 1829 in other areas of the country. Differences based on geographic location, cultural habits, lifestyle habits, and dietary intake patterns should be considered. This can help guide public health leaders and dietetics professionals toward policy changes and educational programming efforts related to vitamin D and wellness.

It is not known how much vitamin D is needed from diet and supplements to maintain optimal vitamin D levels throughout winter months. The amount would likely vary based on gender, age, race, geographic location, BMI, and lifestyle habits. Additional research should be done to examine this more thoroughly and to assist public health leaders in making evidencebased recommendations to the public.

More research should be conducted to examine the factors that might contribute to differences in vitamin D status between college-aged males and females. Dietary intake of vitamin $\mathrm{D}$ and the use of dietary supplements containing vitamin $\mathrm{D}$ should be evaluated between genders in this age group. Physiological differences such as lean body mass, hormone levels, and the use of medications should be examined as possible contributing factors in this age group.

Differences in cultural habits such as consumption of cod liver oil should be examined.

One subject in this study was an international student from Africa who reported consumption of large daily doses of cod liver oil. This individual did in fact have an optimal vitamin D status of 
$37 \mathrm{ng} / \mathrm{mL}$, while all other minorities in this study had suboptimal vitamin D status. This study did not distinguish between African Americans and Africans. More research could be done to look at differences in vitamin $\mathrm{D}$ consumption and vitamin $\mathrm{D}$ status between minority groups from different countries. Results of such research could assist public health leaders worldwide to make evidence-based recommendations regarding vitamin D intake and could help improve the vitamin D status of darker skinned individuals. It would be interesting to explore when the practice of taking cod liver oil started and how this practice originated. Perhaps it was a public health initiative or something passed on through generations such as a wives tale.

Further research should be done in the area of dietary vitamin D consumption patterns based on ethnicity, age, and geographic location. Identification of vitamin D consumption patterns can help guide future directions regarding food fortification with vitamin D.

\section{Summary}

The results of this study indicate that college-aged students at East Tennessee State University are at risk of suboptimal vitamin D status, particularly in winter months when sun exposure is limited. This age group is at particular risk of not meeting the EAR for vitamin D through dietary intake. College-aged individuals in other parts of the country may also be at risk of poor vitamin D status placing them at risk for possible future health consequences. It is crucial that public health leaders explore vitamin D status of all age groups more thoroughly and to give serious consideration to providing more public information regarding vitamin D status and possible health consequences to suboptimal vitamin D status.

Substantial evidence links poor vitamin D status to health consequences. Public health leaders should inform the public about this health concern and for the implications for collegeaged students. Additionally, public health leaders should be proactive and increase efforts to 
educate the public on ways to improve vitamin D status through healthy sun exposure and increased food sources or quality supplements with USP verification labels. 


\section{REFERENCES}

Abrams, S., Griffin, I., Hawthorne, K., Gunn, S., Gundberg, C., \& Carpenter, T. (2005).

Relationships among vitamin D levels, parathyroid hormone, and calcium absorption in young adolescents. The Journal of Endocrinology \& Metabolism 90(10):5576-5581. doi:10.1210/jc.2005-1021

Al-elq, A. (2012). The status of vitamin D in medical students in the preclerkship years of a Saudi medical school. Journal of Family and Community Medicine, 19(2), 100-104. doi: $10.4103 / 2230-8229.98293$

Arunabh, S., Pollack, S., Yeh, J., \& Aloia, J. (2003). Body fat content and 25-hydroxyvitamin D levels in healthy women. The Journal of Clinical Endocrinology \& Metabolism, 88(1), 157-161. doi: 10.1210/jc.2002-020978

Bailey, R., Doss, K., Goldman, J., Gahche, J., Dwyer, J., Moshfegh, A...Picciano, M. (2010). Estimation of total usual calcium and vitamin D intakes in the United States. The Journal of Nutritional Epidemiology, 140, 817-822.

Barger-Lux, M., Heaney, R., Dowell, S., Chen, T., \& Holick, M. (1998). Vitamin D and its major metabolites: Serum levels after graded oral dosing in healthy men. Osteoporosis International 8, 222-230.

Binkley, N., Novotny, R., Krueger, D., Kawahara, T., Daida, Y., Lensmeyer, G.....Drezner, M. (2007). Low vitamin D status despite abundant sun exposure. The Journal of Clinical Endocrinology \& Metabolism, 92(6), 2130-2135. doi:10.1210/jc.2006-2250

Bischoff-Ferrari, H., Giovanni, E., Willett, W., Dietrich, T., \& Dawson-Hughes, B. (2006). Estimation of optimal serum concentrations of 25-hydroxyvitamin D for multiple health outcomes. American Journal of Clinical Nutrition, 84(1), 18-28.

Bradberry, T. \& Graves, J. (2009). Emotional intelligence 2.0.SanDiego, CA: Talent Smart.

Calvo, M., Whiting, S., \& Barton, C. (2005). Vitamin D intake: A global perspective of current status. The Journal of Nutrition, 135(2), 310-316.

Centers for Disease Control and Prevention (2011). Body mass index. Retrieved October 13, 2013 from: http://www.cdc.gov/healthyweight/assessing/bmi/index.html

Center for Disease Control and Prevention (2013). National Health and Nutrition Examination Survey. Retrieved October 13, 2013 from: http://www.cdc.gov/nchs/nhanes.htm

Chapuy, M., Preziosi, P., Maamer, M., Arnaud, S., Galan, P., Hercberg, S., \& Meunier, P. (1997). Prevalence of vitamin D insufficiency in an adult normal population. Osteoporosis International, 7(5), 439-443. 
Cross, H., Bises, G., Lechner, D., Manhardt, T., \& Kallay, F. (2005). The vitamin D endocrine system of the gut-its possible role in colorectal cancer prevention. Journal of Steroid Biochemistry and Molecular Biology, 97, 121-128.

Davis, C., \& Dwyer, J. (2007). The "sunshine vitamin": Benefits beyond bone? Journal of the National Cancer Institute, 99(21), 1563-1565. doi:10.1093/jnci/djm211

Forbes, R. (2011). Vitamin converter. Retrieved October 1, 2013 from: http://www.robertforbes.com/vitamin-converter

Free Dictionary (2013). Hydroxylation. Retrieved October 30, 2013 from: http://medicaldictionary.thefreedictionary.com/hydroxylation.

Fuleihan, G., Nabulsi, M., Choucair, M., Salamoun, M., Shahine, C., \& Tannous, R. (2001). Hypovitaminosis D in healthy schoolchildren. Pediatrics, 107(4), e 53.

Freedman, D., Looker, A., Chang, S., \& Graubard, B. (2007). Prospective study of serum vitamin D and cancer mortality in the United States. Journal of the National Cancer Institute, 99, 1594-1602.

Fung, G., Steffen, L., \& Zhou, X. (2012). Vitamin D intake is inversely related to risk of developing metabolic syndrome in African American and white men and women over 20y: The coronary artery risk development in young adults study. American Journal of Clinical Nutrition, 96(1), 24-29.

Galan, F., Ribas, J., Sanchez-Martinez, P., Calero, T., Sanchez, A., \& Munoz, A. (2012). Serum 25-hydroxyvitamin D in early autumn to ensure vitamin D sufficiency in midwinter in professional football players. Clinical Nutrition, 31, 132-136.

doi:10.1016/j.clnu.2011.07.008

Garland, C., Garland, F., Gorham, E., Lipkin, M., Newmark, H., Mohr, S \& Holick, M. (2006). The role of vitamin D in cancer prevention. American Journal of Public Health, 96(2). 252- 261.

Goleman, D. (1998, November-December). Best of HBR 1998. What makes a leader? Harvard Business Review, 1-12. Retrieved October 4, 2013 from: $\underline{\mathrm{ftp}: / / d n s 1 . b a n f f c e n t r e . c a / L D / C P-L e a d e r}$ article.pdf

Gordon, C., DePeter, K., Feldman, H., Estherann, G., \& Emans, J. (2004). Prevalence of vitamin D deficiency among healthy adolescents. Archives of Pediatrics \& Adolescent Medicine, 158, 531-537.

Gozdzik, A., Barta, J., Wu, H., Wagner, D., Cole, D., Vieth, R., ....\& Parra, E. (2008). Low wintertime vitamin $\mathrm{D}$ levels in a sample of healthy young adults of diverse ancestry 
living in the Toronto area: association with vitamin $\mathrm{D}$ intake and skin pigmentation. BMC Public Health 8:336. doi:10.1186/1471-2458-8-336

Harkness, L., and Cromer, B. (2004). Vitamin D deficiency in adolescent females. Journal of Adolescent Health, 37(1)75.e1-75.e5. doi.org/10.1016/j.jadohealth.2004.07.015

Harris, S. (2006).Vitamin D and African Americans. Symposium: Optimizing vitamin D intake for populations with special needs: Barriers to effective food fortification and supplementation. The Journal of Nutrition, 136, 1126-1129.

Heaney, R., Abrams, S., Dawson-Hughes, B., Looker, A., Marcus, R., Matkovic, V., \&Weaver, C. (2000). Peak bone mass. Osteoporosis International 11:985-1009.

Heaney, R. (2004). Functional indices of vitamin D status and ramifications of vitamin D deficiency. American Journal of Clinical Nutrition, 80, 1706S-9S.

Holick, M. (2005). The vitamin D epidemic and its health consequences. The Journal of Nutrition, 135 (11), 2739S-2748S.

Holick, M. (2006). High prevalence of vitamin D inadequacy and implications for health. Mayo Clinic Proceedings, 81(3), 353-373.

Holick, M. (2007). Vitamin D deficiency. The New England Journal of Medicine, 357, 266281.

Holick, M. (2008) The vitamin D deficiency pandemic and consequences for nonskeletal health. Molecular Aspects of Medicine, 29(6),361-368. doi:10.1016/j.mam.2008.08.008

Holick, M., Binkley, N., Bischoff-Ferrari, H., Gordon, C., Hanley, D., Heaney, R.,...Weaver, C. (2011). Evaluation, treatment, and prevention of vitamin D deficiency: An endocrine society clinical practice guideline. Journal of Clinical Endocrinology \&Metabolism, 96(7), 1911-1930.

Holick, M., \& Chen, C. (2008). Vitamin D deficiency: A worldwide problem with health consequences. American Journal of Clinical Nutrition, 87, 1080S-6S.

Holick, M., Shao, Q., Liu, W., \& Chen,T. (1992). The vitamin D content of fortified milk and infant formula. New England Journal of Medicine, 326, 1178-1181.

Institute of Medicine (1988). The Future of Public Health.Washington, D.C.: National Academy

Institute of Medicine of the National Academies (2011). Dietary reference intakes for calcium and vitamin D. Retrieved September 15, 2013

from: http://www.iom.edu/Reports/2010/Dietary-Reference-Intakes-for-Calcium-andVitamin-D/DRI-Values.aspx 
Jacobs, E., Alberts, D., Foote, J., Green, S., Hollis, B., Yu, Z., \& Martinez, M.( 2008). Vitamin D insufficiency in southern Arizona. American Journal of Clinical Nutrition, 87(3), 608-613.

Kemp, F., Neti, P., Howell, R., Wenger, P., Louria, D., \& Bogden, J. (2007). Elevated blood level concentrations and vitamin D deficiency in winter and summer in young urban children. Environmental Health Perspectives, 115(4), 630-635.

LeBlanc, E., Perrin, N., Johnson, J., Ballatore, A., \& Hillier, T. (2013). Over-the-counter and compounded vitamin D: Is potency what we expect? JAMA Internal Medicine, 173(7), 585-586. doi:10.1001/jamainternmed.2013.3812

Liel, Y., Ulmer, E., Shary, J., Hollis, B. \& Bell, N. (1988). Low circulating vitamin D in obesity. Calcified Tissue International, 43, 199-201.

Lind, L., Hanni, A., Lithell, T., Hvartner, A., Sorensen, O, \& Ljunghall, S. (1995). Vitamin D is related to blood pressure and other cardiovascular risk factors in middle-aged men. American Journal of Hypertension, 8, 894-901.

Looker, A., Johnson, C., Lacher, D., Pfeiffer, C., Schleicher, R., \& Sempos, C. (2011). Vitamin D status: United States, 2001-2006. NCHS data brief, no 59. Hyattsville, MD: National Center for Health Statistics.

Looker, A., Pfeiffer, C., Lacher, D., Schleicher, R., Picciano, M., \& Yetley, E. (2008). Serum 25-hydroxyvitamin D status of the US population: 1988-1994 versus 2000-2004. American Journal of Clinical Nutrition, 88(6), 1519-1527. doi: 10.3945/ajcn.2008.26182

Mayo Foundation for Medical Education and Research (2013). Rickets, definition. Retrieved October 12, 2013 from: http://www.mayoclinic.com/health/rickets/DS00813

McKinney, J., Bailey, B., Garrett, L., Peiris, P., Manning, T., \& Peiris, A. (2011). Relationship between vitamin D status and ICU outcomes in veterans. The Journal of the American Medical Directors Association, 12, 208-211. doi:10.1016/j.jamda.2010.04.004

MedicineNet (2013). Definition of International Unit. Retrieved October 12, 2013 from: http://www.medterms.com/script/main/art.asp?articlekey $=9650$

Moore, C., Murphy, M., East, D., \& Holick, M (2004). Vitamin D intake in the United States. Journal of the American Dietetic Association 104(6): 980-983.

Munger, K., Levin, L., Hollis, B., Howard ,N. \& Aschero, A. (2006). Serum 25hydroxyvitamin D levels and risk of multiple sclerosis. Journal of the American Medical Association, 296 (23), 2832-2838. 
Nakamura, K., Nashimoto, M., Tsuchiya, Y., Obata, A., \& Miyanishi, K. (2001). Vitamin D insufficiency in Japanese female college students: A preliminary report. International Journal for Vitamin and Nutrition Research, 71(5), 302-305. doi: 10.1024/03009831.71.5.302

Nakamura, K., Nashimoto, M., Matsuyama, S., \& Yamamoto, M. (2001). Low serum concentrations of 25-hydroxyvitamin D in young adult Japanese women: A cross sectional study. Nutrition, 17(11), 921-925.

National Institutes of Health (2011). What is metabolic syndrome? Retrieved October 13, 2013 from: http://www.nhlbi.nih.gov/health/health-topics/topics/ms/

Nesby-O’Dell, S., Scanlon, K., Cogswell, M., Gillespie, C., Hollis, B., Looker, A., .. . Bowman,B. (2002). Hypovitaminosis D prevalence and determinants among African American and white women of reproductive age: Third National Health and Nutrition Examination Survey, 1988-1994. American Journal of Clinical Nutrition, 76, 187-192.

Northouse, P. (2010). Leadership theory and practice.(5 ${ }^{\text {th }}$ ed.). Thousand Oaks, CA: Sage.

Novick, L., Morrow, C., \& Mays, G. (2008). Public health administration. (2 ${ }^{\text {nd }}$ ed.).Sudbury, MA: Jones and Bartlett.

Office of Dietary Supplements of the National Institutes of Health (2011). Vitamin D- health professional fact sheet. Retrieved September 15, 2013 from: http://ods.od.nih.gov/factsheets/VitaminD-HealthProfessional/

Office of Dietary Supplements of the National Institutes of Health (2013). Nutrient recommendations: dietary reference intakes. Retrieved October 1, 2013 from: http://ods.od.nih.gov/Health_Information/Dietary_Reference_Intakes.aspx

Parikh,S., Edelman, M., Uwalfo, G., Freedman, R., Semega-Janneh, Reynolds, J., \& Yanoski,J. (2004). The relationship between obesity and serum 1,25-hydroxy vitamin D concentrations in healthy adults. The Journal of Clinical Endocrinology \&Metabolism, 89(3), 1196-1199.

Park, S., \& Johnson (2005). Living in low-latitude regions in the United States does not prevent poor vitamin D status. Nutrition Reviews, 63(6), 2-3-209.

Peiris, A., Bailey, B., \& Manning, T. (2008). The relationship of vitamin D deficiency to health care costs in veterans. Military Medicine 173(12), 1214-1218.

Raiten, D.\& Picciano, M. (2004). Vitamin D and health in the $21^{\text {st }}$ century: Bone and beyond. Executive summary. American Journal of Clinical Nutrition, 80, 1673-1677. 
Reis, J., van Muhlen, D., Miller, E., Michos, E. \& Appel, L. (2009). Vitamin D status and cardiometabolic risk factors in the United States adolescent population. Pediatrics 124 (3), e371-e379. doi: 10.1542/peds.2009-0213

Ross, A., Taylor, C., Yaktine, A., \& Heather, B. (2011). DRI dietary reference intakes calcium vitamin D. Washington, D.C. Institute of Medicine of the National Academies. National Academies Press, Retrieved October 1, 2013 from: http://books.nap.edu/openbook.php?record_id=13050

Rovner, A., \& O’Brien, K. (2008). Hypovitaminosis D among healthy children in the United States: A review of the current evidence. Archives of Pediatric Adolescent Medicine, 162 (6), 513-519.

Rowitz, L. (2014). Public health leadership. (3 ${ }^{\text {rd }}$ ed.). Burlington, MA: Jones and Bartlett.

Scragg, R., Jackson, R., Holdway I., Lim, T., \& Beaglehole, R. Myocardial infarction is inversely associated with plasma 25-hydroxyvitamin $\mathrm{D}_{3}$ levels: A community based study. International Journal of Epidemiology, 19(3), 559-563.

Shin, Y., Kim, K., Lee, C., Shin, H., Kang, M., Lee, H.,\& Lee, Y. (2012). High prevalence of vitamin D insufficiency or deficiency in young adolescents in Korea. European Journal of Pediatrics. 171, 1475-1480. doi: 10.1007/s00431-012-1746-0

Stein, E., Laing, E., Hall, D., Hausman, D., KimLin, M., Johnson, M.....Lewis, R. (2006). Serum25-hydroxyvitamin D concentrations in girls aged 4-8 y living in the southeastern United States. American Journal of Clinical Nutrition 83, 75-81.

Stewart, H., Dong, D., \& Carlson, A.(2013). Why are Americans consuming less fluid milk? A look at generational differences in intake frequency. U.S.Department of Agriculture, Economic Research Service. Retrieved September 15, 2013 from: www.ers.usda.gov/publications/err-economic-research-report/err149.aspx

Stolzberg-Solomon, R., Vieth, R., Azad, A., Pietinen, P., Taylor, S., Virtamo, J., \& Albanes, D (2006). A prospective nested case control study of vitamin D status and pancreatic cancer risk among male smokers. Cancer Research 66 (20), 10213-10219. doi: 10.1158/0008-5472.CAN-06-1876

Sullivan, S., Rosen, C., Halteman, W., Chen, T., \& Holick, M. (2005). Adolescent girls in Maine are at risk for vitamin D insufficiency. Journal of the American Dietetic Association 105 (6), 971-974. doi: 10.1016/j.jada.2005.03.002

Tangpricha, V., Pearce, E., Chen, T., \& Holick, M (2002). Vitamin d insufficiency among freeliving healthy young adults. American Journal Medicine, 112 (8), 659-662. 
Tangpricha, V., Spina, C, Yao, M., Chen, T., Wolfe, M., \& Holick, M. (2005). Vitamin D deficiency enhances the growth of MC-26 colon cancer xenografts in Balb/C mice. Journal of Nutrition, 135, 2350-2354.

Taylor, C., Lamparello, B., Kruczek, K., Anderson, E., Hubbard, J. \& Madhusmita, M. (2009). Validation of a food frequency questionnaire for calcium and vitamin D intake in adolescent girls with anorexia nervosa. Journal of the American Dietetic Association, 109 (3), 479-485.

Thomas, M., Lloyd-Jones, D., Thadhani, R., Shaw, A., Deraska, D., Kitch, B....Finkelstein, J. (1998). Hypovitaminosis D in medical inpatients. New England Journal of Medicine, 338, 777-783. doi: 10.1056/NEJM199803193381201

Umble, K., Steffen, D., Porter, J., Miller, D., Hummer-McLaughlin, K., Lowman, A., \& Zelt, S (2005). The national public health leadership institute: Evaluation of a team-based approach to developing collaborative public health leaders. American Journal of Public Health, 95(4), p 641-644.

US Department of Health and Human Services. Healthy people 2020. Retrieved July 31, 2013 from: http://www.healthypeople.gov.

US Pharmocopeial Convention, (2013). USP dietary supplement standards. Retrieved October 13, 2013 from: http://www.usp.org/dietary-supplements/overview .

Veith, R., Bischoff-Ferrari, H., Boucher, B., Dawson-Hughes, B., Garland, C., Heaney, R....Zittermann, A. (2007). The urgent need to recommend an intake of vitamin D that is effective. American Journal of Clinical Nutrition, 85(3), 649-650.

Wang, Q., \& Seeman, E. (2008). Skeletal growth and peak bone strength. Best Practice \& Research Clinical Endocrinology \&Metabolism, 22(5), 687-700.

doi:10.1016/j.beem.2008.07.008

Wang, T., Pencina, M., Booth, S., Jacques, P., Ingelsson, E. Lanier, K.... Vasan, R. (2008). Vitamin D deficiency and risk of cardiovascular disease. Epidemiology, 117, 503-541.

Weng, F., Shults, J., Leonard, M., Stallings, V. \& Zemel, B. ( 2007). Risk factors for low serum 25-hydroxyvitamin $\mathrm{D}$ concentrations in otherwise healthy children and adolescents. American Journal of Clinical Nutrition, 86, 150-158.

Webb, A., Kline, L., \& Holick, M. (1988). Influence of season and latitude on the cutaneous synthesis of vitamin $\mathrm{D}_{3}$ : Exposure to winter sunlight in Boston and Edmonton will not promote vitamin $\mathrm{D}_{3}$ synthesis in human skin. The Journal of Clinical Endocrinology \&Metabolism, 66, 373-378.

World Health Organization. Public Health. Retrieved August 1, 2013 from: http://www.who.int/trade/glossary/story076/en/ 
Weishaar, T., \& Vergili, J. (2013). Vitamin D status is a biological determinant of health disparities. Journal of the Academy of Nutrition and Dietetics, 113(5), 643-651. doi:10.1016/j.jand.2012.12.011

Wortsman, J., Matsuoka, L., Chen, T., Lu,Z., \& Holick, M (2000). Decreased bioavailability of vitamin D in obesity. American Journal of Clinical Nutrition, 72, 690-693.

Wright, K., Rowitz, L., Merkle, A., Reid, W.M., Robinson, G., Herzog, B.,...Baker, E. (2000). The American Journal of Public Health, 90(8), 1202-1207.

Wu, K., Feskanich,D., Fuchs,C., Willett, W., Hollis, B., \& Giovannucci,E.(2007). Hydroxyviamin D concentrations and risk of colorectal cancer. Journal of National Cancer Institute 99(14):1120-1129.

Vitamin D conversions nmol/L to ng/mL Retrieved July 18, 2013 from: http://www.endmemo.com/medical/unitconvert/Vitamin_D.php

Zitterman, A., (2006). Vitamin D and disease prevention with special reference to cardiovascular disease. Progress in Biophysics \&Molecular Biology, 92, 39-48. 


\section{APPENDICES}

\section{APPENDIX A}

\section{Vitamin D Survey Questionnaire}

ID \#

Height Weight $\%$ Body Fat BMI

1. What is your age?

2. Gender: Male Female

3. What is your race?

4. Asian__AfricanAmerican AmericanIndian___Hispanic Caucasian Other

5. Do you take a vitamin or mineral supplement?

6. Yes No

7. If yes, continue. If no, skip to question 5. Please list the names of all:

8. How often do you take it? Explain, if more than one taken.

9. Once daily 3-6 times per week

2-3 times per week Less than Once weekly

10. Do you participate in the student meal dining plan on campus? Yes No

11. If yes to above, approximately how many meals per week do you eat on campus?

12. What is your current academic major?

13. Have you traveled to a sunny location in the past month? If so, where did you go?

How long did you stay?

14. Have you used a tanning bed in the past month? yes no

\section{PLEASE CONTINUE ON NEXT PAGE!}


How often do you consume the following foods?

\begin{tabular}{|c|c|c|c|c|c|c|c|c|c|c|}
\hline & Serving & Never & $\begin{array}{l}\text { Rarely, } \\
\text { less than } \\
\text { once per } \\
\text { month }\end{array}$ & $\begin{array}{l}\text { Once } \\
\text { per } \\
\text { month }\end{array}$ & $\begin{array}{l}\text { Once per } \\
\text { week }\end{array}$ & $\begin{array}{l}2-3 \times \text { per } \\
\text { week }\end{array}$ & $\begin{array}{l}\text { Once per } \\
\text { day }\end{array}$ & $\begin{array}{l}\text { Twice } \\
\text { per } \\
\text { day }\end{array}$ & $\begin{array}{l}\text { Three } \\
\text { times } \\
\text { per day }\end{array}$ & $\begin{array}{l}\text { Four or } \\
\text { more } \\
\text { times } \\
\text { per day }\end{array}$ \\
\hline $\begin{array}{l}\text { Milk: whole, } \\
\text { low-fat, skim, } \\
\text { choc, soy }\end{array}$ & $8 \mathrm{oz}$ & & & & & & & & & \\
\hline $\begin{array}{l}\text { Vitamin D } \\
\text { fortified orange } \\
\text { juice }\end{array}$ & $4 \mathrm{oz}$ & & & & & & & & & \\
\hline $\begin{array}{l}\text { Salmon, } \\
\text { sockeye, }\end{array}$ & $3 \mathrm{oz}$ & & & & & & & & & \\
\hline Cod liver oil & 1 Tbsp & & & & & & & & & \\
\hline Yogurt, plain & $8 \mathrm{oz}$ & & & & & & & & & \\
\hline $\begin{array}{l}\text { Yogurt, } \\
\text { fortified }\end{array}$ & $8 \mathrm{oz}$ & & & & & & & & & \\
\hline $\begin{array}{l}\text { Tuna fish, } \\
\text { water } \\
\text { Packed }\end{array}$ & $3 \mathrm{oz}$ & & & & & & & & & \\
\hline $\begin{array}{l}\text { Cold } \\
\text { cereal,fortified }\end{array}$ & 1 cup & & & & & & & & & \\
\hline $\begin{array}{l}\text { Milk over } \\
\text { cereal }\end{array}$ & $4 \mathrm{oz}$ & & & & & & & & & \\
\hline $\begin{array}{l}\text { Ice cream or ice } \\
\text { milk }\end{array}$ & $1 / 2$ cup & & & & & & & & & \\
\hline $\begin{array}{l}\text { American or } \\
\text { mozzarella } \\
\text { cheese }\end{array}$ & $1 \mathrm{oz}$ & & & & & & & & & \\
\hline $\begin{array}{l}\text { Hard cheese: } \\
\text { cheddar,swiss, } \\
\text { provolone }\end{array}$ & $1 \mathrm{oz}$ & & & & & & & & & \\
\hline Ravioli, quiche & 1 cup & & & & & & & & & \\
\hline $\begin{array}{l}\text { Macaroni and } \\
\text { cheese, lasagna }\end{array}$ & 1 cup & & & & & & & & & \\
\hline Cheese pizza & 1 slice & & & & & & & & & \\
\hline
\end{tabular}

Adapted with author's permission from: Taylor, C.A., Lamparello, B., Kruczek, K., Anderson, E.J., Hubbard, J., and Madhusmita,M.,(2009). Clinical Research Center at Massachusetts General Hospital, Harvard Catalyst CTSC.). Validation of a food frequency questionnaire for calcium and vitamin D intake in adolescent girls with anorexia nervosa. $\mathrm{J} \mathrm{Am}$ Diet Assoc. 109 (3); 479-485.

\section{Thank you for participating in this survey!}




\section{APPENDIX B}

\section{Permission to Use Vitamin D Food Frequency Questionnaire}

Email received on December 14, 2012:

From: EANDERSON@PARTNERS.ORG

To: Misra, Madhusmita, M.D.; Cress, Eileen M.

Eileen:

Thank you for your interest in our calcium and Vitamin D FFQ. You have our permission to re-format the FFQ for your doctoral dissertation. You may want to consider adding additional sources of vitamin D for your geographic area and study population (college students). If you should adapt or use, please acknowledge the Clinical Research Center at Massachusetts General Hospital, Harvard Catalyst CTSC.

Best in your doctoral completion.

Ellen

Email received on December 13, 2012:

From: mmisra@partners.org

To: Cress, Eileen M.

Dear Eileen,

I have copied Ellen Anderson, my collaborator and co-author on this note so she can help with this.

Best Regards,

Madhu Misra, MD, MPH

Email sent on December 13, 2012: 
From: Cress, Eileen M.

To: Misra, Madhusmita, M.D.

Dear Dr. Madhusmita,

I will be conducting a study of vitamin D status among college-aged students for a doctoral dissertation. I read with interest your article Validation of a food frequency questionnaire for determining calcium and vitamin D intake by adolescent girls with anorexia nervosa which appeared in the J AM Diet Assoc., March 2009. I would like to request your permission to use a similar survey, adapted for vitamin D intake only, for the study I will be doing. Basically, I would like to use the same format, but omit the foods which are calcium rich and insignificant in vitamin D, (such as broccoli, tofu, cottage cheese).

May I have your permission to modify the survey you used for my research purposes?

Thank you.

Kind Regards,

Eileen Cress, MS, RD, LDN 


\section{APPENDIX C}

Frequency Tables

\begin{tabular}{|c|c|c|c|c|c|}
\hline \multicolumn{6}{|c|}{ AGE } \\
\hline & & Frequency & Percent & $\begin{array}{c}\text { Valid } \\
\text { Percent }\end{array}$ & $\begin{array}{c}\text { Cumulative } \\
\text { Percent }\end{array}$ \\
\hline \multirow[t]{13}{*}{ Valid } & 18.00 & 8 & 8.2 & 8.2 & 8.2 \\
\hline & 19.00 & 17 & 17.3 & 17.3 & 25.5 \\
\hline & 20.00 & 18 & 18.4 & 18.4 & 43.9 \\
\hline & 21.00 & 15 & 15.3 & 15.3 & 59.2 \\
\hline & 22.00 & 13 & 13.3 & 13.3 & 72.4 \\
\hline & 23.00 & 5 & 5.1 & 5.1 & 77.6 \\
\hline & 24.00 & 8 & 8.2 & 8.2 & 85.7 \\
\hline & 25.00 & 4 & 4.1 & 4.1 & 89.8 \\
\hline & 26.00 & 1 & 1.0 & 1.0 & 90.8 \\
\hline & 27.00 & 3 & 3.1 & 3.1 & 93.9 \\
\hline & 28.00 & 2 & 2.0 & 2.0 & 95.9 \\
\hline & 29.00 & 4 & 4.1 & 4.1 & 100.0 \\
\hline & Total & 98 & 100.0 & 100.0 & \\
\hline
\end{tabular}

GENDER

\begin{tabular}{|rl|r|r|r|r|}
\hline & & Frequency & Percent & $\begin{array}{c}\text { Valid } \\
\text { Percent }\end{array}$ & $\begin{array}{c}\text { Cumulative } \\
\text { Percent }\end{array}$ \\
\hline Valid & 1.00 & 55 & 56.1 & 56.1 & 56.1 \\
& 2.00 & 43 & 43.9 & 43.9 & 100.0 \\
& Total & 98 & 100.0 & 100.0 & \\
\hline
\end{tabular}




\begin{tabular}{|c|c|c|c|c|c|}
\hline \multicolumn{6}{|c|}{ RACE } \\
\hline & & Frequency & Percent & $\begin{array}{c}\text { Valid } \\
\text { Percent }\end{array}$ & $\begin{array}{c}\text { Cumulative } \\
\text { Percent }\end{array}$ \\
\hline Valid & A & 4 & 4.1 & 4.1 & 4.1 \\
\hline & AA & 4 & 4.1 & 4.1 & 8.2 \\
\hline & African & 4 & 4.1 & 4.1 & 12.2 \\
\hline & Al \& C & 1 & 1.0 & 1.0 & 13.3 \\
\hline & C & 77 & 78.6 & 78.6 & 91.8 \\
\hline & $\mathrm{H}$ & 3 & 3.1 & 3.1 & 94.9 \\
\hline & $\mathrm{O}$ & 5 & 5.1 & 5.1 & 100.0 \\
\hline & Total & 98 & 100.0 & 100.0 & \\
\hline
\end{tabular}

\begin{tabular}{|c|c|c|c|c|c|}
\hline \multicolumn{6}{|c|}{ MEALPLAN } \\
\hline & & Frequency & Percent & $\begin{array}{l}\text { Valid } \\
\text { Percent }\end{array}$ & $\begin{array}{c}\text { Cumulative } \\
\text { Percent }\end{array}$ \\
\hline \multirow[t]{3}{*}{ Valid } & 1.00 & 21 & 21.4 & 21.4 & 21.4 \\
\hline & 2.00 & 77 & 78.6 & 78.6 & 100.0 \\
\hline & Total & 98 & 100.0 & 100.0 & \\
\hline
\end{tabular}


BMI

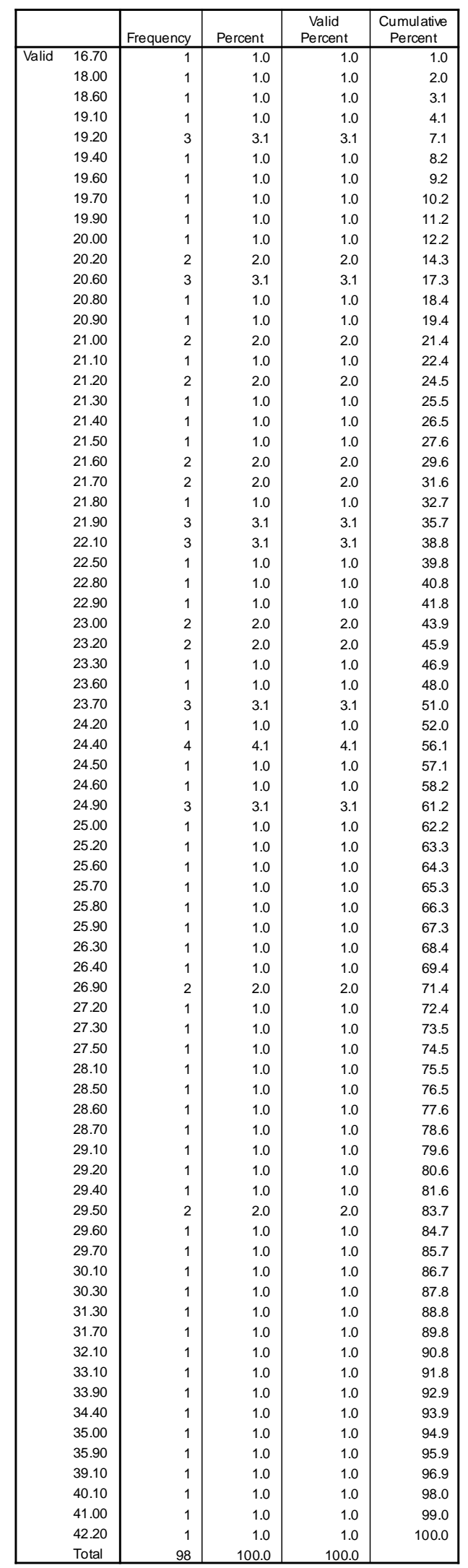


MAJOR2

\begin{tabular}{|c|c|c|c|c|c|}
\hline & & Frequency & Percent & $\begin{array}{c}\text { Valid } \\
\text { Percent }\end{array}$ & $\begin{array}{c}\text { Cumulative } \\
\text { Percent }\end{array}$ \\
\hline \multirow{56}{*}{ 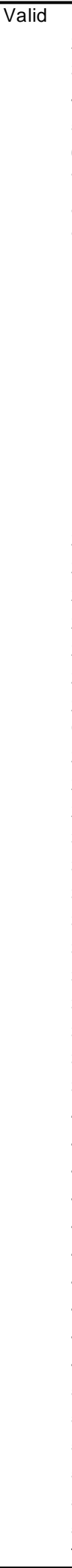 } & 1 "Pre-med, biochemistry" & 1 & 1.0 & 1.0 & 1.0 \\
\hline & 2 Accounting & 1 & 1.0 & 1.0 & 2.0 \\
\hline & 3 Advertising & 1 & 1.0 & 1.0 & 3.1 \\
\hline & 4 Behavioral Neuroscience Psychology & 1 & 1.0 & 1.0 & 4.1 \\
\hline & 5 Biology & 4 & 4.1 & 4.1 & 8.2 \\
\hline & 6 Biology Biochem Conc. & 1 & 1.0 & 1.0 & 9.2 \\
\hline & 7 Biomedical Engineering & 1 & 1.0 & 1.0 & 10.2 \\
\hline & 8 Biomedical Science & 1 & 1.0 & 1.0 & 11.2 \\
\hline & 9 Business & 3 & 3.1 & 3.1 & 14.3 \\
\hline & 10 Chemistry & 3 & 3.1 & 3.1 & 17.3 \\
\hline & 11 Clinical Psychology & 1 & 1.0 & 1.0 & 18.4 \\
\hline & 12 Computer Science & 1 & 1.0 & 1.0 & 19.4 \\
\hline & 13 Criminal Justice & 1 & 1.0 & 1.0 & 20.4 \\
\hline & 14 Digital Media & 1 & 1.0 & 1.0 & 21.4 \\
\hline & 15 Early Childhood Education & 2 & 2.0 & 2.0 & 23.5 \\
\hline & 16 Education/Early Childhood & 1 & 1.0 & 1.0 & 24.5 \\
\hline & 17 Engineering & 1 & 1.0 & 1.0 & 25.5 \\
\hline & 18 English & 2 & 2.0 & 2.0 & 27.6 \\
\hline & 19 Epidemiology & 1 & 1.0 & 1.0 & 28.6 \\
\hline & 20 Exercise Science & 4 & 4.1 & 4.1 & 32.7 \\
\hline & $21 \mathrm{ExSc}$ & 1 & 1.0 & 1.0 & 33.7 \\
\hline & 22 Finance & 1 & 1.0 & 1.0 & 34.7 \\
\hline & 23 General Psychology & 1 & 1.0 & 1.0 & 35.7 \\
\hline & 24 Geography & 1 & 1.0 & 1.0 & 36.7 \\
\hline & 25 Geology & 1 & 1.0 & 1.0 & 37.8 \\
\hline & $\begin{array}{l}26 \text { Grad school-Profes sional } \\
\text { Communication }\end{array}$ & 1 & 1.0 & 1.0 & 38.8 \\
\hline & 27 History & 3 & 3.1 & 3.1 & 41.8 \\
\hline & 28 International Affairs & 1 & 1.0 & 1.0 & 42.9 \\
\hline & 29 K-6 Education & 1 & 1.0 & 1.0 & 43.9 \\
\hline & 30 Man. Engineering & 1 & 1.0 & 1.0 & 44.9 \\
\hline & 31 Mass Communication & 1 & 1.0 & 1.0 & 45.9 \\
\hline & 32 Masters of Business Administration & 1 & 1.0 & 1.0 & 46.9 \\
\hline & 33 Masters of Clinical Nutrition & 1 & 1.0 & 1.0 & 48.0 \\
\hline & 34 Math & 1 & 1.0 & 1.0 & 49.0 \\
\hline & 35 Medical Student & 1 & 1.0 & 1.0 & 50.0 \\
\hline & $36 \mathrm{~N} / \mathrm{A}$ & 1 & 1.0 & 1.0 & 51.0 \\
\hline & 37 Nursing & 9 & 9.2 & 9.2 & 60.2 \\
\hline & 38 Nutrition & 6 & 6.1 & 6.1 & 66.3 \\
\hline & 39 Photo Journalism & 1 & 1.0 & 1.0 & 67.3 \\
\hline & 40 Physical Therapy & 1 & 1.0 & 1.0 & 68.4 \\
\hline & 41 Physics & 1 & 1.0 & 1.0 & 69.4 \\
\hline & 42 Political Science & 1 & 1.0 & 1.0 & 70.4 \\
\hline & 43 Pre-nursing & 1 & 1.0 & 1.0 & 71.4 \\
\hline & 44 Psychiatry Resident & 1 & 1.0 & 1.0 & 72.4 \\
\hline & 45 Psychology & 8 & 8.2 & 8.2 & 80.6 \\
\hline & 46 Public Health & 3 & 3.1 & 3.1 & 83.7 \\
\hline & 47 Public Health Admin & 1 & 1.0 & 1.0 & 84.7 \\
\hline & 48 Public Health/MBA & 1 & 1.0 & 1.0 & 85.7 \\
\hline & 49 Radiography & 2 & 2.0 & 2.0 & 87.8 \\
\hline & 50 Radiology & 2 & 2.0 & 2.0 & 89.8 \\
\hline & 51 Sociology & 1 & 1.0 & 1.0 & 90.8 \\
\hline & 52 Spanish/Biology & 1 & 1.0 & 1.0 & 91.8 \\
\hline & 53 Storytelling & 1 & 1.0 & 1.0 & 92.9 \\
\hline & 54 Theatre & 2 & 2.0 & 2.0 & 94.9 \\
\hline & 55 UD & 5 & 5.1 & 5.1 & 100.0 \\
\hline & Total & 98 & 100.0 & 100.0 & \\
\hline
\end{tabular}


DLEVEL

\begin{tabular}{|c|c|c|c|c|c|}
\hline & & Frequency & Percent & $\begin{array}{l}\text { Valid } \\
\text { Percent }\end{array}$ & $\begin{array}{c}\text { Cumulative } \\
\text { Percent }\end{array}$ \\
\hline \multirow[t]{37}{*}{ Valid } & 6.00 & 1 & 1.0 & 1.0 & 1.0 \\
\hline & 8.90 & 1 & 1.0 & 1.0 & 2.1 \\
\hline & 10.00 & 1 & 1.0 & 1.0 & 3.1 \\
\hline & 11.00 & 2 & 2.0 & 2.1 & 5.2 \\
\hline & 12.00 & 3 & 3.1 & 3.1 & 8.3 \\
\hline & 13.00 & 2 & 2.0 & 2.1 & 10.4 \\
\hline & 14.00 & 2 & 2.0 & 2.1 & 12.5 \\
\hline & 15.00 & 3 & 3.1 & 3.1 & 15.6 \\
\hline & 16.00 & 1 & 1.0 & 1.0 & 16.7 \\
\hline & 17.00 & 5 & 5.1 & 5.2 & 21.9 \\
\hline & 18.00 & 3 & 3.1 & 3.1 & 25.0 \\
\hline & 19.00 & 5 & 5.1 & 5.2 & 30.2 \\
\hline & 20.00 & 3 & 3.1 & 3.1 & 33.3 \\
\hline & 21.00 & 2 & 2.0 & 2.1 & 35.4 \\
\hline & 22.00 & 7 & 7.1 & 7.3 & 42.7 \\
\hline & 23.00 & 5 & 5.1 & 5.2 & 47.9 \\
\hline & 24.00 & 3 & 3.1 & 3.1 & 51.0 \\
\hline & 25.00 & 5 & 5.1 & 5.2 & 56.3 \\
\hline & 26.00 & 3 & 3.1 & 3.1 & 59.4 \\
\hline & 27.00 & 1 & 1.0 & 1.0 & 60.4 \\
\hline & 28.00 & 3 & 3.1 & 3.1 & 63.5 \\
\hline & 29.00 & 5 & 5.1 & 5.2 & 68.8 \\
\hline & 30.00 & 3 & 3.1 & 3.1 & 71.9 \\
\hline & 31.00 & 1 & 1.0 & 1.0 & 72.9 \\
\hline & 33.00 & 3 & 3.1 & 3.1 & 76.0 \\
\hline & 34.00 & 2 & 2.0 & 2.1 & 78.1 \\
\hline & 35.00 & 4 & 4.1 & 4.2 & 82.3 \\
\hline & 36.00 & 1 & 1.0 & 1.0 & 83.3 \\
\hline & 37.00 & 3 & 3.1 & 3.1 & 86.5 \\
\hline & 39.00 & 4 & 4.1 & 4.2 & 90.6 \\
\hline & 41.00 & 2 & 2.0 & 2.1 & 92.7 \\
\hline & 42.00 & 3 & 3.1 & 3.1 & 95.8 \\
\hline & 44.00 & 1 & 1.0 & 1.0 & 96.9 \\
\hline & 45.00 & 1 & 1.0 & 1.0 & 97.9 \\
\hline & 49.00 & 1 & 1.0 & 1.0 & 99.0 \\
\hline & 65.00 & 1 & 1.0 & 1.0 & 100.0 \\
\hline & Total & 96 & 98.0 & 100.0 & \\
\hline Missing & System & 2 & 2.0 & & \\
\hline Total & & 98 & 100.0 & & \\
\hline
\end{tabular}




\begin{tabular}{|c|c|c|c|c|c|}
\hline \multicolumn{6}{|c|}{ DFOOD } \\
\hline & & Frequency & Percent & $\begin{array}{c}\text { Valid } \\
\text { Percent }\end{array}$ & $\begin{array}{c}\text { Cumulative } \\
\text { Percent }\end{array}$ \\
\hline Valid & .00 & 4 & 4.1 & 4.1 & 4.1 \\
\hline & 10.00 & 1 & 1.0 & 1.0 & 5.1 \\
\hline & 11.00 & 1 & 1.0 & 1.0 & 6.1 \\
\hline & 12.00 & 1 & 1.0 & 1.0 & 7.1 \\
\hline & 14.00 & 2 & 2.0 & 2.0 & 9.2 \\
\hline & 20.00 & 4 & 4.1 & 4.1 & 13.3 \\
\hline & 29.00 & 2 & 2.0 & 2.0 & 15.3 \\
\hline & 32.00 & 1 & 1.0 & 1.0 & 16.3 \\
\hline & 35.00 & 10 & 10.2 & 10.2 & 26.5 \\
\hline & 36.00 & 1 & 1.0 & 1.0 & 27.6 \\
\hline & 47.00 & 1 & 1.0 & 1.0 & 28.6 \\
\hline & 48.00 & 1 & 1.0 & 1.0 & 29.6 \\
\hline & 50.00 & 8 & 8.2 & 8.2 & 37.8 \\
\hline & 56.00 & 1 & 1.0 & 1.0 & 38.8 \\
\hline & 63.00 & 1 & 1.0 & 1.0 & 39.8 \\
\hline & 64.00 & 4 & 4.1 & 4.1 & 43.9 \\
\hline & 68.00 & 1 & 1.0 & 1.0 & 44.9 \\
\hline & 69.00 & 1 & 1.0 & 1.0 & 45.9 \\
\hline & 80.00 & 1 & 1.0 & 1.0 & 46.9 \\
\hline & 89.00 & 1 & 1.0 & 1.0 & 48.0 \\
\hline & 123.00 & 1 & 1.0 & 1.0 & 49.0 \\
\hline & 124.00 & 1 & 1.0 & 1.0 & 50.0 \\
\hline & 128.00 & 1 & 1.0 & 1.0 & 51.0 \\
\hline & 138.00 & 1 & 1.0 & 1.0 & 52.0 \\
\hline & 139.00 & 1 & 1.0 & 1.0 & 53.1 \\
\hline & 152.00 & 1 & 1.0 & 1.0 & 54.1 \\
\hline & 153.00 & 2 & 2.0 & 2.0 & 56.1 \\
\hline & 154.00 & 1 & 1.0 & 1.0 & 57.1 \\
\hline & 161.00 & 1 & 1.0 & 1.0 & 58.2 \\
\hline & 162.00 & 1 & 1.0 & 1.0 & 59.2 \\
\hline & 182.00 & 1 & 1.0 & 1.0 & 60.2 \\
\hline & 183.00 & 1 & 1.0 & 1.0 & 61.2 \\
\hline & 187.00 & 1 & 1.0 & 1.0 & 62.2 \\
\hline & 194.00 & 1 & 1.0 & 1.0 & 63.3 \\
\hline & 196.00 & 1 & 1.0 & 1.0 & 64.3 \\
\hline & 199.00 & 1 & 1.0 & 1.0 & 65.3 \\
\hline & 226.00 & 2 & 2.0 & 2.0 & 67.3 \\
\hline & 231.00 & 1 & 1.0 & 1.0 & 68.4 \\
\hline & 233.00 & 1 & 1.0 & 1.0 & 69.4 \\
\hline & 234.00 & 1 & 1.0 & 1.0 & 70.4 \\
\hline & 239.00 & 1 & 1.0 & 1.0 & 71.4 \\
\hline & 248.00 & 2 & 2.0 & 2.0 & 73.5 \\
\hline & 250.00 & 1 & 1.0 & 1.0 & 74.5 \\
\hline & 257.00 & 1 & 1.0 & 1.0 & 75.5 \\
\hline & 265.00 & 1 & 1.0 & 1.0 & 76.5 \\
\hline & 268.00 & 1 & 1.0 & 1.0 & 77.6 \\
\hline & 275.00 & 1 & 1.0 & 1.0 & 78.6 \\
\hline & 324.00 & 1 & 1.0 & 1.0 & 79.6 \\
\hline & 332.00 & 1 & 1.0 & 1.0 & 80.6 \\
\hline & 335.00 & 1 & 1.0 & 1.0 & 81.6 \\
\hline & 341.00 & 1 & 1.0 & 1.0 & 82.7 \\
\hline & 350.00 & 1 & 1.0 & 1.0 & 83.7 \\
\hline & 353.00 & 1 & 1.0 & 1.0 & 84.7 \\
\hline & 354.00 & 1 & 1.0 & 1.0 & 85.7 \\
\hline & 369.00 & 1 & 1.0 & 1.0 & 86.7 \\
\hline & 372.00 & 2 & 2.0 & 2.0 & 88.8 \\
\hline & 373.00 & 1 & 1.0 & 1.0 & 89.8 \\
\hline & 415.00 & 1 & 1.0 & 1.0 & 90.8 \\
\hline & 459.00 & 1 & 1.0 & 1.0 & 91.8 \\
\hline & 474.00 & 1 & 1.0 & 1.0 & 92.9 \\
\hline & 607.00 & 1 & 1.0 & 1.0 & 93.9 \\
\hline & 616.00 & 1 & 1.0 & 1.0 & 94.9 \\
\hline & 632.00 & 1 & 1.0 & 1.0 & 95.9 \\
\hline & 696.00 & 1 & 1.0 & 1.0 & 96.9 \\
\hline & 721.00 & 1 & 1.0 & 1.0 & 98.0 \\
\hline & 1586.00 & 1 & 1.0 & 1.0 & 99.0 \\
\hline & 5504.00 & 1 & 1.0 & 1.0 & 100.0 \\
\hline & Total & 98 & 100.0 & 100.0 & \\
\hline
\end{tabular}


TOTALD

\begin{tabular}{|c|c|c|c|c|c|}
\hline & & Frequency & Percent & $\begin{array}{l}\text { Valid } \\
\text { Percent }\end{array}$ & $\begin{array}{c}\text { Cumulative } \\
\text { Percent }\end{array}$ \\
\hline Valid & .00 & 1 & 1.0 & 1.0 & 1.0 \\
\hline & 10.00 & 1 & 1.0 & 1.0 & 2.0 \\
\hline & 11.00 & 1 & 1.0 & 1.0 & 3.1 \\
\hline & 12.00 & 1 & 1.0 & 1.0 & 4.1 \\
\hline & 14.00 & 2 & 2.0 & 2.0 & 6.1 \\
\hline & 20.00 & 4 & 4.1 & 4.1 & 10.2 \\
\hline & 29.00 & 2 & 2.0 & 2.0 & 12.2 \\
\hline & 32.00 & 1 & 1.0 & 1.0 & 13.3 \\
\hline & 35.00 & 9 & 9.2 & 9.2 & 22.4 \\
\hline & 36.00 & 1 & 1.0 & 1.0 & 23.5 \\
\hline & 47.00 & 1 & 1.0 & 1.0 & 24.5 \\
\hline & 48.00 & 1 & 1.0 & 1.0 & 25.5 \\
\hline & 50.00 & 5 & 5.1 & 5.1 & 30.6 \\
\hline & 56.00 & 1 & 1.0 & 1.0 & 31.6 \\
\hline & 63.00 & 1 & 1.0 & 1.0 & 32.7 \\
\hline & 64.00 & 3 & 3.1 & 3.1 & 35.7 \\
\hline & 69.00 & 1 & 1.0 & 1.0 & 36.7 \\
\hline & 80.00 & 1 & 1.0 & 1.0 & 37.8 \\
\hline & 89.00 & 1 & 1.0 & 1.0 & 38.8 \\
\hline & 124.00 & 1 & 1.0 & 1.0 & 39.8 \\
\hline & 138.00 & 1 & 1.0 & 1.0 & 40.8 \\
\hline & 139.00 & 1 & 1.0 & 1.0 & 41.8 \\
\hline & 153.00 & 1 & 1.0 & 1.0 & 42.9 \\
\hline & 154.00 & 1 & 1.0 & 1.0 & 43.9 \\
\hline & 161.00 & 1 & 1.0 & 1.0 & 44.9 \\
\hline & 162.00 & 1 & 1.0 & 1.0 & 45.9 \\
\hline & 164.00 & 1 & 1.0 & 1.0 & 46.9 \\
\hline & 182.00 & 1 & 1.0 & 1.0 & 48.0 \\
\hline & 183.00 & 1 & 1.0 & 1.0 & 49.0 \\
\hline & 187.00 & 1 & 1.0 & 1.0 & 50.0 \\
\hline & 196.00 & 1 & 1.0 & 1.0 & 51.0 \\
\hline & 199.00 & 1 & 1.0 & 1.0 & 52.0 \\
\hline & 226.00 & 2 & 2.0 & 2.0 & 54.1 \\
\hline & 231.00 & 1 & 1.0 & 1.0 & 55.1 \\
\hline & 234.00 & 1 & 1.0 & 1.0 & 56.1 \\
\hline & 239.00 & 1 & 1.0 & 1.0 & 57.1 \\
\hline & 248.00 & 1 & 1.0 & 1.0 & 58.2 \\
\hline & 250.00 & 1 & 1.0 & 1.0 & 59.2 \\
\hline & 257.00 & 1 & 1.0 & 1.0 & 60.2 \\
\hline & 265.00 & 1 & 1.0 & 1.0 & 61.2 \\
\hline & 268.00 & 1 & 1.0 & 1.0 & 62.2 \\
\hline & 335.00 & 1 & 1.0 & 1.0 & 63.3 \\
\hline & 341.00 & 1 & 1.0 & 1.0 & 64.3 \\
\hline & 350.00 & 1 & 1.0 & 1.0 & 65.3 \\
\hline & 353.00 & 1 & 1.0 & 1.0 & 66.3 \\
\hline & 369.00 & 1 & 1.0 & 1.0 & 67.3 \\
\hline & 372.00 & 1 & 1.0 & 1.0 & 68.4 \\
\hline & 400.00 & 2 & 2.0 & 2.0 & 70.4 \\
\hline & 415.00 & 1 & 1.0 & 1.0 & 71.4 \\
\hline & 433.00 & 1 & 1.0 & 1.0 & 72.4 \\
\hline & 435.00 & 1 & 1.0 & 1.0 & 73.5 \\
\hline & 450.00 & 1 & 1.0 & 1.0 & 74.5 \\
\hline & 459.00 & 1 & 1.0 & 1.0 & 75.5 \\
\hline & 464.00 & 1 & 1.0 & 1.0 & 76.5 \\
\hline & 528.00 & 1 & 1.0 & 1.0 & 77.6 \\
\hline & 594.00 & 1 & 1.0 & 1.0 & 78.6 \\
\hline & 607.00 & 1 & 1.0 & 1.0 & 79.6 \\
\hline & 616.00 & 1 & 1.0 & 1.0 & 80.6 \\
\hline & 648.00 & 1 & 1.0 & 1.0 & 81.6 \\
\hline & 675.00 & 1 & 1.0 & 1.0 & 82.7 \\
\hline & 696.00 & 1 & 1.0 & 1.0 & 83.7 \\
\hline & 721.00 & 1 & 1.0 & 1.0 & 84.7 \\
\hline & 732.00 & 1 & 1.0 & 1.0 & 85.7 \\
\hline & 742.00 & 1 & 1.0 & 1.0 & 86.7 \\
\hline & 753.00 & 1 & 1.0 & 1.0 & 87.8 \\
\hline & 754.00 & 1 & 1.0 & 1.0 & 88.8 \\
\hline & 768.00 & 1 & 1.0 & 1.0 & 89.8 \\
\hline & 772.00 & 1 & 1.0 & 1.0 & 90.8 \\
\hline & 800.00 & 2 & 2.0 & 2.0 & 92.9 \\
\hline & 874.00 & 1 & 1.0 & 1.0 & 93.9 \\
\hline & 923.00 & 1 & 1.0 & 1.0 & 94.9 \\
\hline & 932.00 & 1 & 1.0 & 1.0 & 95.9 \\
\hline & 1173.00 & 1 & 1.0 & 1.0 & 96.9 \\
\hline & 1986.00 & 1 & 1.0 & 1.0 & 98.0 \\
\hline & 2862.00 & 1 & 1.0 & 1.0 & 99.0 \\
\hline & 6304.00 & 1 & 1.0 & 1.0 & 100.0 \\
\hline & Total & 98 & 100.0 & 100.0 & \\
\hline
\end{tabular}




\section{VITA}

\section{EILEEN MCKENNA CRESS}

Education:

Professional Experience:
Public Schools, Piscataway, New Jersey

B.S. Home Economics, University of Tennessee, Knoxville, Tennessee 1980

M.S. Industrial Education, East Tennessee State University, Johnson City, Tennessee 1985

Ed.D. Educational Leadership, East Tennessee State University, Johnson City, Tennessee 2014

Chief Clinical Dietitian, Freidman Hospital, Philadelphia Geriatric Center, Philadelphia, PA 1985-1987

Director, Nutrition Services, Marriott Corporation, Eagleville Hospital, Eagleville, PA 1987-1990

Consultant Dietitian, Tri-Cities Regional Area, Tennessee, 19912010

Nutrition Support Specialist, Coram Healthcare, Johnson City, TN 2001-2008

Assistant Professor, Department of Allied Health Sciences, East Tennessee State University; Johnson City, TN 2010-present

Honors and Awards:

and Dietetics, 2010-2011, 2013-2014.

Outstanding Dietitian of the Year. Tri- Cities Academy of Nutrition and Dietetics, 2011-2012. 